
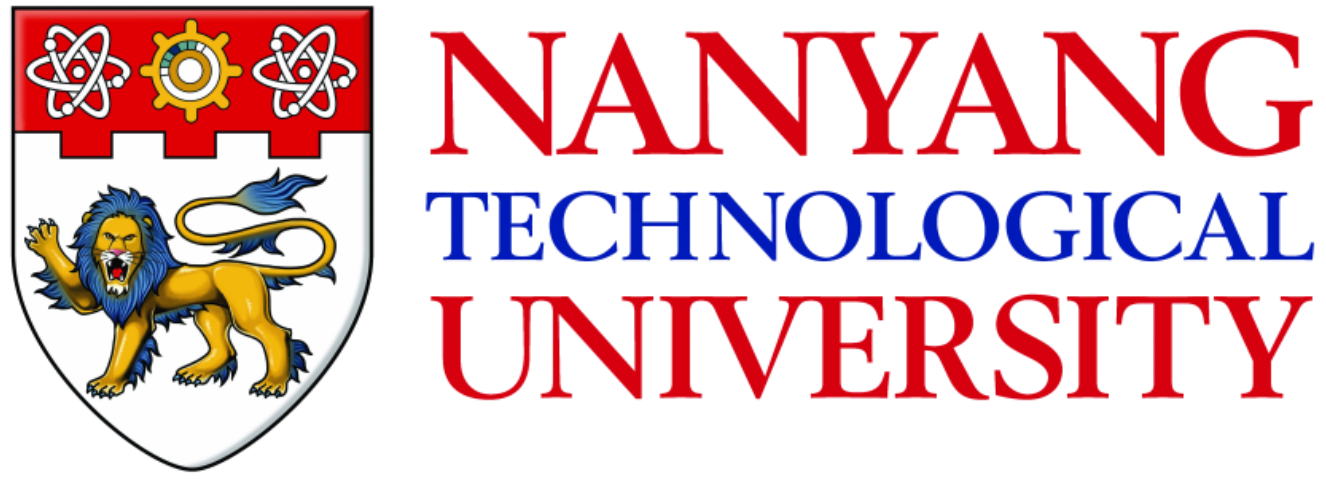

STUDY OF MULTI-STAGE MULTI-EFFECT REGENERATOR FOR LIQUID DESICCANT AIRCONDITIONING SYSTEM

NIRMALYA DATTA

INTERDISCIPLINARY GRADUATE SCHOOL ENERGY RESEARCH INSTITUTE @ NTU (ERI@N) 



\section{STUDY OF MULTI-STAGE MULTI-EFFECT REGENERATOR FOR LIQUID DESICCANT AIR- CONDITIONING SYSTEM}

NIRMALYA DATTA

\section{Interdisciplinary Graduate School Energy Research Institute @ NTU (ERI@N)}

A thesis submitted to the Nanyang Technological University in partial fulfilment of the requirement for the degree of Doctor of Philosophy 



\section{Statement of Originality}

I hereby certify that the work embodied in this thesis is the result of original research and has not been submitted for a higher degree to any other University or Institution.

$08 / 01 / 2017$ NIRMALYA DATTA

Date Student Name 



\begin{abstract}
With increasing importance placed on energy efficiency and indoor-air-quality, the advanced energy efficient liquid desiccant assisted air-conditioning (LDAC) systems have attracted attention in the recent years. The thesis aims to develop a vacuum graded LDAC system with multi-stage-effect dehumidification and regeneration systems employing membrane technology namely VMEMD for improving the efficiency of the conventional LDAC system. The proposed multieffect regeneration test-bed maximizes not only the heat transfer between the heating fluids and salt solution but also mass transfer of water vapour across the hydrophobic membrane.
\end{abstract}

Subsequent findings are obtained through the experimental investigations of multieffect membrane based LDAC system employing various control parameters of the test facility. We found that the conventional VMEMD is not suitable for the regeneration of $\mathrm{LiCl}$ solution for dehumidification purposes. Therefore, the VMEMD system has been modified with one steam three solution (1S-3L) passes system through modelling and simulation. Finally, an experimental investigation is conducted to prove the test-of-concept. The use of $1 \mathrm{~S}-3 \mathrm{~L}$ is the main findings of this work. The thermal efficiency of the proposed 1S-3L VMEMD system is calculated in terms of performance ratio $(\mathrm{PR})$ and change in feed concentration between the inlet and outlet of the regenerator for various solution flow rates and regeneration temperatures. The proposed system is driven at the lowest temperature of $55^{\circ} \mathrm{C}$. The PR value is found $\sim 2$ for VMEMD system, which can be considered a new finding.

In this thesis, a comprehensive testing is conducted for the thermal performance of the conventional VMEMD regenerator of the LDAC test bed under various 
configurations. The desiccant heating load is handled by both the solar thermal and auxiliary heat pump systems. It is found that the PR is mainly influenced by the initial feed concentration and flow rate delivered from the absorber module.

The thermodynamic frameworks of the proposed 1S-3L VMEMD system is developed employing the heat and mass balances for all the stages of VMEMD system, which simulates the working principles of the regeneration process for various driving heat source temperatures. The simulation result proves the validity of changing VMEMD configuration for handling higher inlet feed concentration. The present study shows a test-of-concept to utilize the modified VMEMD for dehumidification purposes in tropical climate. 


\section{Acknowledgements}

I would like to express my sincere gratitude to my Ph.D. supervisor, Asst. Prof. Anutosh Chakraborty for his great patience, invaluable academic inspirations, and unyielding support to my study and research work. It has been a privilege, as well as a pleasure, to be able to discuss research with such a distinguished and enthusiastic scientist daily. It is my honour to be co-author with him in journal papers and international conference papers. Without his instructions and effort by passing down the knowledge of sorption dehumidification and clarifying doubts during my studies, this thesis would be impossible to be accomplished. I am indebted to my Ph.D. co-supervisor, Prof. Ali Iftekhar Maswood and my mentor Prof. Leong Kai Choong for continuous guidance during my research works.

I am also grateful to the Dr. M. Kum Ja, Mr. Li Bing and all other collaborators in Energy Research Institute at NTU (ERI@N) for their assistance during my experiments. I am also thankful to Lily Lim Seok Kim for her constant assistance in an administrative role.

I owe gratitude to our current group members: Teo How Wei Benjamin, Fan Wu and Dr. Sibnath Kayal. Those discussions and conversations were always helpful and fun. I would especially like to mention Mr. Syed Muztuza Ali for his unwavering support throughout my research. I would also like to emphasize my appreciation to the Nanyang Technology University, Singapore for the research scholarship during the course of candidature. This 4-year-time research period will be one of the highlights in my life.

I also dedicate this report to my parents Khem Ranjan Datta, Chhanda Datta and to my brother Nilabha Datta for their unconditional moral support and love 
throughout the process of the research and my life in general. Finally, I wish to express gratitude to my fiancée, Ms. Adrija Nag, for being a constant source of emotional support in the past 6 years. 


\section{Table of Contents}

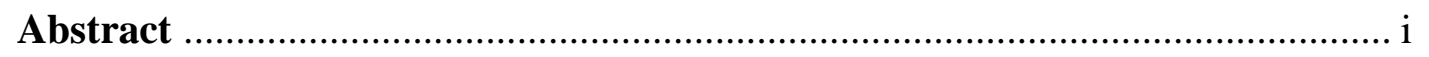

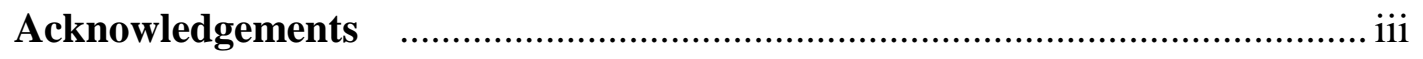

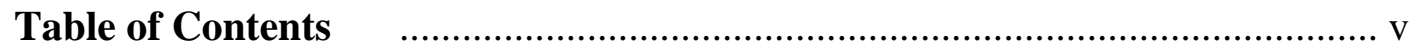

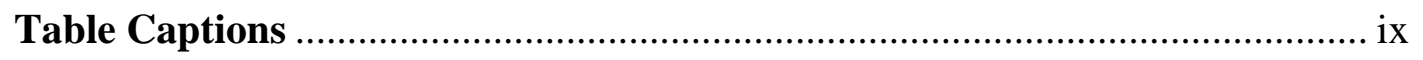

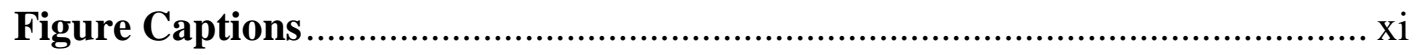

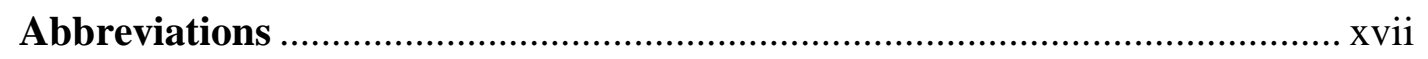

Chapter $1 \quad$ Introduction.................................................................... 1

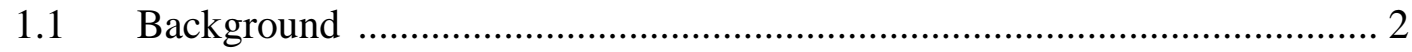

1.1 .1 Air-conditioning processes ......................................................... 2

1.1.2 Moisture control for air-conditioning .............................................. 2

1.2 Objectives and Scopes ....................................................................... 7

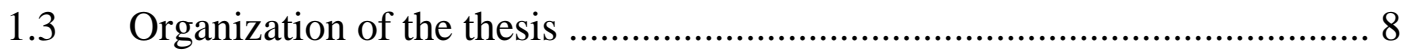

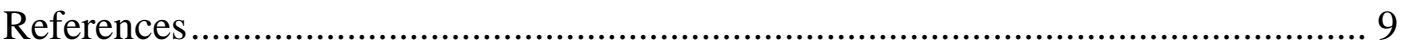

Chapter 2 Literature Review ........................................................... 11

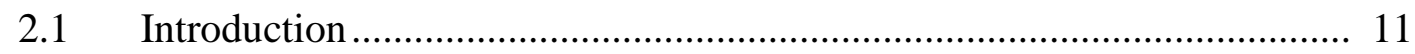

2.2 Thermo-physical properties of liquid desiccant systems ....................... 12

2.2.1 Equilibrium Vapour Pressure ........................................................ 12

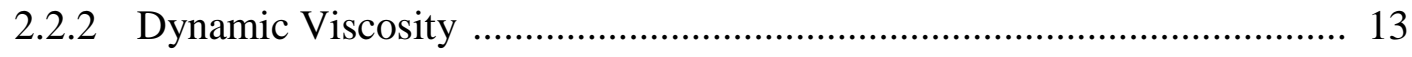

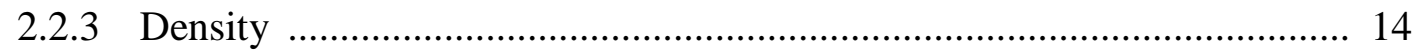


2.2.4 Specific heat Capacity ……………….................................................... 14

2.2.5 Thermal Conductivity ………………………................................. 15

2.2.6 Diffusion Coefficient ……………………….................................. 15

2.3 Liquid desiccant air-conditioning systems............................................... 15

2.4 Membrane assisted LDAC system and progresses ................................... 20

2.5 Control factors for LDAC optimizations ……………………................. 26

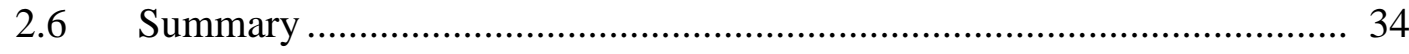

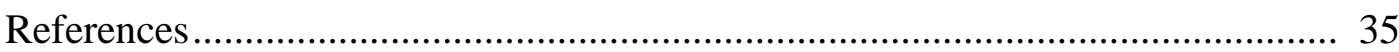

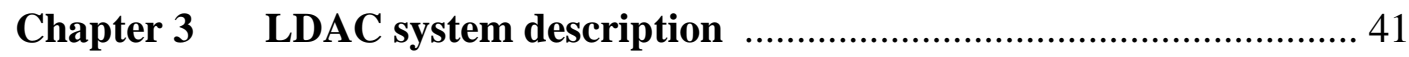

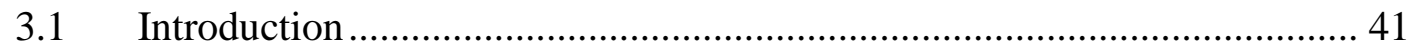

3.2 Overall System Prototype ……………………................................. 42

3.2.1 Selection of the desiccant solution............................................................... 47

3.2.2 Preparation of the desiccant solution ........................................................ 48

3.2.3 Instrumentation and measurements.......................................................... 49

3.3 Membrane based dehumidification system................................................ 50

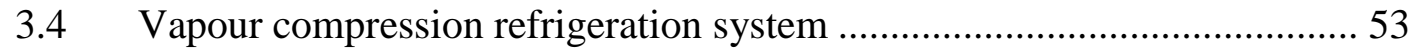

3.5 Vacuum assisted multi-effect membrane based regenerator or VMEMD .. 54

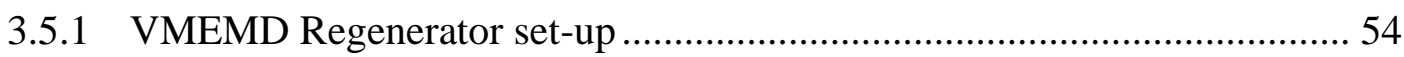

3.5.2 Multi-stage and multi-effect regeneration unit ........................................ 55

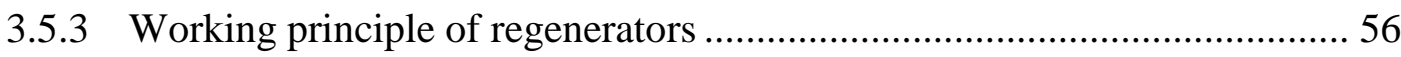

3.6 Performance Indicators and effects of control parameters...........................59

3.7 Solar thermal system and chemical energy storage system ........................ 60

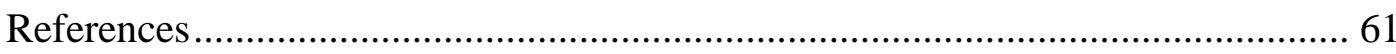

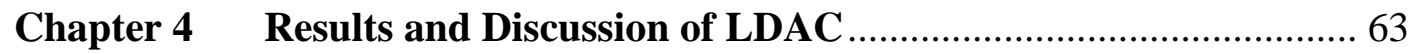

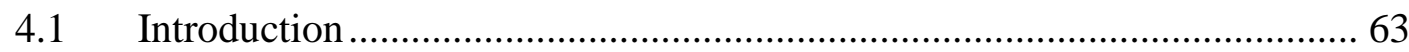

4.2 Effects of controlled parameters on the system performances..................... 64 


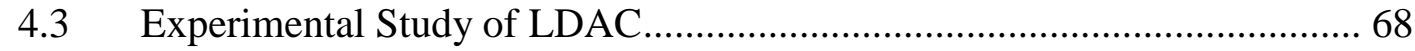

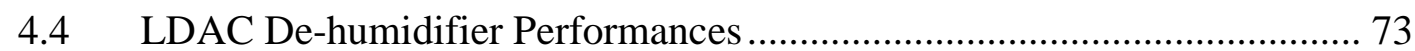

4.5 Experimental investigation of VMEMD regenerator................................... 74

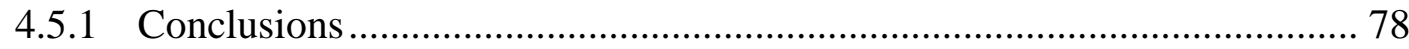

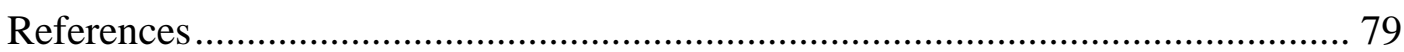

Chapter 5 Thermodynamic Study of LDAC Regenerator System ............. 81

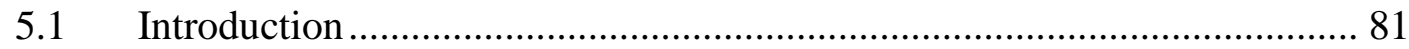

5.2 One Steam-Three Solution (1S-3L) VMEMD systems ………….............. 83

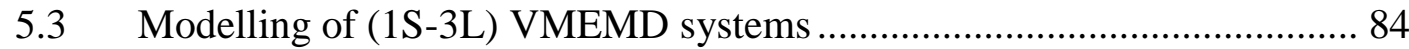

5.3.1 Thermodynamic model of desiccant regeneration unit.............................. 85

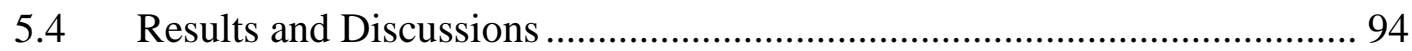

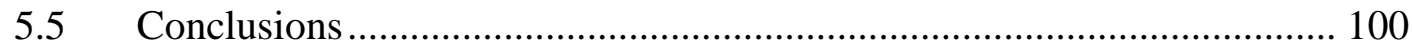

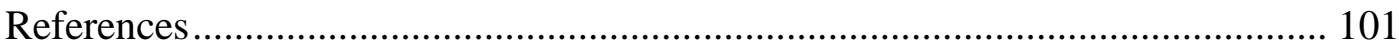

Chapter 6 Experimental Investigation of 1S-3L VMEMD System ........... 103

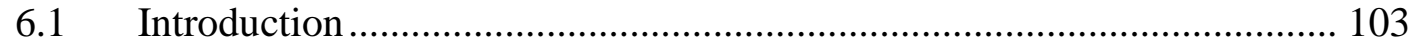

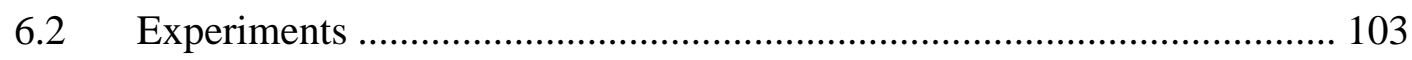

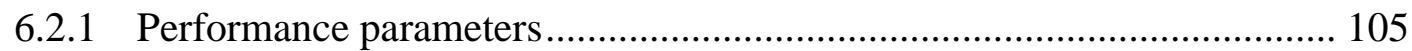

6.3 Single Stage-Steam-Three-Stages-desiccant (1S-3L) ............................... 106

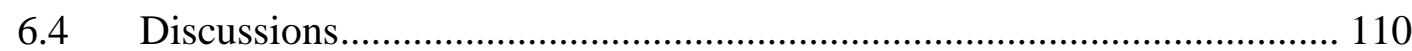

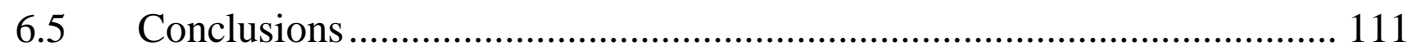

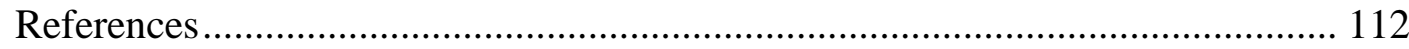

Chapter 7 Conclusion and Recommendations ……………………….... 113

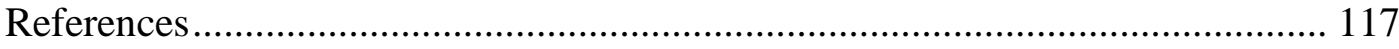




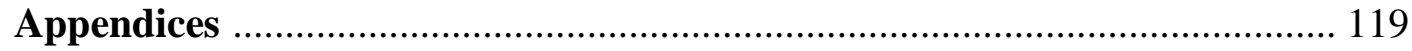

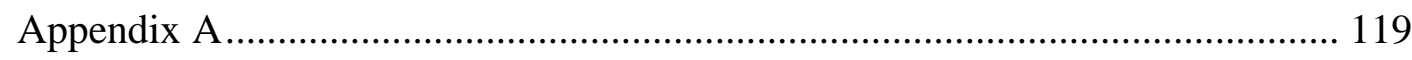

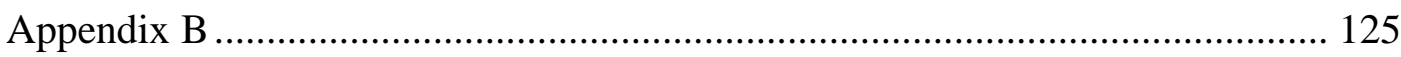

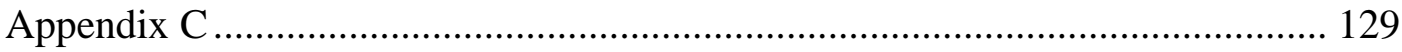




\section{Table Captions}

\section{Chapter 2}

Table 2.1 Properties of the hydrophobic membrane

22

Table 2.2 Summary of various membrane distillations driven by low grade heat source 25

Table 2.3 Summary of liquid desiccant dehumidification/regeneration for airconditioning (AC) applications.

27

\section{Chapter 3}

Table 3.1 List of notations and subscripts used in the schematic diagram of LDAC

\section{Chapter 4}

Table 4.1 Performance analysis of the LDAC Dehumidifier 74

\section{Chapter 5}

Table 5.1 Performance analysis of the LDAC Dehumidifier 93 


\section{Figure Captions}

\section{Chapter 1}

Figure 1.1 Optimum relative humidity ranges for human health...................... 3

Figure 1.2 Psychometric chart showing the process of latent cooling A-B and reheating B-C for conventional vapour compression $\mathrm{AC}$........................................ 4

Figure 1.3 Corrosion damage to air supply channel of a large auditorium by

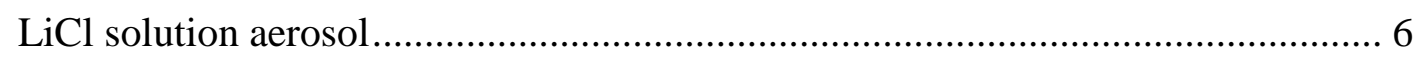

\section{Chapter 2}

Figure 2.1 Schematic representation of a solar driven L-DAC system (developed at Energy Research Institute, NTU, Singapore) ...16

Figure 2.2 Working principles of PTFE membrane for water-vapour separation from supply air channel due to vapour pressure difference. The transfer of water molecules are shown through the membrane ............................................... 21

Figure 2.3 (a) SEM image of front side PP..................................................... 23 Figure 2.3 (b) SEM image of rear side reinforced PTFE hydrophobic membrane

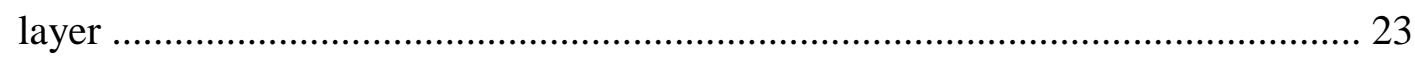




\section{Chapter 3}

Figure 3.1 Schematic diagram of membrane based LDAC system using

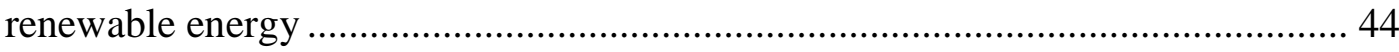

Figure 3.2 Layout drawing of the test bed system ............................................ 46

Figure 3.3 Data communication diagram between Inverters, Energy meters,

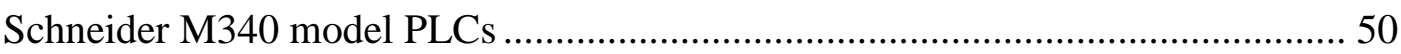

Figure 3.4 (a) Arrangements of the plastic foil frames and the membrane frame .

Figure 3.4 (b) Pictorial view of the dehumidifier along with the fluid flow

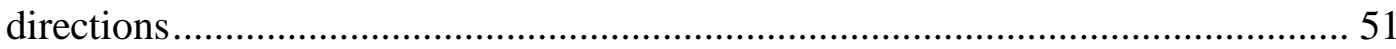

Figure 3.5 (a) Membrane frame of the treble flow dehumidifier with flow directions of fluid components …………………………..................................... 52

Figure 3.5 (b) Foil frame of the treble flow dehumidifier with flow directions of

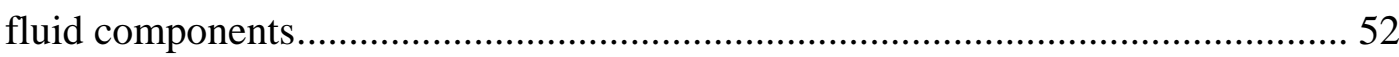

Figure 3.6 Schematic diagram of the conventional vacuum assisted multi-effect membrane distillation system (VMEMD) system....................................................... 57

Figure 3.7 The pictorial view for the experimental setup of VMEMD system ..... 58 


\section{Chapter 4}

Figure 4.1 Humidity ratio $(\omega)$ for various air inlet and outlet velocities under air resident with high and low pressures. 64

Figure 4.2 Air velocity, inlet-outlet air temperature, relative humidity, inlet-outlet water temperature, lithium chloride concentration and flow-rate, as a function of time for the LDAC dehumidifier system 66

Figure 4.3 Humidity ratio of air inlet and outlet for the decrease in cooling water temperatures from $16^{\circ} \mathrm{C}$ to $28^{\circ} \mathrm{C}$ 67

Figure 4.4 Six inlet parameters and three outlet parameters of membrane based dehumidifier, where $\mathrm{T}$ is the temperature, and $\mathrm{RH}$ indicates relative humidity. .... 69

Figure 4.5 The flow chart illustrating 48 experiments conducted at minimum and maximum possible Inlet air conditions of LDAC dehumidifier. Here OA indicates outdoor air, MA is mixed air, RA defines return air, DA is Dehumidified air and SA stands for supply air. 71

Figure 4.6 Coverage range of air inlet conditions and resulted air outlet conditions.

Figure 4.7 Temperature profiles against time of 4-stage VMEMD regenerator under steady state conditions for feed concentration $8 \%$ and $55{ }^{\circ} \mathrm{C}$ heating temperature 75 
Figure 4.8 Performance ratio against solution flow rates for (a) inlet feed concentration of $8 \%$ at $50-60{ }^{\circ} \mathrm{C}$, (b) inlet feed concentration of $15 \%$ at $55-$ $65{ }^{\circ} \mathrm{C}$, and (c) inlet feed concentration of $22 \%$ at $70-80{ }^{\circ} \mathrm{C}$ 76

Figure 4.9 Concentration increase against solution flow rates for (a) inlet feed concentration of $8 \%$ at $50-60{ }^{\circ} \mathrm{C}$, (b) inlet feed concentration of $15 \%$ at $55-$ $65{ }^{\circ} \mathrm{C}$, and (c) inlet feed concentration of $22 \%$ at $70-80{ }^{\circ} \mathrm{C}$ 77

\section{Chapter 5}

Figure 5.1 Schematic model of 1S-3L VMEMD regenerator 84

Figure 5.2 Schematic diagram of the system modelling 84

Figure 5.3 Temperature profile of the fluids at the outlet of (a) Module 1, (b) Module 2 and (c) Module 3 of the 1S-3L LDAC regenerator; inlet concentration $32 \%$, heating temperature $65^{\circ} \mathrm{C}$ 96

Figure 5.3 Performance ratio (PR) against solution flow rates of one-steam-threesolution regenerator configuration for the inlet feed concentrations of (a) $27 \%$ (b) $32 \%$ (c) $34 \%$ and (d) $36 \%$ for different heating temperatures ........................... 97

Figure 5.4 Distillate against solution flow rates of one-steam-three-solution regenerator configuration for the inlet feed concentrations of (a) $27 \%$ (b) $32 \%$ (c) $34 \%$ and (d) $36 \%$ for different heating temperatures ..................................... 99 


\section{Chapter 6}

Figure 6.1 Pictorial views of (a) $1 \mathrm{~S}-3 \mathrm{~L}$ VMEMD Regenerator (b) $1 \mathrm{~S}-3 \mathrm{~L}$

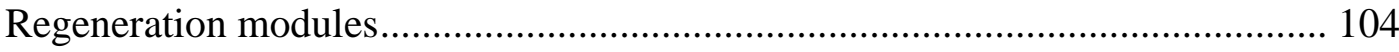

Figure 6.2 Schematic of the 1S-3L VMEMD regenerator ............................... 105

Figure 6.3 Temperature profiles of various components of $1 \mathrm{~S}-3 \mathrm{~L}$ regenerator under steady state conditions.............................................................................. 106

Figure 6.4 (a) Increase in concentration, (b) Performance ratio (PR) against solution flow rates of $1 \mathrm{~S}-3 \mathrm{~L}$ regenerator configuration for the inlet feed

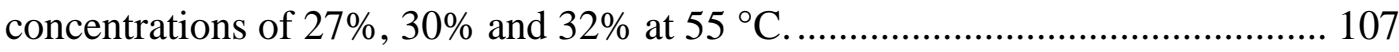

Figure 6.5 (a) Increase in concentration and (b) performance ratio (PR) against solution flow rates of one-steam-three-solution regenerator configuration for the inlet feed concentrations of $27 \%, 30 \%, 34 \%$ and $38 \%$ at $65^{\circ} \mathrm{C} \ldots \ldots \ldots \ldots \ldots \ldots \ldots \ldots \ldots . . . . . . . . . . . .108$

Figure 6.6 (a) Increase in concentration and (b) performance ratio (PR) against solution flow rates of one-steam-three-solution regenerator configuration for the inlet feed concentrations of $31 \%, 34 \%$ and $37 \%$ at $75{ }^{\circ} \mathrm{C}$.................................. 109

\section{Chapter 7}

Figure 7.1 Schematic of hybrid 2S-4L VMEMD system (steam flows in two stages and liquid desiccant flows in four stages). 


\section{Abbreviations}

\section{Abbreviation Meaning}

ABS

Absorber

$\mathrm{AC}$

Air Conditioning

AGMD

Air Gap Membrane Distillation

ASTM

American Society for Testing and Materials

$\mathrm{COM}$

Compressor

COP

Coefficient Of Performance

DCMD

Direct Contact Membrane Distillation

DX

Direct Expansion

HEX

Heat Exchanger

HVAC

Heating ventilation and air-conditioning

IAQ

Indoor Air Quality

IPA

Isopropyl alcohol

LAMEE

Liquid-Air-Membrane Energy Exchanger

LDAC

Liquid Desiccant Air-Conditioning

LDCS

Liquid Desiccant Cooling System

MED

Multi Effect Distillation

MEG

Mono Ethylene Glycol

MEMD

Multi-Effect Membrane Distillation

M-LDAC

Membrane- Liquid desiccant Air-Conditioning

MR

Mass Ratio

Nom.

Nominal

NTU

Number of Transfer Units

PET

Polyethylene Terephthalate

PLC

Programmable Logic Controller 


$\begin{array}{ll}\text { PP } & \text { Polypropylene } \\ \text { PPHE } & \text { Polymer Plate Heat Exchanger } \\ \text { PR } & \text { Performance Ratio } \\ \text { psi } & \text { pounds per square inch } \\ \text { PTFE } & \text { Polytetrafluoroethylene } \\ \text { PU } & \text { Pump } \\ \text { PVC } & \text { Poly-Vinyl Chloride } \\ \text { PVDF } & \text { Polyvinylidene Fluoride } \\ \text { RAMEE } & \text { Run-Around-Membrane Energy Exchanger } \\ \text { REG } & \text { Regenerator } \\ \text { RH } & \text { Relative Humidity } \\ \text { SEM } & \text { Scanning Electron Microscope } \\ \text { SGMD } & \text { Sweeping Gas Membrane Distillation } \\ \text { VC } & \text { Vapour Compression } \\ \text { VMD } & \text { Vacuum Membrane Distillation } \\ \text { VMEMD } & \text { Vacuum Multi-Effect Membrane Distillation } \\ & \end{array}$




\section{Greek Symbols}

$\begin{array}{llr}\text { Symbols } & \text { Meaning } & \text { Units } \\ \Pi & \text { Vapour pressure } & {[-]} \\ \xi & \text { Mass fraction of the solute } & {[\mathrm{kgsalt} / \mathrm{kgsol}]} \\ \eta & \text { Dynamic viscosity } & \mathrm{m}^{2} / \mathrm{s} \\ \rho & \text { Density } & \mathrm{kg} / \mathrm{m}^{3} \\ \omega & \text { Relative humidity } & {[-]} \\ \tau & \text { Tortuosity } & {[-]} \\ \delta & \text { Thickness } & \mathrm{mm} \\ \varepsilon & \text { Porosity } & {[-]} \\ \gamma & \text { Activity of water } & {[-]}\end{array}$

\section{Latin and Other Symbols}

$\begin{array}{llr}\text { Symbols } & \text { Meaning } & \text { Units } \\ A & \text { area } & \mathrm{m}^{2} \\ d & \text { pore size } & \mathrm{nm} \\ C_{P} & \text { heat capacity } & \mathrm{J} /(\mathrm{kg} \cdot \mathrm{K}) \\ D_{A B} & \text { diffusivity } & \mathrm{m}^{2} / \mathrm{s} \\ V & \text { volume } & \mathrm{m}^{3} \\ T & \text { temperature } & \mathrm{K} \\ M & \text { molecular weight } & \mathrm{kg} \\ \dot{\mathrm{m}} & \text { mass flow rate } & \mathrm{kg} / \mathrm{s}\end{array}$




$\begin{array}{llr}U & \text {-overall heat transfer coefficient } & \mathrm{W} / \mathrm{m}^{2} \cdot \mathrm{K} \\ P & \text {-pressure } & \mathrm{Pa} \\ h & \text {-enthalpy } & \mathrm{J} \\ R & \text {-Universal gas constant } & \mathrm{kJ} / \mathrm{kmol} \cdot \mathrm{K} \\ X_{n} & \text {-number of fluid elements in a } & {[-]} \\ & \text { module } & \\ Y_{A} & \text {-mole fraction of air }\end{array}$

\section{Subscripts}

\section{Symbols}

S

H

Ch

Cw

Cond

dist

in

Wv

sol
Meaning

solution

hot water

channel

chilled water

condenser

distillate

inlet

water vapour

solution 


\section{Chapter 1}

\section{Introduction}

The developments in building designs with the progress of human civilization were accompanied by the ideas of air-conditioning. During the Roman civilization, a primitive form of air-conditioning became popular. It allowed the rich residents to pump cold water through the walls of their homes during summer months. The first form of modern air conditioning was introduced by Willis Carrier when he invented the vapour compression technology for transferring heat from low temperature region to high temperature region. This breakthrough caught the interest of many researchers and scientists for the consequent improvement in vapour compression air-conditioning over the years. As a result, the vapour compression systems have been popular world-wide with a wide range of operating conditions, such as power, heat source, ambient temperature and cooling load etc.

Energy consumption by buildings contributes to as high as $40 \%$ of the total energy consumption [1-3]. Energy and sustainability studies have revealed that airconditioning contributes to $60 \%$ of the total energy consumptions making airconditioners as one of the biggest energy consumer in the building sector especially in commercial buildings. The conventional heating ventilation and airconditioning (HVAC) system has a major drawback that lies in the energy spent in cooling the atmospheric humid air to below its dew point temperature to reduce the moisture content necessary for indoor consumptions. The heating energy is often spent in re-heating of the dehumidified air to achieve acceptable comfort cooling levels. With continuous shifting of industrial focus towards energy savings and increasing government mandates on the reduction of carbon dioxide emission, the 
absorption systems are gaining more and more importance and attention in industrial applications. There are increasing importance placed on climate change, energy conservation, energy security and air quality. So, a more energy efficient air-conditioning with zero carbon footprints is needed.

\subsection{Background:}

\subsubsection{Air conditioning Processes}

The air-conditioning system primarily entails into two processes; namely sensible and latent heat effects. The sensible heat involves the change in dry-bulb temperature at constant relative humidity $(\mathrm{RH})$, while the latent heat deals with the change in $\mathrm{RH}$ at constant dry-bulb temperature. In conventional vapour compression systems, both the sensible and latent heat changes are controlled simultaneously with respect to acceptable indoor conditions. The conventional airconditioning systems are largely efficient in handling the sensible load, and it faces numerous problems for controlling the latent load efficiently.

It should be noted here that a promising substitute to the prevalent vapour compression systems would be the combination of liquid desiccant dehumidification systems with the conventional compression chillers for controlling both temperature and humidity more effectively with minimum energy usage [4].

\subsubsection{Moisture control for air-conditioning}

Moisture control is a very important facet of any air-conditioning application as it dictates the quality of indoor air for human consumption. Inefficient moisture 
control is a prevalent problem in the building sector, particularly in hot and humid climatic regions. The indoor air quality affects the comfort and hygiene of the occupants of the building space. The poor indoor air quality may lead to the growth in germs such as bacteria, virus etc. causing allergies and respiratory diseases. One such study on the undesirable effects of air indoor quality been shown in Figure 1.1 [5].

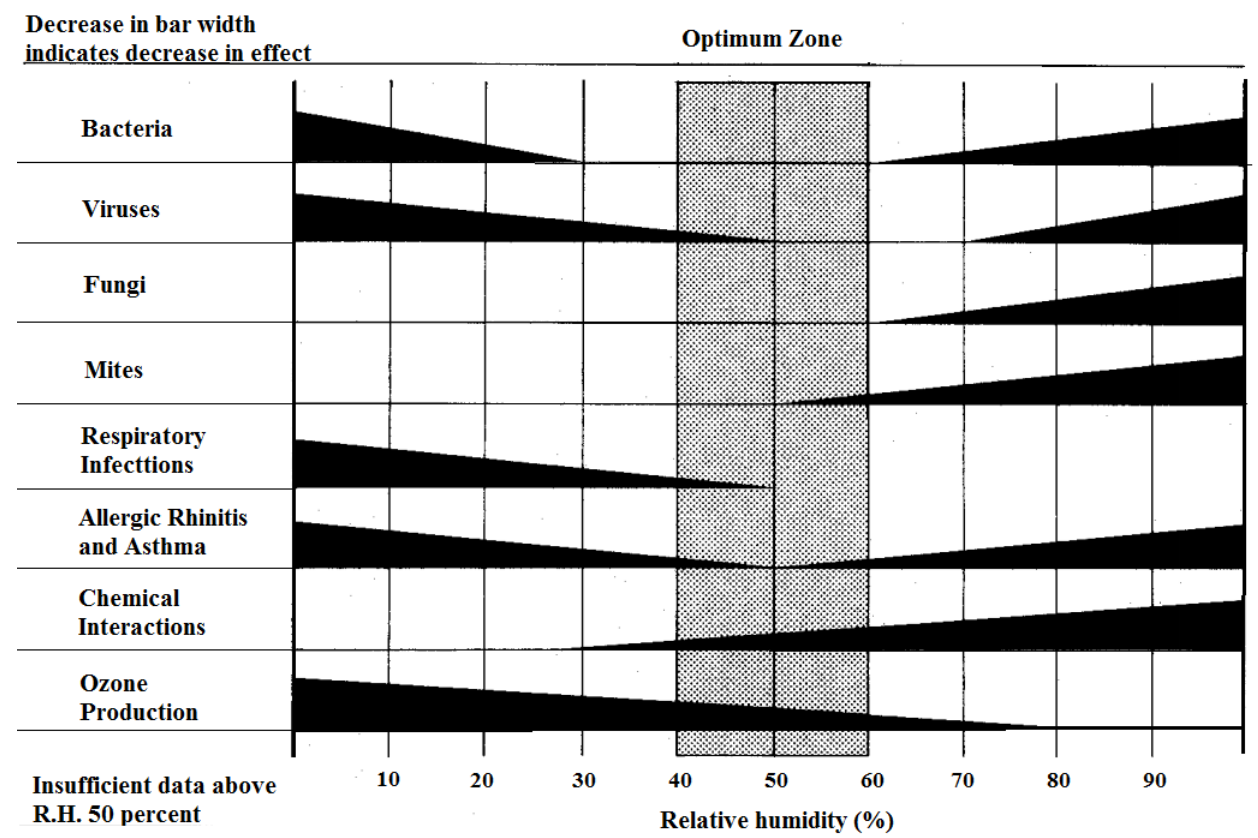

Figure 1.1: Optimum relative humidity ranges for human health [5]

A single coil heat exchanger arrangement handles both the sensible and latent loads at the same time. In order to remove the latent heat, the chill-water temperature is needed to be lowered below the dew-point temperature of the ambient air shown in process A-B in Figure 1.2 at the single-coil inlet; thereby resulting in an energy inefficient chiller. This limitation is addressed by having two separate coils, the PAU (Primary Air Unit) for handling latent heat and FCU (Fan Coil Unit) for handing the sensible heat. However this increases the number of moving parts of the system along with another undesirable attribute that the air cooled below the 
dew point temperature at the PAU is often required to be re-heated for it to be suitable for human consumption, thus squandering even more energy as shown in process B-C in Figure 1.2. Further, the condensation of moisture on the fan coils leads to dampness and microbial growth, which consequently leads to the deterioration of the indoor air quality. Thus the development of an alternative airconditioning technology that is energy efficient in handling heat loads without compromising the indoor air quality is highly desirable.

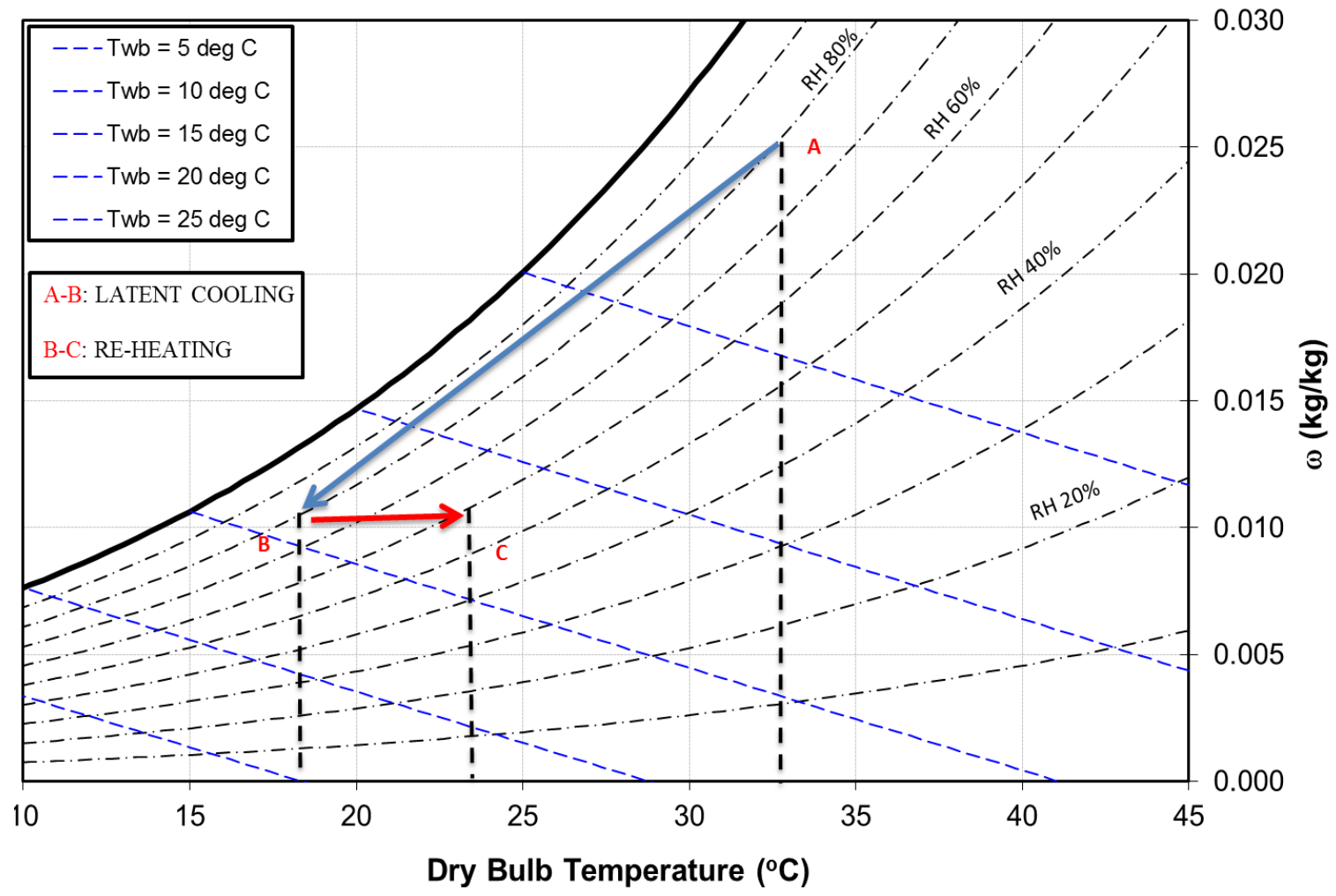

Figure 1.2: Psychometric chart showing the process of latent cooling A-B and reheating B-C for conventional vapour compression AC.

Efficient moisture control can be achieved using solid or liquid desiccant dehumidification process. Both solid and liquid desiccants absorb water vapour 
from the airstream by the process of absorption/adsorption and involve heat. In a solid desiccant AC system, the air stream is simultaneously heated and dehumidified in the desiccant wheel. It should be noted here that the solid desiccant air-conditioning is well known for being highly energy efficient as compared to conventional air-conditioning system. However the size of solid desiccant wheel is large and is not effective for practical application if the driving heat source temperature is below $65{ }^{\circ} \mathrm{C}$. Liquid desiccant is an alternative candidate for dehumidification purpose as it is proved highly efficient in absorbing moisture from the air and the size of the system is also small [6-11].

The liquid desiccant technologies have gained much attention in research over the past decade, especially for production of chilled water. However, the dehumidification research employing liquid desiccant is not fully established. The interest arises due to the fact that the liquid desiccant technology is able to handle the latent heat while dehumidifying the atmospheric air and is capable of desiccant regeneration with the driving heat source temperature of $60{ }^{\circ} \mathrm{C}$ or below as a function of ambient conditions. Liquid desiccants exhibit high affinity with water, and this property is the key to building cooling systems that has the ability to dehumidify air without over-cooling it. The liquid desiccants can be used as an intermediate energy storage medium for regeneration purposes, which also increase the system performance $[8,9,12,13]$.

Despite the advantages, the conventional direct contact liquid desiccant air conditioning system has a major drawback of the desiccant solution aerosol carryover into the airstream. The desiccant solutions such as lithium chloride, lithium bromide etc. are highly corrosive and corrodes the metallic parts of the system as well as the air ducts, vanes and the building. 


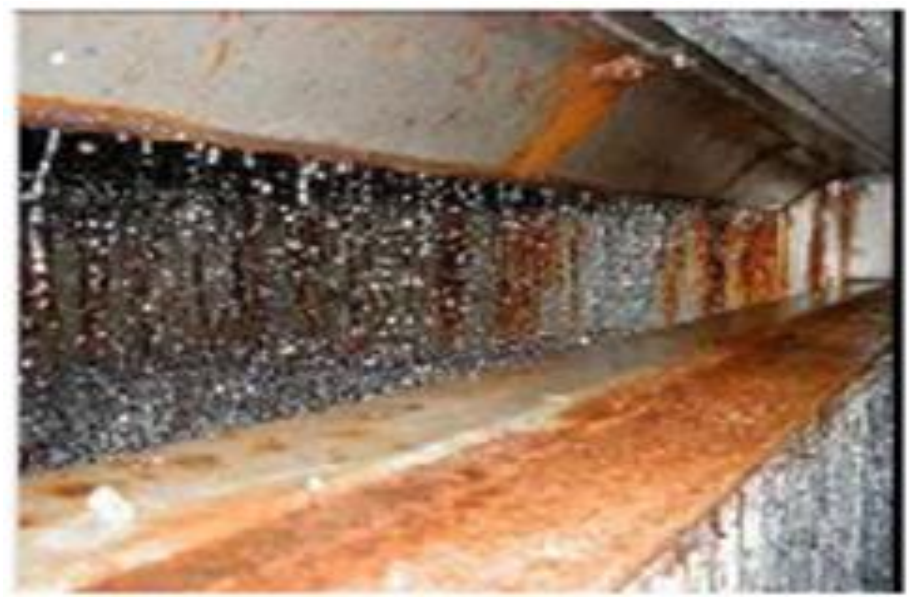

Figure 1.3: Corrosion damage to air supply channel of a large auditorium by $\mathrm{LiCl}$ solution aerosol [6]

Figure 1.2 shows a pictorial view of the corrosive effects of liquid desiccant aerosols on the air supply channel. Some of the desiccant vapours such as lithium bromide and Glycol are highly toxic in nature as such the vapours of these desiccants are highly undesirable in the indoor air supply stream due to their unhygienic impacts on human health.

Despite intensive research on desiccant based absorption systems (mainly direct contact type) exhibiting higher energy efficiency the inherent drawbacks has limited its ability to replace existing vapour compression systems. It should be noted here that membrane can be applied in the absorber and regenerator heat exchangers to solve corrosion and aerosol carryover problems. A membrane based liquid desiccant air-conditioning system is proposed and investigated in this thesis to find suitable solutions for the existing drawbacks. 


\subsection{Objectives and Scopes:}

The main goal of the thesis is to study the existing literature and come up with solutions for the limitations that have prevented a wide spread use of the liquid desiccant air conditioning (LDAC) technology in the building sector. Here, the conventional LDAC system has been modified by introducing membranes with three channels for the flows of heat transfer fluids, liquid desiccant solutions and water vapour, separately.

The main objectives of this thesis is to investigate and propose a novel multi-stage and multi-effect membrane distillation system for the regeneration of highly concentrated liquid desiccant employing low grade heat sources ranging from 50 ${ }^{\circ} \mathrm{C}$ to $80{ }^{\circ} \mathrm{C}$ for dehumidification purposes.

The main scopes of the research activities are as follows:

1) Design and development of LDAC system employing hydrophobic membranes and plastic frames to minimize corrosion, scaling and fouling.

2) Experimental investigation of the complete LDAC system and study of vacuum graded multi-effect membrane distillation (VMEMD) for various concentrations, feed flow rates and regeneration temperatures.

3) Mathematical modelling and simulation of the multi-effect regeneration system for better understanding of the theoretical aspects of the regeneration process dynamics.

4) Experimental investigation of the regeneration unit employing the proposed configuration for various controlling parameters, such as feed concentration, solution flow rates and regeneration temperatures. 


\subsection{Organisation of the thesis:}

This report begins with an introduction from Chapter 1, which is followed by a literature review in Chapter 2. Brief description of the liquid desiccant airconditioning (LDAC) is presented, including various descriptions of existing LDAC systems, typical regeneration and absorption processes and their corresponding limitations, hydrophobic membrane desalination principles and computational models, energy savings in regeneration units, as well as the working principles of membrane based desalination. Advances of other researchers' distinguished works are also provided in this chapter.

Chapter 3 includes a detailed description of the LDAC test-bed that was used to carry out the experimental studies during this research. This chapter reports in detail the various components of the test-bed and also gives an insight into the design, development and fabrication of the LDAC system. The various fluid and energy cycles are also explained. The chapter also focusses on the VMEMD regeneration system of the LDAC test bed and explains the principle guidelines for the dehumidification processes. The conventional multi-effect membrane based distillation unit suitable for desalination plants, however modification are made to the conventional working principles to render it suitable for $\mathrm{AC}$ purpose and the modifications are reported in this chapter.

Chapter 4 discusses the experimental analysis of the LDAC system; and also reports the experimental findings of conventional 4-stage VMEMD regenerator. The results display the effect of various control parameters on the system performance and discuss the un-suitability of the conventional 4-stage configuration for AC purposes based on performance analysis. 
Chapter 5 discusses the mathematical modelling and simulation study of the membrane based absorber and the regenerator unit of the LDAC system. Energy and mass balance equations developed from the rigors of thermodynamics are solved by the numerical methods. The physical significance of the simulation studies is also explained in this chapter.

Chapter 6 analyses the alternative configurations of the VMEMD regenerator to obtain the best configuration for AC applications. The proposed regeneration system performance is analysed based on experimentally measured data and simulation results. The comparison of experimental data, simulation results and the literature data are presented in the chapter which verifies that the proposed regeneration system exhibits better performance than conventional regeneration units and chapter 7 summarises the major findings up to now along with further recommendations for future research directions.

For better understanding the research objectives and scopes, the next chapter begins with a detailed literature review of LDAC systems with various regeneration processes.

\section{References}

[1] D. Kolokotsa, et al., A roadmap towards intelligent net zero- and positiveenergy buildings. Solar Energy, 2011. 85(12): p. 3067-3084.

[2] D.P.Wyon, The effects of indoor air quality on performance and productivity. Indoor Air 14, 2004: p. 92-101.

[3] A.M. Omer, Energy, environment an sustainable development. Renew.Sustain.Energy Rev. 12, 2008: p. 2265-2300. 
[4] L.Mei and Y.J. Dai, A technical review on use of liquid-desiccant dehumidification for air-conditioning applications. Renew. Sustain. Energy Rev., 2008. 12: p. 662-689.

[5] E.M. Sterling, A. Arundel and Sterling T.D., Criteria for human exposure to humidity in occupied buildings. ASHRAE Transactions, 1985. 91: p. 611-622.

[6] Petit and Manuel-Conde. Liquid Desiccant Based Air-conditioning systemsLDAC. in 1st European Conference on Polygeneration 2007. Tahoma.

[7] X.H. Liu, et al., Combined cogeneration and liquid-desiccant system applied in a demonstration building. Energy and Buildings, 2004. 36(9).

[8] M.M. Elsayed, H.N. Gari, and A.M. Radhwan, Effectiveness of heat and mass transfer in packed beds of liquid desiccant system. Renewable Energy, 1993. 3: p. 661-668.

[9] V. Martin and D.Y. Goswami, Effectiveness of heat and mass transfer processes in a packed bed liquid desiccant dehumidifier/regenerator. Hvac\&R Research, 2000. 6(1): p. 21-39.

[10] K. Gommed and G. Grossman, Experimental investigation of a liquid desiccant system for solar cooling and dehumidification. Solar Energy, 2007. 81: p. 131 - 138.

[11] Yin. Yonggao, et al., Experimental study on a new internally cooled/heated dehumidifier/regenerator of liquid desiccant systems. International Journal of Refrigeration, 2008. 31(5): p. 857.

[12] X.H Liu, et al., Experimental investigation of the heat and mass transfer betwwen air and liquid desiccant in a cross flow regenerator. Renewable Energy 2007. 32: p. 1623-1636.

[13] S. Alizadeh, Performance of a solar liquid desiccant air conditioner - An experimental and theoretical approach. Solar Energy, 2008. 82(6): p. 563572. 


\section{Chapter 2}

\section{Literature Review}

\subsection{Introduction}

The efficiency of liquid desiccant air-conditioning (LDAC) depends on a number of factors such as performance of the absorber and regenerator, efficiency of the driving energy supplier i.e. solar plates or waste heat source, quality of air at inlet and outlet, mass transfer of water vapour across the membrane, absorbent concentration and mass flow rate, and heat recovery in the regenerator. Bacteriostatic and corrosion characteristics of the system also determine its utility as an air-conditioner [1]. In order to understand the working mechanism of the LDAC, following aspects of knowledge are needed:

- $\quad$ Experimental study of LDAC systems.

- Regeneration of the desiccant solution and its thermodynamics.

- The essential driving force for absorption of water vapour by the desiccant.

- Theoretical modelling and analysis of desiccant regenerator.

- $\quad$ Effect of the membrane on the absorption / de-sorption process.

- Desiccant material selection and their properties.

- Working mechanism and control parameters of the absorber, regenerator and the heat exchangers.

- Benefits of unconventional input heat source e.g. solar collectors, waste heat etc. 
This chapter aims to give a literature justification of existing design that leads to the necessity to propose a novel LDAC design, with a multi-stage-multi-effect regeneration system.

\subsection{Thermo-physical properties of liquid desiccant systems}

Liquid desiccant has been used in industrial dehumidifier since the 1930s. These solutions have a high affinity with water vapour and thus can be used to dry air entering the dehumidifier without over cooling it. This unique property has led to its prevalent use in the air conditioning industry. These absorbents are usually strong solutions of ionic salts like $\mathrm{CaCl}_{2}$ or $\mathrm{LiCl}$ [2]. It has the ability to form stronger bonds with $\mathrm{H}_{2} \mathrm{O}$ molecules (relative to the bond strength of $\mathrm{H}_{2} \mathrm{O}$ molecules in pure liquid water). The capacity to absorb moisture from the air decreases with the increase in temperature of the absorbent. Whenever the solution absorbs moisture from the air, its temperature increases. Hence a coolant is often used to continuously remove heat from desiccants. These salts are extremely corrosive in nature and extreme care needs to be taken to protect the wetted parts of the LDAC as well as to prevent aerosol formation.

The selection of liquid desiccant for dehumidification purposes depends upon various thermo-physical properties. These are summarized in the following sections.

2.2.1 Equilibrium Vapour Pressure - The ability of desiccant to dehumidify air depends upon its equilibrium vapour pressure. It has been observed by various researches that the equilibrium vapour pressure increases exponentially with increase in temperature of the desiccant-water system. The equilibrium It also increases with the decrease in concentration of the desiccant solution [3]. 
A dilute desiccant has a higher equilibrium vapour pressure compared to a concentrated desiccant. The one with lower saturation humidity has greater ability to dehumidify the air and is also less inclined towards crystallization. The study reveals that $\mathrm{LiBr}$ has the maximum drying ability while $\mathrm{MgCl}_{2}$ has minimum drying ability.

The equation proposed by M.Conde [4] for equilibrium vapour pressure (П) in terms of relative vapour pressure is of the general form:

$$
\Pi=\frac{P_{s o l}(\xi, T)}{P_{H_{2} O}(T)}
$$

Where, $P_{\text {sol }}(\xi, T)$ is the pressure of the liquid desiccant as a function of mass fraction of the solute $(\xi)$ and temperature of the solution $(\mathrm{T})$. And $P_{\mathrm{H}_{2} \mathrm{O}}(T)$ is the pressure of water at the same temperature.

2.2.2 Dynamic Viscosity- It is the measure of a fluid's resistance to flow, therefore solutions with high viscosity needs driving force to make them flow. The viscosity of electrolytic solutions shows non uniform change. At lower concentrations, the viscosity increases slightly with the increase in temperature whereas at higher concentrations of the solution viscosity increases significantly with increase in concentration. The correlation developed by Zaytsev and Aseyev [5] can predict viscosity values for of dilute solutions (up to $30 \%$ for $\mathrm{LiBr}$ and less than $15 \%$ for $\mathrm{MgCl}_{2}$ ) [5]. The correlation provided by Conde [4] can predict viscosity for concentrations up to its saturation level and the general form of dynamic viscosity $(\eta)$ for lithium chloride and calcium chloride is given by,

$$
\eta_{\text {sol }}(\zeta, \theta)=\eta_{H_{2} O}(\theta) e^{\eta_{1} \zeta^{3.6}+\eta_{2} \zeta+\frac{\eta_{3} \zeta}{\theta}+\eta_{4} \zeta^{2}}
$$

where, $\zeta$ is defined as $\zeta=\xi /(1-\xi)^{1 / 0.6}$ and $\theta=\frac{T}{228}-1$, and $\eta_{\text {sol }}(\zeta, \theta)$ is the dynamic viscosity of the salt solution as a function of salt concentration and 
temperature (T). For higher concentrations of $\mathrm{MgCl}_{2}$ and $\mathrm{LiBr}$, the correlation by Muhiuddin and Ismail [6] and Lee et al. is [7] is used for viscosity calculations .

2.2.3 Density- It is required for the energy balance in the fluid streams as well as to determine the pressure drop of the liquid in the solution cycle. Several corelations have been developed for the density calculations of liquid desiccants. In 1992, Zaytsev and Aseyev [5] developed a generalised correlation for density calculations of different electrolytes, and the correlation could be extended to 133 electrolytes. Novotny and Sohnel developed correlations for density calculations of 360 different salt solutions [8].

It can be observed from the studies that the density of the salt solutions shows very small variations with change in temperature but the variation in concentration has a serious effect on the density of the solution. The equation proposed by Wimby and Berntsson for density $(\rho)$ measurement of aqueous $\mathrm{LiCl}$ solution is as follows:

$$
\begin{gathered}
\rho=d_{1}+d_{2} T+d_{3} T^{2}+d_{4} \xi+d_{5} \xi^{2}+d_{6} \xi T+d_{7} \xi^{2} T+d_{8} \xi T^{2} \\
+d_{9} \xi^{3}+d_{10} \xi^{4}
\end{gathered}
$$

where $d_{1}, d_{2}, d_{3}, \ldots \ldots \ldots, d_{10}$ are parameters listed in [9].

2.2.4 Specific Heat capacity- It is an important property for desiccant solutions because it determines the change in its temperature due to energy exchange with air while it flows in the solution channel. Hence it affects the temperature distribution in the solution channel, which in turns governs the capacity of de-humidification and possibilities of crystallization. 
2.2.5 Thermal Conductivity- It governs the rate of heat exchange between air stream and the solution stream. Thermal conductivity values for various salts are available in the literature [4, 5]. The study by Zaytsev and Aseyev [5], indicates that the thermal conductivity of the salt solutions decreases linearly versus concentration. Whereas the correlation proposed by Conde [4] exhibits a non-linear behaviour for lithium chloride and calcium chloride solutions.

2.2.6 Diffusion coefficient- The binary diffusion coefficient of water in the salt solution dictates the mass transfer process between the air and solution channels. The convective mass transfer coefficient of the liquid desiccant is calculated based on its diffusion coefficient. The diffusion coefficient is inversely related to the liquid desiccant concentration, i.e. rate of diffusion of water decreases with increase in solution concentration. As expected from kinetic theory diffusion coefficient and hence diffusion increases with increase in temperature [4].

All these information is needed for the modelling and simulation of LDAC system.

\subsection{Liquid desiccant air-conditioning systems}

Liquid desiccant air-conditioning systems utilizes the hydrophilic properties of liquid desiccant materials to control the indoor air quality (IAQ). The system can be used either independently or in conjunction with conventional vapour compression air-conditioning units. Vapour compression systems spend a lot of energy is cooling the ambient air below its dew point temperature for dehumidification purposes and then further re-heating it to acceptable indoor air temperature. However, in LDAC systems, the latent heat load is handled by the absorber and the evaporator handles only the sensible heat load. The energy required for the regeneration of the liquid desiccant is available from low grade 
heat source like solar panels, waste heat etc. Hence, LDAC systems can dehumidify the ambient air in a more energy efficient way than conventional ACs and reduce the overall energy consumption in the building cooling sector. The schematic of a basic LDAC system is shown in Figure 2.1.

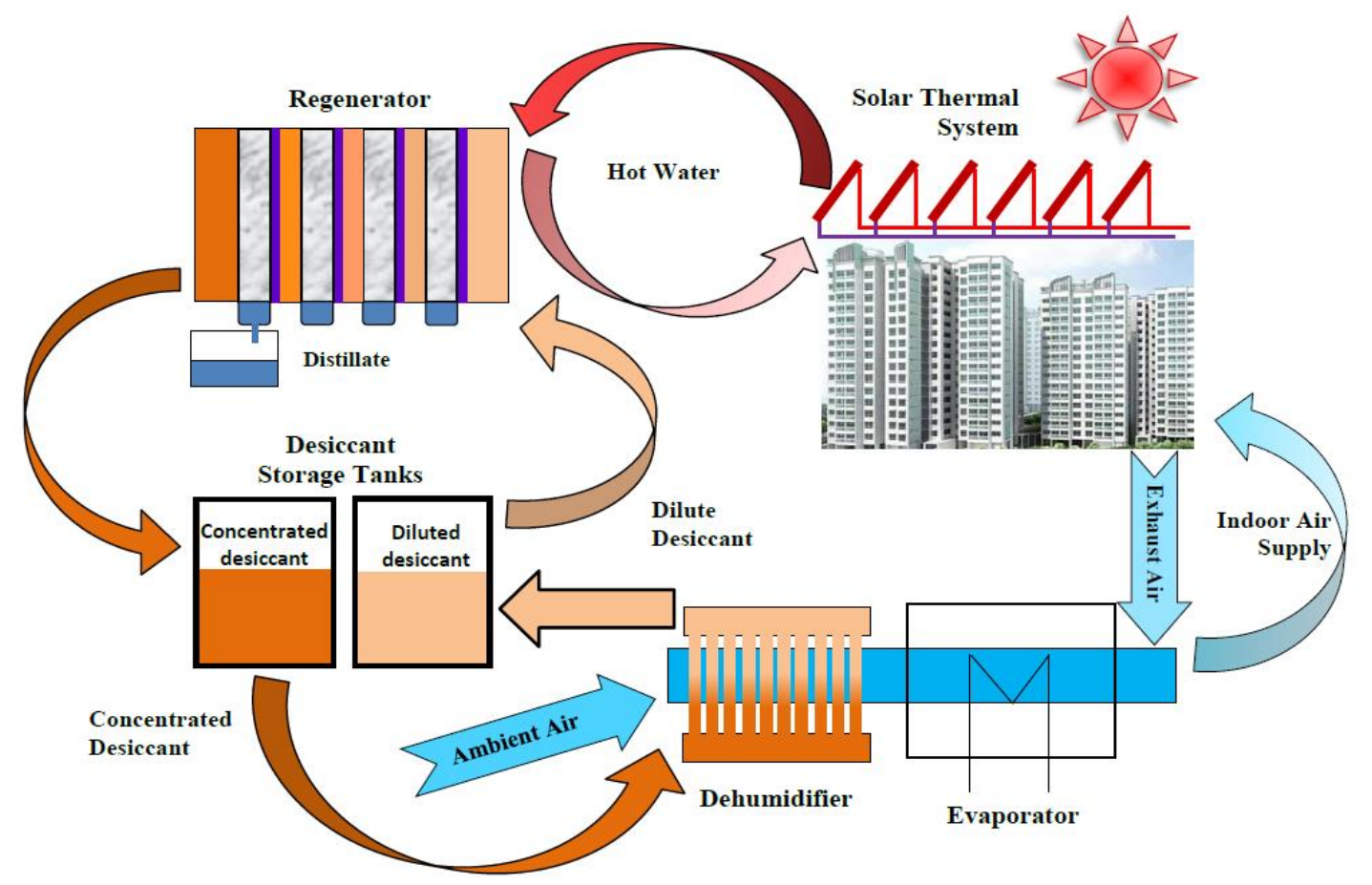

Figure 2.1: Schematic representation of a solar driven L-DAC system (developed at Energy Research Institute, NTU, Singapore)

The dehumidifier and the regenerator performance dictate the overall performance of the liquid desiccant air-conditioning system. The difference in the vapour pressure between the air stream and the salt solution primarily drives the mass transfer between them. A variety of equipment designs were tested over the years for improving heat and mass transfer performances of the absorber and the regenerator. These include spray towers, packed towers, and wetted wall towers etc. The spray towers provide a large air-desiccant contact area especially for high viscosity desiccants and also exhibits low pressure drop in the air channel. 
However, carryover of liquid droplets into the air stream along with clogging due to dust and dirt prevents it from being practicable. Wetted wall tower offers a stability of flow along with providing continuous contact between the air and solution, but the surface area for heat and mass transfer is relatively small. Packed towers can provide a large gas-liquid contacting area with acceptable air pressure drop and have encouraged many researchers to study packed towers as the dehumidifier and regenerator. Random packing and structured packing are often used in packed towers but they are not able to address the problems arising from solution vapours carryover into the air stream, fouling, scaling etc.

Fumo and Goswami (2002) [10]: Studied a packed bed dehumidifier experimentally using lithium chloride as desiccant, and compared the results with a modified form of the "Finite Difference" mathematical model developed by Oberg and Goswami (1998b) [11]. They used acrylic tube for construction of the absorption cum regeneration tower for better flow visualization and used polypropylene rings for packing the tower. Aqueous solution of lithium chloride was sprayed over the packing by using three spray nozzles arranged in an equilateral triangular configuration. The major advantages of the design was use of plastic packing to reduce corrosion by lithium chloride solution and the surface area for heat and mass exchange is maximized. However due to direct contact between air-stream and desiccant the risk of corrosion and fouling are very high.

Factor and Grossman [12] constructed a packed bed contactor and carried out experiments to study its ability to perform as a dehumidifier and regenerator for solar powered absorption cooling operations. The desiccants used were: a) Mono Ethylene Glycol (MEG) b) Aqueous solution of lithium bromide. MEG exhibited good water absorption properties but also has the tendency to evaporate into the airstream. The major problem was formation of oily droplets in the ducts leading to 
contamination. They concluded that the system exhibited feasibility of liquid desiccant absorption and regeneration; however the pressure drop across the packing affected the efficiency and lighter packing materials will improve the performance of the units.

Y.J. Dai et al. (2001) [13] constructed a hybrid LDAC system in which the sensible load was handled by conventional vapour compression system. The latent heat load was handled at the dehumidifier using liquid desiccant and the diluted desiccant was regenerated at the regenerator. A honeycomb paper packing provided desired contact surface for heat and mass transfer between the air and the liquid desiccant. The regeneration was driven by solar energy. The cooling was found to be 20-30\% more than the conventional vapour compression system acting alone.

Potnis and Lenz [14] studied a solar-assisted liquid desiccant system with $\mathrm{LiBr}$ as the desiccant salt. They studied both random and structured packing, and concluded that for both type of contactors the liquid phase is in a state of turbulence. Lazzarin [15] experimentally studied the counter-flow packed tower dehumidifier. They analysed the effects gas-liquid mass flux ratio on moisture removal rate and dehumidifier efficiency. Longo and Gasparella [16] experimentally investigated a packed column desiccant regeneration using lithium bromide as the desiccant and the results showed the temperature levels of around $50^{\circ} \mathrm{C}$ is required for regeneration. Moreover, they also concluded regeneration efficiency for random packing is $20-25 \%$ higher than structured column but structured towers showed $65-75 \%$ less pressure drop on the air-side.

The advantage of structured packing is lower pressure drop on the air-side and offers a large surface for mass exchange, and this led to the researchers taking high interest in design, development and testing of structured towers for desiccant 
dehumidification and regeneration. They can be broadly classified on the direction of flow of its components e.g. parallel flow, cross flow or counter-flow. Internally cooled dehumidifier (structured packed bed-type) uses cooling coils to remove the heat generated during dehumidification thereby maintaining the ability of liquid desiccant to continue dehumidification efficiently.

Jiang et al. $[17,18]$ proposed a multi-stage dehumidifier where the cooling took place in two separate stage; In the first stage the high temperature heat load was cooled by circulating water at a temperature of $26-30^{\circ} \mathrm{C}$ and the low moisture content stage was cooled by water at a temperature of $18-21^{\circ} \mathrm{C}$. As a result, the dehumidification performance was improved. Yin et al. [19,20] developed a novel internally cooled dehumidifier and internally heated regenerator using plate-fin heat exchanger for desiccant cooling/heating. The experimental results showed significant improvement in dehumidification and regeneration performances as compared to adiabatic systems. Moreover internally heated regenerators exhibited higher energy efficiency and worked well even for lower desiccant flow rates.

Further development in solar energy studies and material science has encouraged researchers to use cost effective solar energy to drive the regeneration process. Many experts combined liquid desiccant dehumidification, conventional vapour compression and solar driven desiccant regeneration to come up with airconditioning systems that are able to control air temperature and humidity independently, and can also operate at a higher COP compared to conventional airconditioning systems. Yin et al. [21] developed a LDAC system comprising of three primary components; a dehumidifier, a regenerator and an evaporative cooler. The atmospheric air was dehumidified using liquid desiccant in the dehumidifier and the dehumidified air was cooled and re-humidified by the evaporative cooler before supplying it indoors. The diluted desiccant exiting from the dehumidifier 
was regenerated using low grade heat source with temperatures between $60-80^{\circ} \mathrm{C}$. Jiang et al. [22] presented a heat pump driven two-stage liquid desiccant fresh air unit. The reported a COP of the fresh air unit was 5.0 under full load operations, and could go as high as 5.9 under partial load conditions. They also reported that the COP of the integrated heat pump was 4.0 at full load and 5.70 at part load, conditions.

\subsection{Membrane assisted LDAC system and progresses}

The advancements in material science and technology have introduced polymeric membranes with high porosity and better kinetic properties for mass transfer across the membrane. The unique property of these membranes lies in its ability to allow passage of water vapour across it. The LDAC systems utilize these membranes to separate the desiccant solution from the air channel therefore reducing the risk of corrosion and fouling. Research and development works on membrane distillation have been in progress for over the past two decades.

The hydrophobic polymeric membranes provide high surface area for interaction between the fluids resulting in higher heat and mass transfer rates across the membrane. It should also be noted here that the PTFE (Poly tetra-fluoro ethylene) hydrophobic membranes are micro-porous flat sheet type with good gas

permeability, and can be used for LDAC research [23]. Figure 2.2 illustrates the working principle of PTFE membrane for water-vapour separation from the supply air channel.

The membrane module comprises thin layers of six polypropylene (PP) foil frames and five PP membrane frames friction-welded together alternatively. A spacer is 
adjoined between each foil frame and membrane frame and it serves as a barrier to create a channel for uniform solution flow.

The hydrophobic membranes used in the modules are micro-porous and made of Polytetrafluoroethylene (PTFE). The properties of the membrane are shown in Table 2.1.

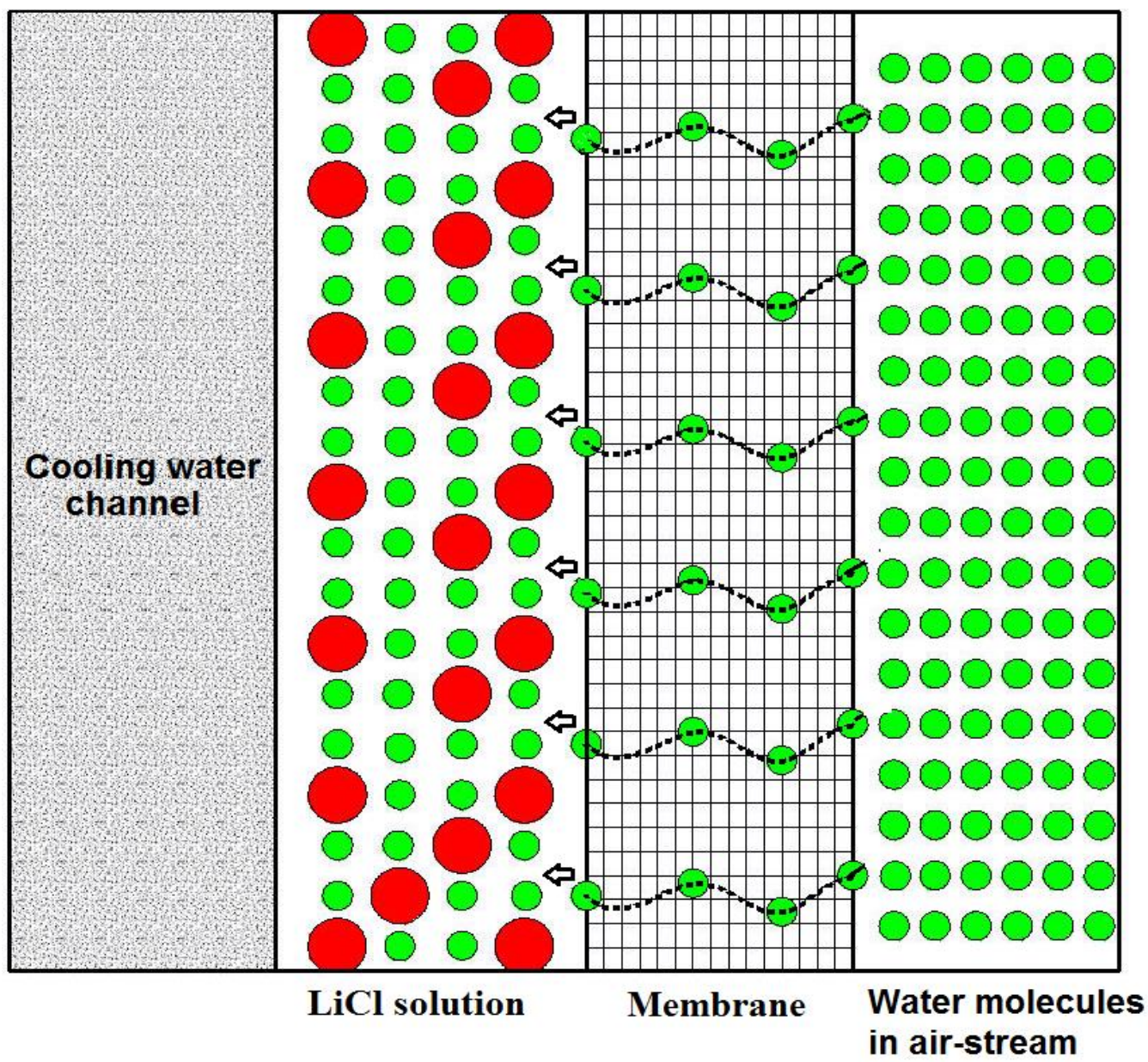

Figure 2.2: Working principles of PTFE membrane for water-vapour separation from supply air channel due to vapour pressure difference. The transfer of water molecules are shown through the membrane. 
Table 2.1: Properties of the hydrophobic membrane

Description: $\quad$ Hydrophobic ePTFE Membrane Laminate Functional Layer: Poly tetra-fluoro ethylene (PTFE) Backer Material: Polypropylene (PP)

\begin{tabular}{|l|l|}
\hline Reference Pore Size & $0.2 \mu \mathrm{m}$ \\
\hline Wressure & $>50 \mathrm{psi}(3.5$ bar) average, ASTM D751 \\
\hline Air Permeability & $\begin{array}{l}\text { Nom. } 0.1-0.4 \mathrm{ft}^{3} / \mathrm{ft}^{2} / \mathrm{min} @ 125 \mathrm{~Pa}\left(10-401 / \mathrm{cm}^{2} / \mathrm{h} @ 0.07\right. \\
\text { bar), ASTM D737 }\end{array}$ \\
\hline Thickness & Nom. $5-8$ mil $(0.12-0.20 \mathrm{~mm})$ ASTM D1777 \\
\hline $\begin{array}{l}\text { IPA bubble Point } \\
\text { Available } \\
\text { Dimensions }\end{array}$ & $\begin{array}{l}\text { OEM membranes as custom slit roll goods; Membrane } \\
\text { vents in customised shapes. }\end{array}$ \\
\hline $\begin{array}{l}\text { All above data are nominal; provided for information only and is subject to } \\
\text { change. All metric conversions are approximate. }\end{array}$
\end{tabular}

Figures 2.3 (a) and 2.3 (b) show the SEM (Scanning Electron Microscope) images of the front side PP and rear side reinforced PTFE hydrophobic membrane layer respectively. They demonstrate good gas permeability because of its highly porous surface as shown in Figure 2.3. Moreover, the all plastic approach i.e. using PP in all the module components minimizes corrosion, fouling and scaling issues, which are faced by metallic components. The major drawbacks of corrosion and contamination have been addressed in recent research using hydrophobic membranes to separate the liquid desiccant from the airstream during absorption and regeneration. 

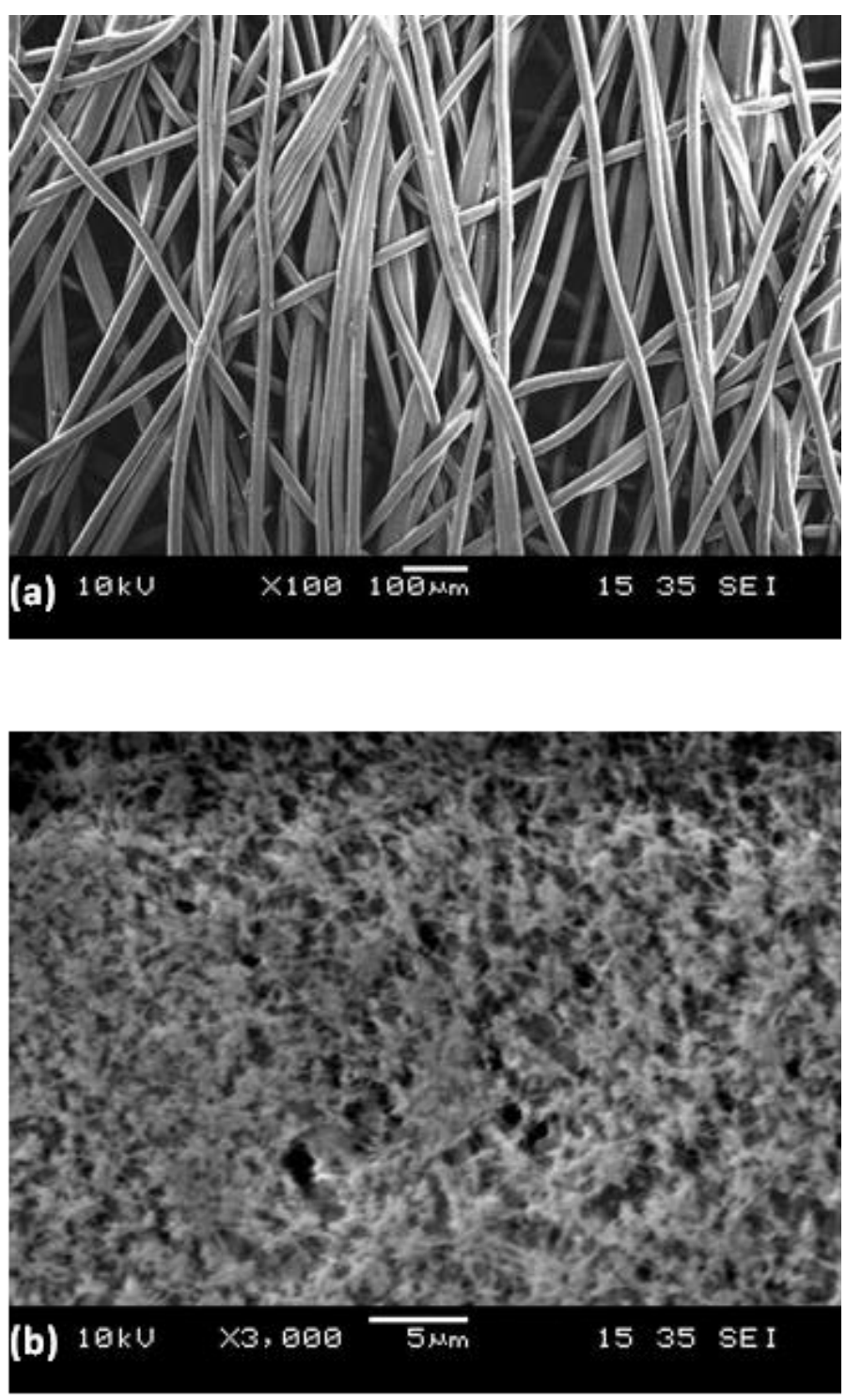

Figure 2.3(a): SEM image of front side PP.

Figure 2.3(b): SEM image of rear side reinforced PTFE hydrophobic membrane layer.

Up to now, two types of membrane technologies are gained attention in LDAC research. One is the LAMEE (liquid-air-membrane energy exchanger) for HVAC applications [24] and the other is RAMEE (run-around-membrane energy exchanger) for passive energy recovery in buildings [25]. Mahmud et al. [25] constructed and tested a counter cross-flow RAMEE (Run-around membrane 
energy exchanger) in 2011. One exchanger in the RAMEE system was installed in the supply air stream channel, and the other exchanger was installed in the exhaust air stream channel. Aqueous solution of magnesium chloride at $32 \%$ inlet concentration was used in the RAMEE. The effectiveness of the system increased with both number of transfer units (NTU) and specific heat ratio (Csol/Cair) of solution to air or when the air flow rate is reduced and solution flow rate is increased. The subscripts sol and air represents solution and air respectively. A maximum total effectiveness of $53 \%$ during the summer for a specific heat ratio of 4.8 and a maximum total effectiveness of $55 \%$ during the winter for a specific heat ratio of 2.8 was reported. The effect of membrane properties, membrane geometry and diverse membrane contactor configurations on trans-membrane has been well documented in scientific literature. Zhang [26] studied the effects of membrane characteristics on the mass diffusion during absorption and regeneration processes, and reported that the vapour transfer across the membrane increases when the membrane pore size and porosity is increased. However, for membranes with higher values of thickness and tortuosity, the vapour transfer is low. Zhang [27], proposed a supported liquid membrane. Two PVDF membranes were used to support a cellulose acetate membrane from either side. The effect of support membrane characteristics on the performance [28, 29] were consistent with their predictions [26].

Jason Woods and Eric Kozubal [30] investigated desiccant enhanced evaporative air conditioner in 2013. A sheet of polyethylene terephthalate (PET) of $0.1 \mathrm{~mm}$ thickness bounded on both the supply and exhaust sides with a polystyrene-backed wicking material to ensure even distribution of desiccant and water was used. They found it difficult to achieve energy balance due to heat loses from the system and also found it difficult to measure the humidity of saturated air at intermediate levels. 
Bergero and Chiari [31] studied the energy performances of membrane energy exchangers in a hybrid membrane LDAC system and suggested that their system can save up to $60 \%$ more energy compared to conventional AC systems. Abdel Salam et al. [32] studied a LAMEE (Liquid-air-membrane energy exchanger) under different control parameters in 2013. They concluded that the system performance shows significant improvement when NTU (number of transfer units) was increased up-to a value of 10 . However, the performance did not show much improvement when NTU value was increased beyond 10. It was advised to set the desiccant temperatures to the dehumidifier and regenerator inlets at $15-20{ }^{\circ} \mathrm{C}$ and $45-55^{\circ} \mathrm{C}$, respectively, to achieve optimum performance.

The recent development and perspective of membrane distillation are highlighted in Table 2.2.

Table 2.2: Summary of various membrane distillations driven by low grade heat source.

\begin{tabular}{|c|c|c|}
\hline Distillation type & Basic feature & Performances \\
\hline $\begin{array}{l}\text { Direct-contact- } \\
\text { membrane } \\
\text { distillation (DCMD) } \\
{[33,34]}\end{array}$ & $\begin{array}{l}\text { - No external condenser is } \\
\text { required. } \\
\text { - Both hot and cold } \\
\text { aqueous streams are in } \\
\text { direct contact with } \\
\text { membrane surface. } \\
\text { - Requires relatively higher } \\
\text { temperature. }\end{array}$ & $\begin{array}{l}\text { - Performance ratio ranges } \\
\text { from } 0.2 \text { to } 0.9 \text { depending on } \\
\text { inlet feed temperatures. } \\
\text { - Permeate flux varies from } 20 \\
\mathrm{~kg} / \mathrm{m}^{2} \mathrm{~h} \text { to } 80 \mathrm{~kg} / \mathrm{m}^{2} \mathrm{~h} .\end{array}$ \\
\hline $\begin{array}{l}\text { Air-gap-membrane } \\
\text { distillation (AGMD) } \\
{[35,36]}\end{array}$ & $\begin{array}{l}\text { - Conductive heat loss } \\
\text { through the membrane is } \\
\text { significantly reduced. }\end{array}$ & $\begin{array}{l}\text { - Energy efficiency ranges } \\
\text { from } 80 \% \text { to } 90 \% \text { for a } 3 \mathrm{~mm} \\
\text { air gap. }\end{array}$ \\
\hline
\end{tabular}




\begin{tabular}{|c|c|c|}
\hline & $\begin{array}{l}\text { - Air gap increases the } \\
\text { mass and heat transfer } \\
\text { resistances. } \\
\text { - Lower permeate flux. }\end{array}$ & $\begin{array}{l}\text { - Minimum required } \\
\text { temperature to drive the } \\
\text { system is } 65^{\circ} \mathrm{C} \text {. } \\
\text { - Energy efficiency id reduced } \\
\text { to } 70 \% \text { for the air gap of } 1.5 \\
\mathrm{~mm}\end{array}$ \\
\hline $\begin{array}{l}\text { Sweep-gas- } \\
\text { membrane } \\
\text { distillation (SWMD) } \\
\text { [37] }\end{array}$ & $\begin{array}{l}\text { - Provides high mass } \\
\text { transfer rate. } \\
\text { - Relatively lower heat } \\
\text { loss. } \\
\text { - Complex heat recovery } \\
\text { system. }\end{array}$ & $\begin{array}{l}\text { - Permeate flux varies from } 5 \\
\text { to } 25 \mathrm{~kg} / \mathrm{m}^{2} . \mathrm{h} \text {. }\end{array}$ \\
\hline $\begin{array}{l}\text { Vacuum membrane } \\
\text { distillation (VMD) } \\
{[38,39]}\end{array}$ & $\begin{array}{l}\text { - Reduce absolute pressure } \\
\text { in the downstream side of } \\
\text { the membrane. } \\
\text { - Overcomes the problem } \\
\text { of air resistance to heat } \\
\text { transfer. } \\
\text { - Rapid vapour transfer } \\
\text { due to pressure } \\
\text { gradients. }\end{array}$ & 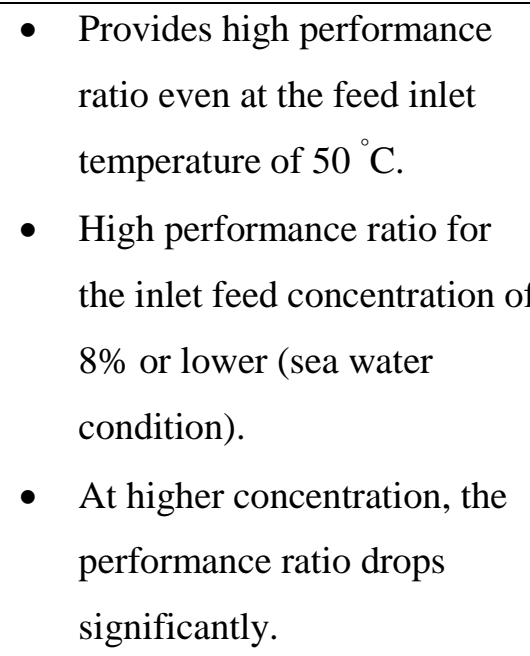 \\
\hline
\end{tabular}

\subsection{Control factors for LDAC optimizations}

The performance of the desiccant regenerator depends on a number of factors, which include: inlet and outlet air conditions, desiccant inlet and outlet conditions, flow rates of fluid components, internal heating, pressure variation across the membrane etc. Research activities studying the parameters and control factors of LDAC systems are shown in Table 2.3. 
Table 2.3: Summary of liquid desiccant dehumidification/regeneration for air-conditioning (AC) applications.

\begin{tabular}{|c|c|c|c|}
\hline Source & Description & Results & Contribution \\
\hline $\begin{array}{l}\text { K.Gommed, } \\
\text { G.Grossman } \\
{[40,41]}\end{array}$ & $\begin{array}{l}\text { Parametric study, } \\
\text { investigating the } \\
\text { effect of different } \\
\text { design parameters } \\
\text { on cooling and } \\
\text { dehumidification } \\
\text { performance. The } \\
\text { system was driven } \\
\text { by solar power. } \\
\text { Building a } \\
\text { prototype and } \\
\text { carried out } \\
\text { experimental study. }\end{array}$ & $\begin{array}{l}\text { - Higher the heating } \\
\text { temperature, higher } \\
\text { is the desiccant } \\
\text { concentration at the } \\
\text { regenerator outlet. } \\
\text { - The solution flow } \\
\text { rate is optimum in } \\
\text { the range of 0.4-0.6 } \\
\text { kg/s for effective } \\
\text { dehumidification of } \\
\text { supply air. }\end{array}$ & $\begin{array}{l}\text { - The effect of air inlet } \\
\text { temperature is relatively } \\
\text { low. } \\
\text { - The effect of flow rates } \\
\text { and temperatures of the } \\
\text { heating water, cooling } \\
\text { water and the desiccant } \\
\text { solution has significant } \\
\text { effect and some of these } \\
\text { parameters have to be at } \\
\text { optimum levels to meet } \\
\text { supply air humidity } \\
\text { requirements. } \\
\text { - Thermal COP of about } \\
\text { 0.8 (parasitic loses } 10 \\
\text { \%) was reported. }\end{array}$ \\
\hline $\begin{array}{l}\text { N.Fumo, } \\
\text { D.Y. } \\
\text { Goswami } \\
{[10]}\end{array}$ & $\begin{array}{l}\text { - Experimental study } \\
\text { of a packed bed } \\
\text { liquid desiccant } \\
\text { dehumidifier and a } \\
\text { regenerator. } \\
\text { - Desiccant used as } \\
\text { working fluid is } \\
\text { aqueous solution of } \\
\text { lithium Chloride }\end{array}$ & $\begin{array}{l}\text { - Rate of water } \\
\text { evaporation } \\
\text { increases with the } \\
\text { air velocity and } \\
\text { inlet temperature of } \\
\text { desiccant with a } \\
\text { slope of } 0.5 \text { and } 5 \\
\text { respectively } \\
\text { - Rate of water }\end{array}$ & $\begin{array}{l}\text { - Design variables with } \\
\text { most significant impact } \\
\text { on the desiccant } \\
\text { regenerator } \\
\text { performance are: } \\
\text { temperature and } \\
\text { concentration of } \\
\text { desiccant. } \\
\text { - Humidity effectiveness }\end{array}$ \\
\hline
\end{tabular}


Table 2.3

\begin{tabular}{|c|c|c|c|}
\hline & 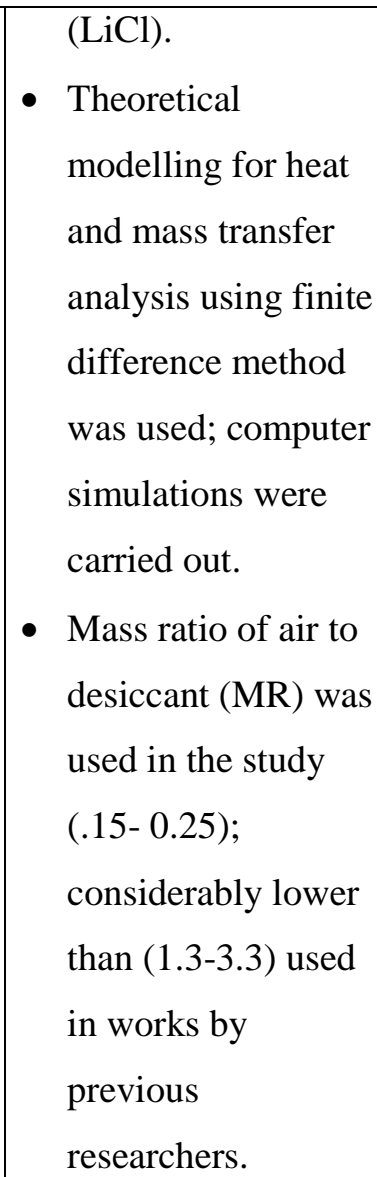 & $\begin{array}{l}\text { evaporation } \\
\text { decreases with the } \\
\text { inlet concentration } \\
\text { of desiccant and } \\
\text { relative humidity of } \\
\text { inlet air with a } \\
\text { slope -1.8 and -0.3 } \\
\text { respectively. } \\
\text { - Evaporation } \\
\text { increases with feed } \\
\text { flow rate with a } \\
\text { slope of } 0.3 \text {. } \\
\text { Humidity } \\
\text { effectiveness } \\
\text { decreases with } \\
\text { increase in air flow } \\
\text { rate and desiccant } \\
\text { flow rate. }\end{array}$ & $\begin{array}{l}\text { of the regenerator } \\
\text { ranged between } 71 \% \\
\text { and } 87 \% \text { for MR } \\
\text { varied between } 0.15 \\
\text { and } 0.25 \text {. }\end{array}$ \\
\hline $\begin{array}{l}\text { H.M. Factor, } \\
\text { G.Grossman } \\
{[12]}\end{array}$ & $\begin{array}{l}\text { - Design and } \\
\text { experimental study } \\
\text { of a packed bed air- } \\
\text { liquid contactor } \\
\text { using mono- } \\
\text { ethylene glycol and } \\
\text { lithium bromide as } \\
\text { desiccants driven } \\
\text { by solar energy for } \\
0.5 \text { ton air- } \\
\text { conditioning. } \\
\text { Theoretical }\end{array}$ & $\begin{array}{l}\text { MEG evaporates in } \\
\text { small quantities } \\
\text { leading to } \\
\text { contamination of } \\
\text { the system } \\
\text { (formation of oily } \\
\text { droplets in the } \\
\text { outlet ducts) } \\
\text { making it un- } \\
\text { suitable for air- } \\
\text { conditioning } \\
\text { systems. }\end{array}$ & $\begin{array}{l}\text { - Performance of the } \\
\text { regenerator is enhanced } \\
\text { by pre-heating the air } \\
\text { stream at inlet. } \\
\text { - Optimum L/G ratio is } \\
0.5-0.8 \text { from both mass } \\
\text { transfer and pressure } \\
\text { drop considerations. } \\
\text { - Satisfactory } \\
\text { regeneration is obtained }\end{array}$ \\
\hline
\end{tabular}


Table 2.3

\begin{tabular}{|c|c|c|}
\hline $\begin{array}{l}\text { modelling for } \\
\text { performance } \\
\text { evaluation under } \\
\text { various operating } \\
\text { conditions was } \\
\text { developed. } \\
\text { - Computer aided } \\
\text { simulations based } \\
\text { on the theoretical } \\
\text { model were carried } \\
\text { out and compared } \\
\text { with the } \\
\text { experimental data. } \\
\text { Liquid mass flux } \\
\text { per gas mass flux } \\
\text { (L). The values of } \\
\mathrm{L} \text { varied between } \\
1470-8810 \mathrm{~kg} / \mathrm{hr}- \\
\mathrm{m}^{2} \text { and } \mathrm{G} \text { varied } \\
\text { between } 7340-9790 \\
\mathrm{~kg} / \mathrm{hr}-\mathrm{m}^{2} \text {. }\end{array}$ & $\begin{array}{l}\text { - Inlet concentration } \\
\text { of LiBr solution } \\
\text { was between } 54 \% \\
\text { and } 60 \% \text { for the } \\
\text { experimental runs. } \\
\text { - The experimental } \\
\text { inlet values were } \\
\text { used as inputs for } \\
\text { the simulation and } \\
\text { the overall } \\
\text { agreement was } \\
\text { good. } \\
\text { Computer model } \\
\text { yields higher } \\
\text { temperatures than } \\
\text { physical model } \\
\text { because the } \\
\text { theoretical model } \\
\text { was ideally } \\
\text { adiabatic whereas } \\
\text { the physical model } \\
\text { lacked insulation } \\
\text { Mass transfer } \\
\text { increases with } \\
\text { increase in L/G } \\
\text { ratio but the energy } \\
\text { ratio increases. }\end{array}$ & $\begin{array}{l}\text { at } 80{ }^{\circ} \mathrm{C} \text { liquid } \\
\text { regeneration } \\
\text { temperature. } \\
\text { - Minimum of } 65^{\circ} \mathrm{C} \\
\text { temperatures are } \\
\text { required for } \\
\text { regeneration. } \\
\text { - Major disadvantage- } \\
\text { High pressure drop in } \\
\text { packed bed design. }\end{array}$ \\
\hline
\end{tabular}


Table 2.3

\begin{tabular}{|c|c|c|c|}
\hline $\begin{array}{l}\text { Y.Yin et al. } \\
{[21]}\end{array}$ & 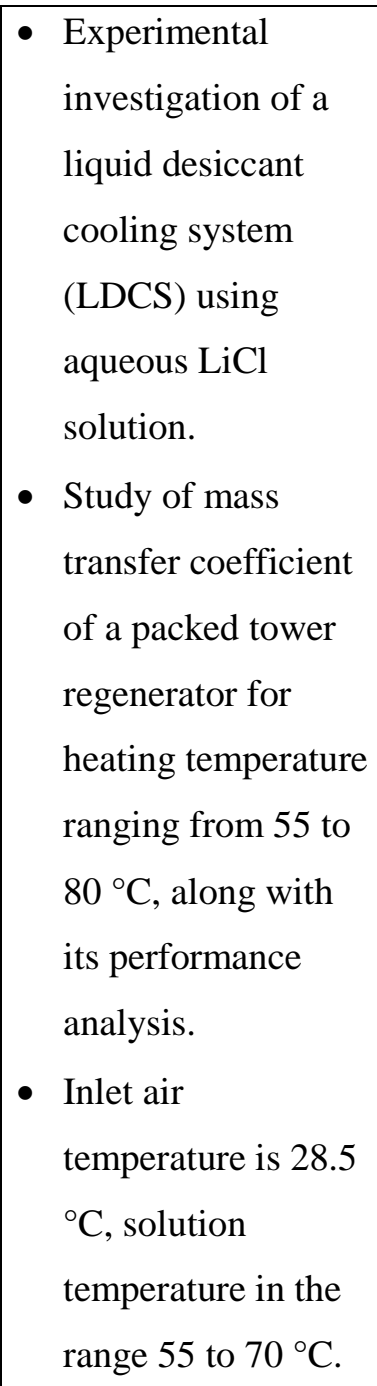 & $\begin{array}{l}\text { - Average mass } \\
\text { transfer coefficient } \\
\text { of the packing } \\
\text { tower regenerator } \\
\text { is } 4 \mathrm{~g} / \mathrm{m}^{2} \mathrm{~s} \text {. } \\
\text { - Maximum mass } \\
\text { transfer coefficient } \\
\text { is } 7.5 \mathrm{~g} / \mathrm{m}^{2} \mathrm{~s} \text { for } \\
\text { desiccant } \\
\text { concentration } 22 \% \\
\text { and heating } \\
\text { temperature } 77.5 \\
{ }^{\circ} \mathrm{C} \text {. } \\
\text { - Air outlet } \\
\text { temperature ranges } \\
\text { between } 32 \text { to } 35 \\
{ }^{\circ} \mathrm{C} \text {. } \\
\text { - Solution outlet } \\
\text { temperature ranges } \\
\text { between } 39.5 \text { to } 43 \\
{ }^{\circ} \mathrm{C} \text {. }\end{array}$ & $\begin{array}{l}\text { - The mass transfer } \\
\text { coefficient increases } \\
\text { with increasing heating } \\
\text { temperature. } \\
\text { - Outlet air and desiccant } \\
\text { solution temperatures } \\
\text { increase slightly with } \\
\text { increase in heating } \\
\text { temperature. } \\
\text { - When air humidity at } \\
\text { inlet is below } 12.1 \mathrm{~g} / \mathrm{kg} \text {, } \\
\text { the rate of } \\
\text { dehumidification varies } \\
\text { linearly with change in } \\
\text { air inlet humidity. } \\
\text { - The maximum value of } \\
\text { specific tower } \\
\text { efficiency is achieved at } \\
\text { air inlet humidity } \\
15.6 \mathrm{~g} / \mathrm{kg} \text {. }\end{array}$ \\
\hline $\begin{array}{l}\text { X.H. Liu et } \\
\text { al.[42] }\end{array}$ & $\begin{array}{l}\text { - A theoretical model } \\
\text { was developed } \\
\text { using NTU and } \\
\text { Lewis number to } \\
\text { predict air and } \\
\text { solution parameters } \\
\text { inside the } \\
\text { dehumidifier and }\end{array}$ & $\begin{array}{l}\text { - The salt solution } \\
\text { outlet temperature } \\
\text { was highest at the } \\
\text { inlet and lowest at } \\
\text { the outlet during } \\
\text { dehumidification } \\
\text { - The salt solution } \\
\text { outlet temperature }\end{array}$ & $\begin{array}{l}\text { - The two-dimensional } \\
\text { theoretical model } \\
\text { showed good agreement } \\
\text { with the experimental } \\
\text { records, and it was able } \\
\text { to predict the } \\
\text { temperature and } \\
\text { concentration }\end{array}$ \\
\hline
\end{tabular}


Table 2.3

\begin{tabular}{|c|c|c|c|}
\hline & $\begin{array}{l}\text { the regenerator for } \\
\text { cross-flow } \\
\text { arrangement. } \\
\text { - Experiments were } \\
\text { carried out on a } \\
\text { Celdek structure } \\
\text { packing modules } \\
\text { using LiBr to } \\
\text { determine the } \\
\text { enthalpy } \\
\text { effectiveness and } \\
\text { moisture } \\
\text { effectiveness to } \\
\text { determine the } \\
\text { dehumidifier/regen } \\
\text { erator performance. } \\
\text { Theoretical data } \\
\text { was compared to } \\
\text { the experimental } \\
\text { findings for } \\
\text { validation. }\end{array}$ & $\begin{array}{l}\text { decreased along the } \\
\text { length of the } \\
\text { module following a } \\
\text { linear trend; lowest } \\
\text { at } \mathrm{z}=0 \text { and } \\
\text { maximum at } \mathrm{z}=\mathrm{L} \\
\text { during } \\
\text { regeneration; where } \\
\mathrm{z} \text { is the co-ordinate } \\
\text { axis and } \mathrm{L} \text { is the } \\
\text { length of the } \\
\text { module. }\end{array}$ & $\begin{array}{l}\text { distributions inside the } \\
\text { dehumidifier/regenerato } \\
\text { r. } \\
\text { - For dehumidification: } \\
\text { average absolute } \\
\text { discrepancies for } \\
\text { enthalpy and moisture } \\
\text { effectiveness are } 7.9 \% \\
\text { and } 8.5 \% \text { respectively. } \\
\text { - For regeneration: an } \\
\text { average absolute } \\
\text { discrepancy for } \\
\text { enthalpy effectiveness } \\
\text { is } 5.8 \% \text { and moisture } \\
\text { effectiveness is } 6.9 \% \text {. }\end{array}$ \\
\hline $\begin{array}{l}\text { Z.Q. Xiong } \\
\text { et al [43] }\end{array}$ & $\begin{array}{l}\text { - A two-stage liquid } \\
\text { desiccant } \\
\text { dehumidification } \\
\text { system based on } \\
\text { exergy analysis was } \\
\text { developed. } \\
\text { - Desiccant salt: } \\
\text { Calcium chloride, }\end{array}$ & $\begin{array}{l}\text { - The exergy } \\
\text { efficiency is } \\
\text { increase from } 6.8 \\
\% \text { for single stage } \\
\text { to } 18.7 \% \text { for } 2- \\
\text { stage. } \\
\text { - COP is increased } \\
\text { from } 0.24 \text { to } 0.58\end{array}$ & $\begin{array}{l}\text { - The improvement in } \\
\text { exergy and COP is a } \\
\text { result of pre- } \\
\text { dehumidification of } \\
\mathrm{CaCl}_{2} \text { and variation of } \\
\text { feed concentration. } \\
\text { - The different heat } \\
\text { exchangers consume } 80\end{array}$ \\
\hline
\end{tabular}


Table 2.3

\begin{tabular}{|c|c|c|c|}
\hline & $\begin{array}{l}\text { Lithium chloride; } \\
\text { different stages } \\
\text { occupy different } \\
\text { desiccant salt } \\
\text { solution. } \\
\text { - Comparison study } \\
\text { was conducted with } \\
\text { single stage liquid } \\
\text { desiccant } \\
\text { dehumidification } \\
\text { systems to study the } \\
\text { various parameters } \\
\text { and the } \\
\text { performance of the } \\
\text { system. } \\
\text { The component of } \\
\text { the system is made } \\
\text { out of PVC (poly- } \\
\text { vinyl chloride) to } \\
\text { prevent corrosion. }\end{array}$ & $\begin{array}{l}\text { on applying 2-stage } \\
\text { operation. } \\
\text { - Pre- } \\
\text { dehumidification of } \\
\mathrm{CaCl}_{2} \text { solution for } \\
\text { 2-stage operation } \\
\text { increases exergy } \\
\text { efficiency to } 23 \% \\
\text { and COP to } 0.73 \text {. } \\
\text { - Optimum level of } \\
\text { operation leading } \\
\text { to highest COP and } \\
\text { exergy is achieved } \\
\text { at } 55 \% \text { of the } \\
\text { regenerator volume } \\
\text { is assigned to LiCl } \\
\text { regenerator. }\end{array}$ & $\begin{array}{l}\% \text { of the net exergy lost } \\
\text { in the system. } \\
\text { - Energy storage capacity } \\
\text { of } \mathrm{CaCl}_{2} \text { and } \mathrm{LiCl} \\
\text { solution at } 40 \% \\
\text { concentration increased } \\
\text { from } 237.8 \text { to } 395.1 \\
\mathrm{MJ} / \mathrm{m}^{3} \text {. } \\
\text { - Regeneration } \\
\text { temperature affects the } \\
\text { performance of the } \\
\text { system significantly. }\end{array}$ \\
\hline $\begin{array}{l}\text { G.Longo, } \\
\text { A. } \\
\text { Gasparella } \\
{[44]}\end{array}$ & $\begin{array}{l}\text { - Experimental study } \\
\text { of a random- } \\
\text { packing column for } \\
\text { air } \\
\text { dehumidification } \\
\text { and desiccant } \\
\text { regeneration system } \\
\text { for air-conditioning } \\
\text { applications. } \\
\text { - Desiccant: aqueous }\end{array}$ & $\begin{array}{l}\text { - Dehumidification } \\
\text { efficiency increases } \\
\text { from } 30 \% \text { to } 90 \% \\
\text { with change in flow } \\
\text { rate ratio from } 0.2 \\
\text { to } 0.3 \text {. } \\
\text { - Regeneration } \\
\text { efficiency increases } \\
\text { from } 20 \% \text { to } 75 \% \\
\text { with change in flow }\end{array}$ & $\begin{array}{l}\text { - Regeneration and } \\
\text { dehumidification } \\
\text { efficiency is affected } \\
\text { significantly by the } \\
\text { choice of desiccant. } \\
\text { - Theoretical model is } \\
\text { able to produce } \\
\text { dehumidification and } \\
\text { regeneration rates } \\
\text { similar to the }\end{array}$ \\
\hline
\end{tabular}


Table 2.3

\begin{tabular}{|c|c|c|c|}
\hline & $\begin{array}{l}\text { solution of } \mathrm{LiCl} \text {, } \\
\text { aqueous solution of } \\
\mathrm{LiBr} \text {, aqueous } \\
\text { solution of } \\
\text { potassium formate } \\
\text { (KCOOH). } \\
\text { Theoretical analysis } \\
\text { and simulation for } \\
\text { heat and mass } \\
\text { transfer studies. }\end{array}$ & $\begin{array}{l}\text { rate ration from } 0.3 \\
\text { to } 0.35 \text {. } \\
\text { - Desiccant } \\
\text { regeneration } \\
\text { requires a } \\
\text { temperature level } \\
\text { of } 40-50{ }^{\circ} \mathrm{C} \text {. }\end{array}$ & $\begin{array}{l}\text { experimental studies. } \\
\text { - KCOOH solution } \\
\text { produces better } \\
\text { regeneration results, } \\
\text { while } \mathrm{LiBr} \text { and } \mathrm{LiCl} \\
\text { show better } \\
\text { dehumidification } \\
\text { results. }\end{array}$ \\
\hline $\begin{array}{l}\text { S.Alizadeh } \\
\text { [45] }\end{array}$ & $\begin{array}{l}\text { - Experimental study } \\
\text { of a } 20 \mathrm{~kW} \text { capacity } \\
\text { LDAC system } \\
\text { prototype, for } \\
\text { humid region. } \\
\text { - Dehumidification } \\
\text { takes place in a } \\
\text { polymer plate heat } \\
\text { exchanger (PPHE); } \\
\text { Regeneration } \\
\text { occurs in a } \\
\text { scavenger air } \\
\text { regenerator. }\end{array}$ & $\begin{array}{l}\text { - The scavenger air } \\
\text { and the weak } \\
\text { solution is heated at } \\
70{ }^{\circ} \mathrm{C} \text { for effective } \\
\text { regeneration. } \\
\text { - COP of the } \\
\text { scavenger air } \\
\text { regenerator is } 0.65 \\
\text { but can be } \\
\text { improved to } 1.25 \\
\text { by pre-heating the } \\
\text { desiccant solution } \\
\text { upstream of the } \\
\text { regenerator. }\end{array}$ & $\begin{array}{l}\text { - Optimum air and } \\
\text { desiccant solution flow } \\
\text { rate for LDAC to be } \\
\text { effective is } 60,000 \\
\text { Ltr/min and } 3 \mathrm{Ltr} / \mathrm{min} \\
\text { respectively. } \\
\text { - The prototype was } \\
\text { satisfactory in } \\
\text { controlling the } \\
\text { temperature and } \\
\text { humidity of } 120 \mathrm{~m}^{2} \text { area } \\
\text { with effectiveness of } 82 \\
\% \text {. } \\
\text { The prototype can run } \\
\text { continuously for } 4 \text { hours } \\
\text { with uninsulated } \\
\text { desiccant storage tank } \\
\text { of capacity } 180 \mathrm{~L} \text {. }\end{array}$ \\
\hline
\end{tabular}




\subsection{Summary}

After an extensive literature survey it is observed that there are plenty of limitations that have prevented the growth of LDAC systems. In brief, the problems faced by LDAC systems include liquid desiccant aerosol formation, corrosion of metallic parts, formation of oil droplets in air ducts, poor indoor air quality, heat losses from the system, inefficient heat recovery and regeneration, and inability to operate under wide range of operating conditions etc. Therefore there exists a lot of scope for improvement in LDAC research

We have modified the conventional liquid desiccant air-conditioning system employing membrane technology with the addition of vacuum grade multi-effect membrane distillation (VMEMD) system. This thesis aims to address the problems associated with corrosion and desiccant aerosol formation as well as developing a novel LDAC capable of performing efficiently over a wide range of operating conditions.

The next chapter discusses the experimental investigation of the LDAC system. 


\section{References}

[1] Petit and Manuel-Conde. Liquid Desiccant Based Air-conditioning systemsLDAC. in 1st European Conference on Polygeneration 2007. Tahoma.

[2] P. Andrew Lowenstein, Review of Liquid Desiccant Technology for HVAC\&R Research, 2008. 14(6).

[3] M. Afshin, Selection of the Liquid Desiccant in a Run-Around Membrane Energy Exchanger 2010: Saskatoon.

[4] M. Conde, Properties of aqueous solutions of lithium and calcium chlorides: formulations for use in air conditioning equipment design. International Journal of Thermal Sciences 2004. 43: p. 367-382.

[5] I.D. Zaytsev and G.G. Aseyev, Properties of Aqueous Solutions of Electrolytes, . 1992, CRC Press: Florida.

[6] S. Mahiuddin, , and K. Ismail, Concentration Dependence of the Viscosity of Aqueous Electrolytes. A Probe into Higher Concentration. J. Phys. Chern., 1983. 87: p. 5241-5244.

[7] R.J. Lee, et al., Properties of Lithium Bromide-water solutions at high temperatures and concentrations. IL Density and Viscosity. ASHRAE Transactions, 1990. 96(1): p. 709-714.

[8] P. Novotny and O. Sohnel, Densities of aqueous solutions of inorganic substances. Acta Crystallographica Section B, 1985. 41(3): p. 208.

[9] J.M. Wimby, \& T. S. Berntsson, Viscosity and Density of Aqueous Solutions of LiBr, LiCl,ZnBrz, CaC12. Chem. Eng. Data, 1994. 5.

[10] N. Fumo and D.Y. Goswami, Study of an aqueous lithium chloride desiccant system: Air dehumidification and desiccant regeneration. Solar Energy, 2002. 72(4): p. 351-361. 
[11] V. Oberg, and D.Y. Goswami, Experimental study of the heat and mass transfer in a packed bed liquid desiccant air dehumidifier. Journal of Solar Energy Engineering-Transactions of the Asme, 1998. 120(4): p. 289-297.

[12] H.M. Factor and G. Grossman, A PACKED-BED DEHUMIDIFIERREGENERATOR FOR SOLAR AIR-CONDITIONING WITH LIQUID DESICCANTS. Solar Energy, 1980. 24(6): p. 541-550.

[13] Y.J. Dai, et al., Use of liquid desiccant cooling to improve the performance of vapour compression air conditioning. Applied Thermal Engineering, 2001. 21(12): p. 1185-1202.

[14] S.V. Potnis and T.G. Lenz, Dimensionless mass-transfer correlations for packed-bed liquid-desiccant contactors. Industrial \& Engineering Chemistry Research, 1996. 35(11): p. 4185-4193.

[15] R.M. Lazzarin, A. Gasparella, and G.A. Longo, Chemical dehumidification by liquid desiccants: theory and experiment. International Journal of Refrigeration, 1996. 22(4).

[16] G.A. Longo, and A. Gasparella, Experimental analysis on desiccant regeneration in a packed column with structured and random packing. Solar Energy, 2009. 83(4).

[17] X. Xie, et al., Simulation analysis on the fresh air handling unit with liquid desiccant total heat recovery, in Building Simulation 2007: Beijing, China. p. 642-648.

[18] X.H. Liu, et al., Combined cogeneration and liquid-desiccant system applied in a demonstration building. Energy and Buildings, 2004. 36(9).

[19] Y. Yin, et al., Model validation and case study on internally cooled/heated dehumidifier/regenerator of liquid desiccant systems. International Journal of Thermal Sciences, 2009. 48(8): p. 1664. 
[20] Yin. Yonggao, et al., Experimental study on a new internally cooled/heated dehumidifier/regenerator of liquid desiccant systems. International Journal of Refrigeration, 2008. 31(5): p. 857.

[21] Y. Yin, X. Zhang, and Z. Chen, Experimenatl study on dehumidifier and regenerator of liquid desiccant cooling air conditioning system. Building and Environment, 2007. 42: p. 2505-2511.

[22] T. Zhang, X. Liu, and Y. Jiang, Performance optimization of heat pump driven liquid desiccant dehumidification systems. Energy and Buildings, 2012. 52: p. 132-144.

[23] D. Singh and K.K. Sirkar, High temperature direct contact membrane based distillation using PTFE hollow fibers. Chemical Engineering Science, 2014. 116: p. 864 - 833.

[24] A. Salam, et al., State-of-the-art liquid-to-air membrane energy exchangers (LAMEEs): A comprehensive review. Renewable and Sustainable Energy Reviews, 2014. 39: p. 700 - 728.

[25] K. Mahmud, et al., Performance testing of a counter-cross-flow run-around membrane energy exchanger (RAMEE) system for HVAC applications. Energy and Buildings, 2010. 42(7): p. 1139-1147.

[26] S.-M. Huang, and L.-Z. Zhang, Researches and trends in membrane-based liquid desiccant air dehumidification. Renewable and Sustainable Energy Reviews, 2013. 28.

[27] X.R. Zhang, et al., One-step fabrication and analysis of an asymmetric cellulose acetate membrane for heat and moisture recovery. Journal of Membrane Science, 2011: p. 158-165.

[28] L.Z. Zhang, Progress on heat and moisture recovery with membranes: form fundamentals to engineering applications. Energy Conservation and Management 2012. 63. 
[29] L.Z. Zhang, and S.M. Huang, Coupled heat and mass transfer in a counter flow hollow fiber membrane module for air humidification. nternational Journal of Heat and Mass Transfe, 2011. 54.

[30] J. Woods, and E. Kozubal, A desiccant-enhanced evaporative air conditioner: Numerical model and experiments. Energy Conversion and Management, 2013. 65: p. 208-220.

[31] S. Bergero, and A. Chiari, Performance analysis of a liquid desiccant and membrane contactor hybrid air-conditioning system. Energy and Buildings, 2010. 42(11).

[32] A. Salam, Performance analysis of a membrane liquid desiccant airconditioning system, pp. 559-569, . Energy Build., 2013. 62: p. 559-569.

[33] Y.D. Kim, et al., Performance investigation of a solar assisted direct contact membrane distillation system. Journal of Membrane Science, 2013. 427: p. 345 - 364.

[34] J.G. Lee, et al., performance modelling of direct contact membrane distillation (DCMD) seawater desalination process using a commercial composite membrane. Journal of Membrane Science, 2015. 478: p. 85 - 95.

[35] C.M. Guijt, et al., Air-gap membrane distillation: 2. Model validation and hollow fibre module performance analysis. Separation and Purification technology, 2005. 43: p. 245 - 255.

[36] R. Aryapratama, et al., Performance evaluation of hollow fiber air gap membrane distillation module with multiple cchannels. Desalination, 2016. 385: p. $58-68$.

[37] M.M.A. Shirazi, A. Kargari, and M. Tabatabaei, Sweeping Gas Membrane Distillation (SGMD) as an Alternative for Integration of Bioethanol Processing: Study on a Commercial Memrane and Operating Parameters. Chemical Engineering Communications, 2015. 202: p. 457 - 466. 
[38] S. Wang and Y. Wang, Investigation of the through plane effective oxygen diffusivity in the porous media of PEM fuel cells: Effects of the pore size distribution and water saturation distribution. International Journal of Heat and Mass Transfer, 2016. 98: p. 541 - 549.

[39] Zhao, K., et al., Experimental study of the memsys vacuum multi-effectmembrane-distillation (VMEMD) module. Desalination, 2013. 323: p. 150 160.

[40] K.Gommed and G.Grossman, A liquid desiccant system for solar cooling and dehumidification. J. Solar Energy Engg., 2004. 126: p. 879-885.

[41] K.Gommed and G.Grossman, Experimental investigation of a liquid desiccant system for solar cooling and dehumidification. Solar energy, 2007(81): p. 131-138.

[42] Liu, X.H., Y. Jiang, and K.Y. Qu, Heat and mass transfer model of cross flow liquid desiccant air dehumidifier/regenerator. Energy Conversion and Management, 2007. 48(2): p. 546-554.

[43] Z.Q.Xiong, Y.J.Dai, and R.Z.Wang, Development of a novel two-stage liquid desiccant dehumidification system assisted by CaCl2 solutuion using exergy analysis method. Applied Energy, 2010. 87: p. 1495-1504.

[44] G.A. Longo and A. Gasperella, Experimental and theoretical analysis of heat and mass transfer in a packed column dehumidifier/regenerator with liquid desiccant. Int J. Heat and Mass Tranfer, 2005. 48: p. 5240-5254.

[45] S. Alizadeh, Performance of a solar liquid desiccant air conditioner - An experimental and theoretical approach. Solar energy, 2008. 82: p. 563-572. 


\section{Chapter 3}

\section{Experimental study of LDAC system}

\subsection{Introduction}

In the present, heating ventilation and air-conditioning (HVAC) systems are most prevalent for cooling applications in the building sectors. Conventional vapour compression systems remove the sensible and latent heat of air at the fan-coil unit. In order to remove the latent heat, chill water temperature is lowered below the dew-point temperature of the ambient air at the fan-coil inlet; thereby resulting in an energy inefficient chiller. Another undesirable attribute of this system is that the air cooled below the dew point temperature is often required to be re-heated for it to be suitable for human comfort, thus squandering even more energy. Conventional liquid desiccant air-conditioning is more energy efficient in handling the latent heat load. Despite the advantages, the conventional direct contact liquid desiccant air conditioning system has a major drawback of the desiccant solution aerosol carryover into the airstream. The desiccant solutions such as lithium chloride, lithium bromide etc. are highly corrosive, toxic in nature and corrodes the metallic parts of the system as well as the air ducts, vanes and the building. The quality of indoor air is not acceptable due to vapours of desiccants present in the air stream.

The aim of this chapter is to overcome these inherent limitations of direct contact packed tower dehumidification systems through design and development of an LDAC system incorporating polymeric hydrophobic membranes and an all plastic approach, which ensures zero carryover of desiccant aerosols into the airstream and corrosion of wet metallic parts of the system. This eliminates the problems of air- 
contamination and corrosion faced by direct contact liquid desiccant airconditioning systems. The sorption reactor containing salt solution and flat sheet hydrophobic membranes maximizes the area for water vapour transfer and minimizes conductive heat transfer.

The main objectives of this chapter include:

i) Design and installation of a LDAC test-bed capable of cooling an area of 50 $\mathrm{m}^{2}$.

ii) Design and fabrication of a membrane module for the absorber and the regenerator to minimize the energy consumption.

iii) Preparation of the desiccant solution.

\subsection{Overall system prototype}

The membrane based LDAC (Liquid Desiccant Air Conditioning) system integrated with VC (Vapour Compression Cycle) provides cooling and dehumidification within a $50 \mathrm{~m}^{2}$ floor area of an office space for air-conditioning. The blue-print of the LDAC test bed is provided in the appendix section of this report. The LDAC test-bed comprises of six main components, they are:

i) Air ducts for fresh air and exhaust air transport

ii) Membrane-based air dehumidifier unit

iii) Vacuum multi-effect membrane based desiccant regenerator

iv) Vapour compression refrigeration system

v) Solar thermal system

vi) Desiccant solution energy storage system.

The schematic diagram of the test bed is shown in Figure 3.1. It consists of three working cycle, they are the absorption cycle, the regeneration cycle and the 
refrigeration cycle. The absorbent cycle comprises of a hydrophobic membrane based dehumidifier depicted as ABS in the schematic (Figure 3.1), a hydrophobic membrane based regenerator depicted as REG in the schematic, and intermediate storage tanks for concentrated and dilute absorbents depicted as TANK $_{\mathrm{Lcon}}$ and TANK $_{\text {Ldil }}$ respectively.

The desiccant used for the experiments is aqueous solution of lithium chloride. The storage tanks are custom made Polypropylene (PP) tanks. It can handle intermittent temperatures up to $95{ }^{\circ} \mathrm{C}$ for the stored material and are resistant to the corrosive nature of lithium chloride. The volumetric capacities of the tanks are 30 litres each. It is cylindrical in shape and provided with PP nozzles for transportation of the fluid.

A heat exchanger is employed for energy exchange between the dilute and the concentrated absorbent depicted as HEX 3. The absorbent aqueous solution of Lithium chloride is depicted by $\mathrm{L}$ in the schematic. Two centrifugal / reciprocating pumps are used in this absorbent circuit, one at the exit of the regenerator depicted as $\mathrm{PU}_{\text {reg }}$ and another at the exit of the concentrated tank depicted as $\mathrm{PU}_{\mathrm{Lcon}}$. Butterfly valves are used to control the flow rate of lithium chloride solution depicted as GVL-1 and GVL-2 at entry and exit of the absorber respectively. Butterfly valves depicted as GVWc-1 and GVWc- 2 is used to control the flow rate of cold water at inlet and exit of the absorber.

The refrigerant cycle comprises of a compressor depicted as COM used for pumping in the refrigerant into the cycle in a superheated phase. The heat exchanger HEX-1 is for heat exchange between the super-heated refrigerant and the hot water which in turn is available from a low energy heat source such as solar collector or waste heat or natural gas. The superheated refrigerant passes through 
an expansion valve where it cools down and further proceeds towards heat exchanger HEX-2, heat exchange occurs between the cold water and the refrigerant. The cold water is then circulated in the system by a pump $\mathrm{PU}_{\mathrm{wc}}$. The refrigerant used for the study is R-134a. The symbols and the subscripts indicating system components are reported in Table 3.1.

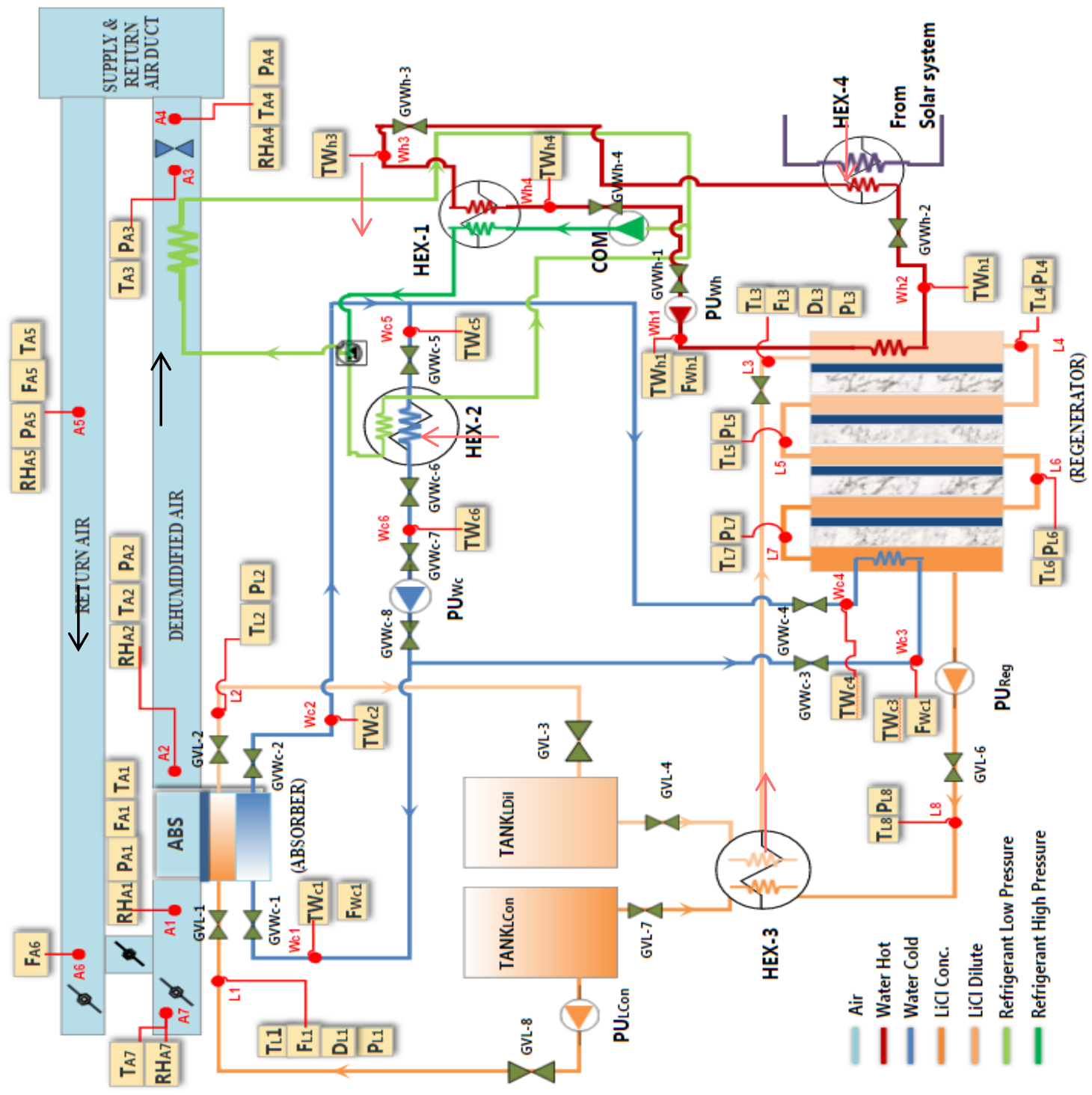

Figure 3.1: Schematic diagram of membrane based LDAC system using renewable energy. 
Table 3.1: List of notations and subscripts used in the schematic diagram of LDAC

\begin{tabular}{|l|l|}
\hline RH & Relative humidity sensor \\
\hline T & Temperature sensor \\
\hline P & Pressure sensor \\
\hline F & Flow rate sensor \\
\hline D & Density sensor \\
\hline A1-A7 & Solution flow location indicator \\
\hline W $1-\mathrm{W}_{\mathrm{c} 8}$ & Air flow location indicator \\
\hline $\mathrm{W}_{\mathrm{h} 1-\mathrm{W}_{\mathrm{h} 4}}$ & Chilled water flow location indicator \\
\hline GV & Hot water flow location indicator \\
\hline PU & Butterfly Valve \\
\hline HEX & Pump \\
\hline ABS & Heat exchanger \\
\hline COM & Absorber \\
\hline
\end{tabular}

The heat exchangers used in the plant are $9 \mathrm{KW}$ rated water/gas heat exchanger flat plate type. The pump $\mathrm{PU}_{\mathrm{Wh}}$ is installed in the hot water loop near the entry to the regenerator which maintains the hot water flow in the cycle. The pumps handling water as the fluid are centrifugal type and the pumps handling lithium chloride solution as the fluid are diaphragm type. The mechanical diaphragm pumps are suitable for high flow rate. The LDAC plant uses the pumps with the adjust flow of 50 litres/hr to 1800 litres/hour at a maximum discharge pressure of 10 bar and temperature range: $-30{ }^{\circ} \mathrm{C}$ to $+70{ }^{\circ} \mathrm{C}$. The function of the installed pumps is to 
maintain a steady volumetric flow rate of the fluids in the system. The air ducts carry conditioned air into the room and is fitted with air dampers. The function of the dampers is to regulate the air flow, and also prevent it from entering specified areas. By controlling air flow, the duct damper can be used to control air temperature and humidity. It can also restrict the flow of dangerous fumes or smoke. The power consumption of air dampers of the test bed is $2 \mathrm{~V}$ while running and $1 \mathrm{~V}$ while holding. The layout drawing of the LDAC test bed system is shown in Figure 3.2.

The suitable working conditions for these dampers are:

i) Ambient temperature: $-30^{\circ} \mathrm{C}$ to $+50^{\circ} \mathrm{C}$.

ii) Non operation temperature: $-40^{\circ} \mathrm{C}$ to $+80^{\circ} \mathrm{C}$.

iii) Humidity up to $95 \%$ non-condensing.

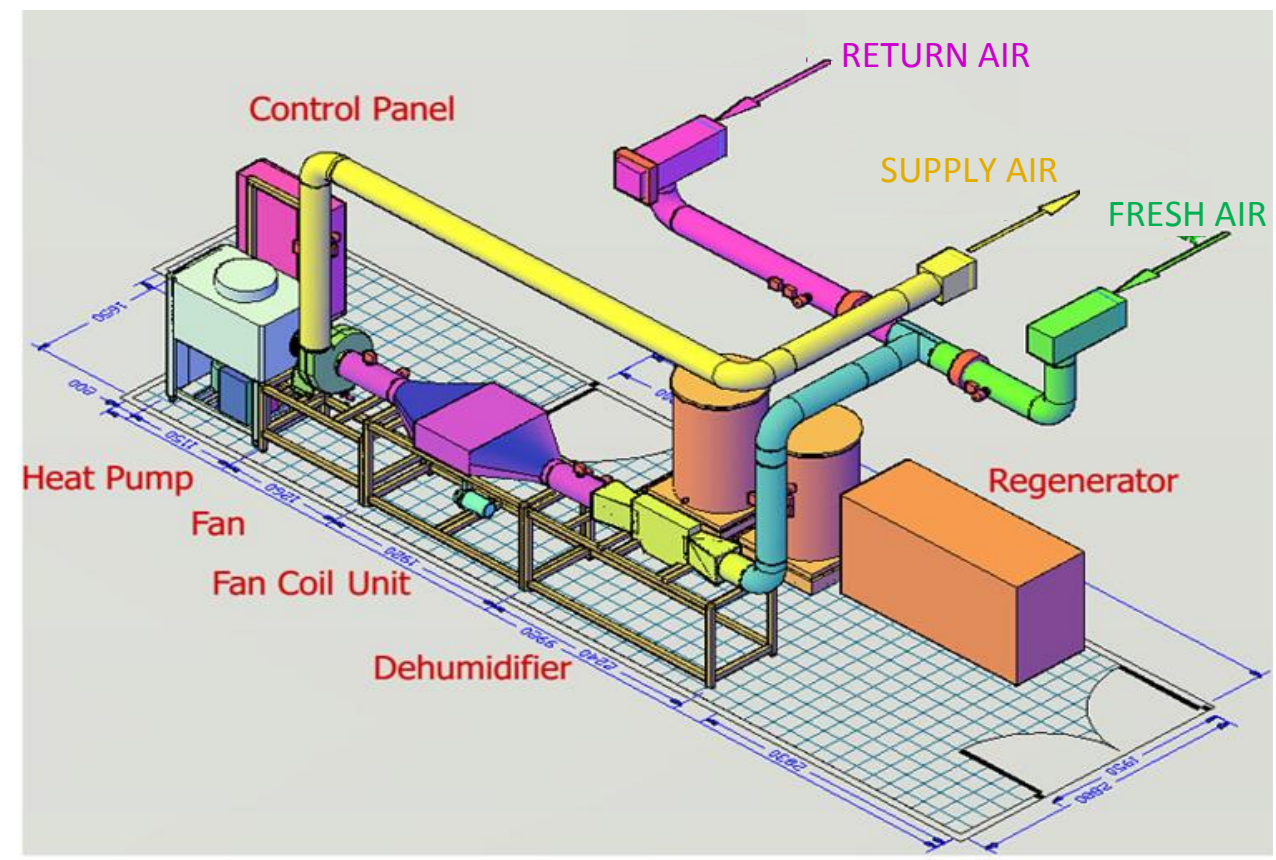

Figure 3.2: Layout drawing of the test bed system. 
Figure 3.2 exhibits a 3D-model for better understanding of the experimental setup the various processes and components shown in the schematic diagram in Figure 3.1 can be related to it. The heat pump in Figure 3.2 refers to the heat exchanger loops containing the refrigerant, heat exchangers HEX-1 and HEX-2, compressor COM and a DX coil for cooling the dehumidified air before supply.

\subsubsection{Selection of the desiccant solution}

Glycols and solutions of halide salts are prevalent dehumidifiers in industrial equipment even today. Both have their significant advantages and disadvantages. Most abundantly used glycol of dehumidification purposes are Tri-ethylene glycol and Polypropylene glycol. Advantages of the glycols are that they are less toxic and compatible with most metals, these properties led to their use in research for LDAC applications.

However, they are volatile in nature and this result in loss of glycols from the system. This is unacceptable in terms of both economics of the system and environmental impact. It has been observed in the literature that a mixture of $96 \%$ Tri-ethylene glycol and $4 \%$ water dries the air to the same dew point temperature as a $43 \%$ aqueous solution of $\mathrm{LiCl}$, but a molar concentration of the glycol in the air will be much higher [2].

Advantages of ionic salts is that they have very high capacity of drying the air owing to their low relative vapour pressure and has high thermal capacity for storing the thermal energy. Although $\mathrm{LiCl}$ has been more extensively used in the industry, and $\mathrm{LiBr}$ has been almost exclusively used in LDACs which uses water as the refrigerant. The reason though remains unclear but it is the odour given out 
by Bromine $(\mathrm{Br})$ gas that has act a deterrent in its use. Slightly acidic solution of high concentration $\mathrm{LiBr}$ tends to give out $\mathrm{Br}$ gas, which is also toxic in nature.

After an extensive literature review, aq. $\mathrm{LiCl}$ solution is found to be the best fit to be used as liquid desiccant for air-conditioning applications for our experimental research purpose.

\subsubsection{Preparation of the desiccant solution}

Anhydrous salt of lithium chloride with a minimum purity of $99.9 \%$ were used in preparation of the salt solution. Dry mass of the sample is required to calculate the concentration $\xi$ of aqueous solution (mass fraction [kgsalt $/ \mathrm{kgsol}]$ ). Before measuring the dry mass of desiccant salt the samples were heated up to $90{ }^{\circ} \mathrm{C}$ and kept for 4 hours under vacuum condition by using HERAEUS VACUTHERM vacuum oven to make sure that there is no moisture in the samples. Distilled water was used as the solvent in all aqueous solutions. PRECISA micro balance, with $\pm 0.0001 \mathrm{~g}$ accuracy, was applied to measure the mass of solvent and solutes (dry salitres). The concentration parameter is calculated from the known mass of solute and solution. The density of aqueous solution at known concentration is measured by means of Anton Paar DMA 5000M (Vibrating tube density meter; accuracy density: $0.000005 \mathrm{~g} / \mathrm{cm}^{3}$ ) at various temperature points (accuracy Temperature: $\left.0.01{ }^{\circ} \mathrm{C} / 0.02{ }^{\circ} \mathrm{C}\right)$. The densities of aqueous solutions were measured at temperatures ranging from $15{ }^{\circ} \mathrm{C}$ to $80{ }^{\circ} \mathrm{C}$ and concentrations up to $46 \%$ mass fraction. The prepared salt solution is added to the desiccant storage tank (concentrated) from where it is circulated to the absorber via poly-propene (PP) pipes with help of diaphragm-type solution pumps. 


\subsubsection{Instrumentation and measurements}

The four different working fluids are air, water, desiccant solution and R134 refrigerant. Various temperature, relative humidity, flow rate, Coriolis meters and pressure sensors are used to measure the required data from the test facility. The pressure sensors are installed at various points of the system for measuring the pressure at inlet and outlet of the absorber. Special pressure sensors (uncertainty, $\pm 2 \%$ of measurement scale) are installed at the inlet and the outlet line of the solution, which are resilient to corrosion by the absorbent. A Coriolis flow meter (error $\pm 0.5 \%$ of the full scale) is installed to measure the mass flow rate of the desiccant solution at the inlet of the absorber.

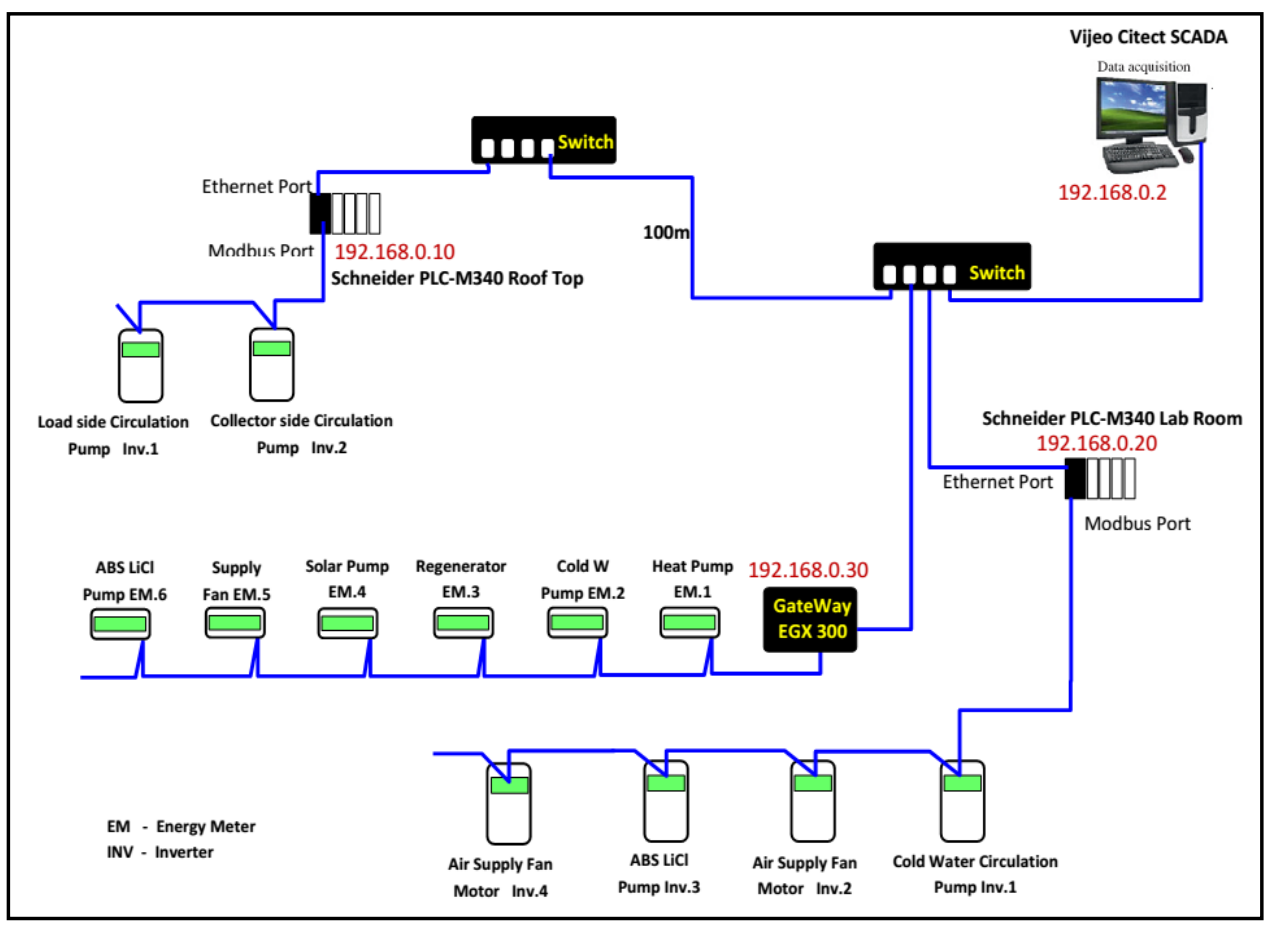

Figure 3.3: Data communication diagram between Inverters, Energy meters, Schneider M340 model PLCs. 
The pressure is also measured at air inlet and air exit of the absorber. The velocity meter is used for measuring the velocity of air entering the absorber. The relative

humidity is measured at the inlet and outlet of air channel using relative humidity sensors. Volumetric flow meters are used to measure the volumetric flow rates at the cooling and heating water outlets. All data are recorded by Schneider Electric data logger for further analysis. Employing uncertainty analysis, the PR error ranges from $1 \%$ to $8 \%$ depending on $\mathrm{LiCl}$ solution flow rates.

The inverter and the damper motors are controlled by two Schneider M340 PLCs. Data from the sensors and energy meters are acquired by the same PLCs, and is send to the computer for monitoring the system. Video Citect SCADA software is used to program the display of the data. Unity PRO software is used for programming of the PLCs. Figure 3.3 shows the data communication diagram between inverters, energy meters and the PLCs.

\subsection{Membrane based dehumidification system}

Membrane based flat-type treble flow dehumidifier is used for air dehumidification. The unit comprises of two frames; plastic foil frame and membrane frame. Figure $3.4 \mathrm{a}$ and $3.4 \mathrm{~b}$ shows membrane frame and the plastic foil frame respectively along with the flow directions of the fluids. The membrane and the foil frame are stacked together alternately creating three channels: a) Liquid desiccant channel, b) Air flow channel, c) Cooling water channel. The arrangement of the frames is shown in Figure 3.4(a) and the pictorial view of the dehumidifier along with the fluid flow directions is shown in Figure 3.4(b). 


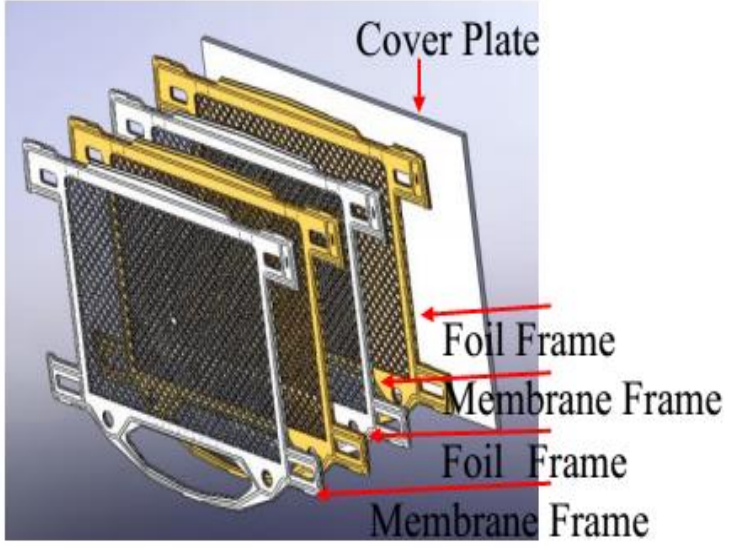

(a)

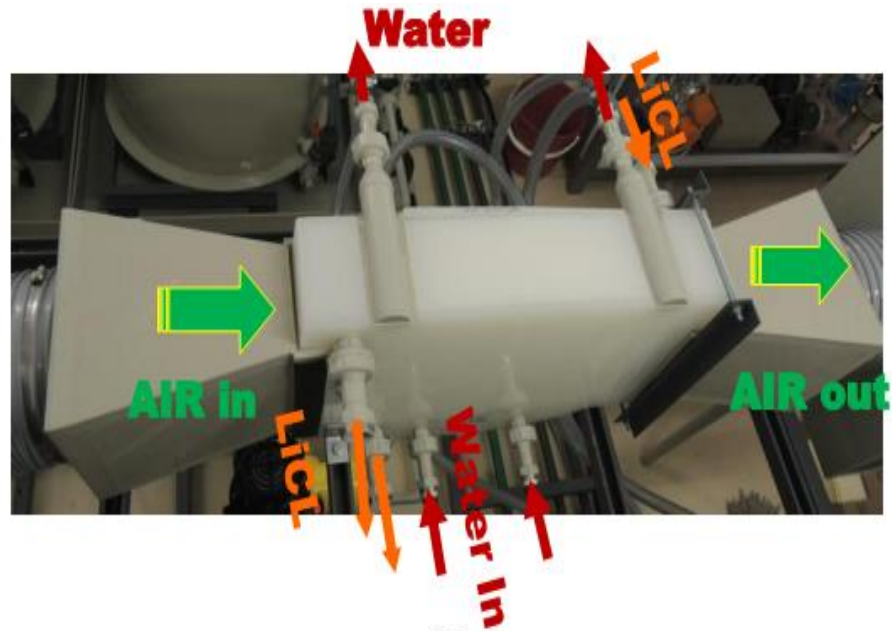

(b)

Figure 3.4(a): Arrangements of the plastic foil frames and the membrane frame.

Figure 3.4(b): Pictorial view of the dehumidifier along with fluid flow directions.

The dehumidifier essentially has three channels as explained previously. The vapour pressure and temperature difference between the air-stream and the desiccant channel acts as the driving force for removal of water vapour molecules from the air channel. The water molecules travel across the micro-porous membrane and are absorbed by the desiccant. However the desiccant molecules cannot travel in the opposite direction and enter the air-stream which minimizes the primary drawbacks of direct contact dehumidifier units. As the water vapour condenses across the membrane and enters the desiccant solution, the heat of condensation is released which raises the temperature of both the air stream and the desiccant solution. The cooling water channel serves as an internal cooler for the dehumidifier limiting the rise in temperature of the desiccant stream. Figure 3.5 illustrates the membrane and foil frames in a dehumidifier module along with the flow direction of the fluids (air, desiccant solution and cooling water) through the module. 


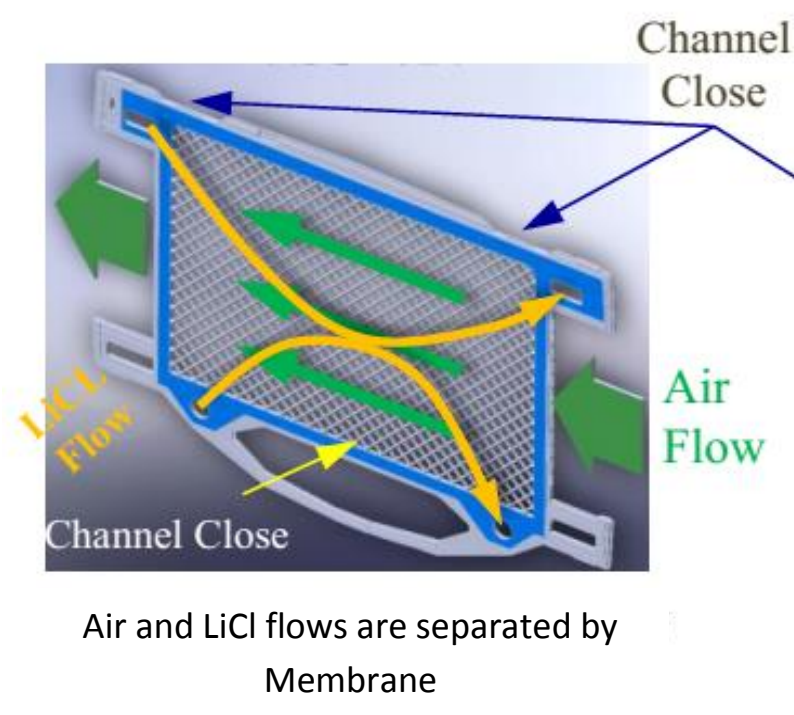

(a)

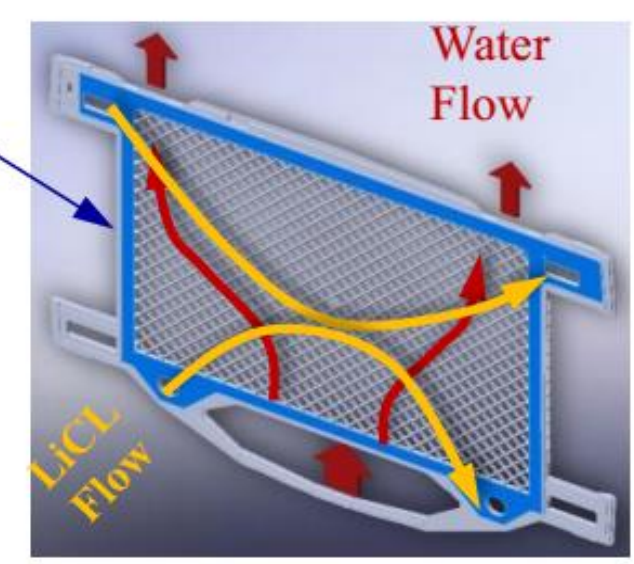

Water and LiCl flows are separated by Plastic Foil

(b)

Figure 3.5: (a) Membrane frame and (b) Foil frame of the treble flow dehumidifier with flow directions of fluid components.

The desiccant channel and the cooling water channel are separated by non-porous polypropylene (PP) foil. The necessity of cooling the desiccant arises from inherent properties of desiccants. Liquid desiccants have a low vapour pressure and therefore exhibits high affinity with water, however with increase in concentration and temperature its vapour pressure rises leading to a decrease in its capability to absorb more moisture from the air-stream. Hence, it is needed to be cooled. The desiccant has to be cooled carefully, as overcooling can lead to crystallization which is highly un-desirable. The cooling water is generated in the vapour compression refrigeration cycle and circulated with the help of centrifugal pumps. Another advantage of incorporating the internal cooling channel is that it reduces the foot print area of the dehumidifier. The warm and dehumidified air leaving the absorber is needed to be cooled by the DX coil of the vapour compression cycle before supplying indoors. 


\subsection{Vapour compression refrigeration system}

The VC refrigeration system uses refrigerant R134a as the working fluid. The system consists of a compressor, two evaporators, a condenser and an expansion valve. The first evaporator acts as refrigerant-to-water heat exchanger, it cools the water in the cooling water loop, which in turn acts as the coolant for the dehumidifier. During dehumidification process, heat is transferred simultaneously from both the lithium chloride solution channel (which constantly builds up heat as it tends to absorb the moisture and sensible heat from the process air) and air channel (lesser heat transferred due to small temperature difference between the adjacent layers), to the cooling water channel as heat tends to travel from hot to cold medium. Heat from all the cooling water channels pass to the connecting water loops of the LDAC system. The overall vapour compression system is shown schematically in Figure 3.1.

The water loop system is then cooled by the evaporator heat exchanger where heat from the water loop system is transferred to the evaporator with the aid of the refrigerant which is initially at a cold low pressure liquid gaseous state. The refrigerant R134a has a low boiling point so it vaporizes easily absorbing more heat from the cooling water loop. The gaseous refrigerant is then compressed by the compressor which raises its temperature and pressure. The high pressure refrigerant is cooled and liquefied by the condenser and enters the expansion valve which regulates the refrigerant flow into the evaporator, thereby reducing its pressure. Then it flows to the evaporator again, and the process is repeated for the next cycle.

The second evaporator is used as a DX cooling coil placed downstream of the dehumidifier; it directly cools the dehumidified process air to the desired room 
temperature before supplying it to the air-conditioned room. The heat from the processed air is transferred to the DX cooling coil. The pictorial view of the vapour compression refrigeration system is shown in the appendix section of this report. The heat released by the refrigerant during condensation acts as a supplement thermal energy in addition to the solar energy pre-heating the diluted desiccant solution before it enters the VMEMD regenerator. The next section discusses the regeneration of the liquid desiccant process.

\subsection{Vacuum assisted multi-effect membrane based regenerator or VMEMD}

The desiccant solution becomes warm and diluted after absorbing water vapour from the processed air in the absorber and its ability to absorb water vapour is reduced. The diluted salt solution is needed to be concentrated again for regaining its ability to dehumidify moist air, this process of regeneration of the desiccant salt solution occurs in the multi-effect regenerator. The VMEMD regenerator blends the advantages of multi-effect desalination and membrane's mass transfer allowing energy recovery, thereby reducing the overall thermal energy consumption [1].

\subsubsection{VMEMD Regenerator set-up}

Regenerator or multi-effect-membrane distillation, in which a thermally driven process allows water vapour (generated from the weak liquid desiccant solution) to transport through hydrophobic porous membranes. The test-bed also includes intermediate storage tanks made up of polypropylene for concentrated and dilute absorbent solutions. The storage tanks can handle intermittent temperatures up to $95{ }^{\circ} \mathrm{C}$ for the stored material and are resistant to the corrosive nature of $\mathrm{LiCl}$. An auxiliary heat exchanger (HEX 3 of Figure 3.1) is also employed for energy 
exchange between the dilute and the concentrated solutions. Two centrifugal/reciprocating pumps are used in this liquid desiccant circuit, one is at the exit of the regenerator and the other is at the exit of the concentrated tank. The butterfly valves are used to control the flow rate of $\mathrm{LiCl}$ solution at entry and exit of the absorber respectively. The valves are also used to control the flow rate of cold water at the inlet and exit of the absorber.

The regeneration unit as shown in Figure 3.1 performs the regeneration of water vapour from the dilute desiccant solution arriving from the absorber via dilute storage tank. The regenerator comprises multiple stages, and each stage consists of six poly-propylene (PP) plastic foil frames and five poly tetra-fluoro ethylene (PTFE) membrane frames. The modules are welded alternately with space between the foil frame and the membrane frame. This space provides the channel for a uniform flow of the desiccant solution for the regeneration of each stage. The concentrated desiccant at the exit of the regenerator is pumped back to the concentrated desiccant tank from where it is again used for dehumidification in the absorber. The air ducts carry conditioned air into the room and is fitted with air dampers.

\subsubsection{Multi-stage and multi-effect regeneration unit}

The VMEMD regeneration unit is an assembly of five key components; they are the steam riser, the condenser, multi-stage distillation modules, heat exchangers and vacuum pump. The steam-riser is constructed using PTFE membranes supported by PP plates and the condenser is made up of PP foils supported by PP plates. The multiple stages of the regenerator are separated using PP-plates which change direction of the solution flow and the vapour. The cover plates are welded 
to the frame in order to ensure a vacuum tight set-up. The construction of the VMEMD regenerator is identical to that of the absorber.

The regenerator is driven by solar power and the vacuum tube solar collector integration is installed on the roof of the building along with hot water storage tanks. The low grade heat required for regeneration of the desiccant is provided by the solar collectors via hot water tanks. The hot water can also be generated by using an auxiliary heater driven by waste heat. The schematic of VMEMD is shown in Figure 3.1.

\subsubsection{Working principle of regenerators}

The key components of the multi-effect regenerator are steam riser, regenerating modules, condenser, heat exchangers and a vacuum pump. The steam riser module is made of PTFE membrane and the condenser module is constructed using PP foils.

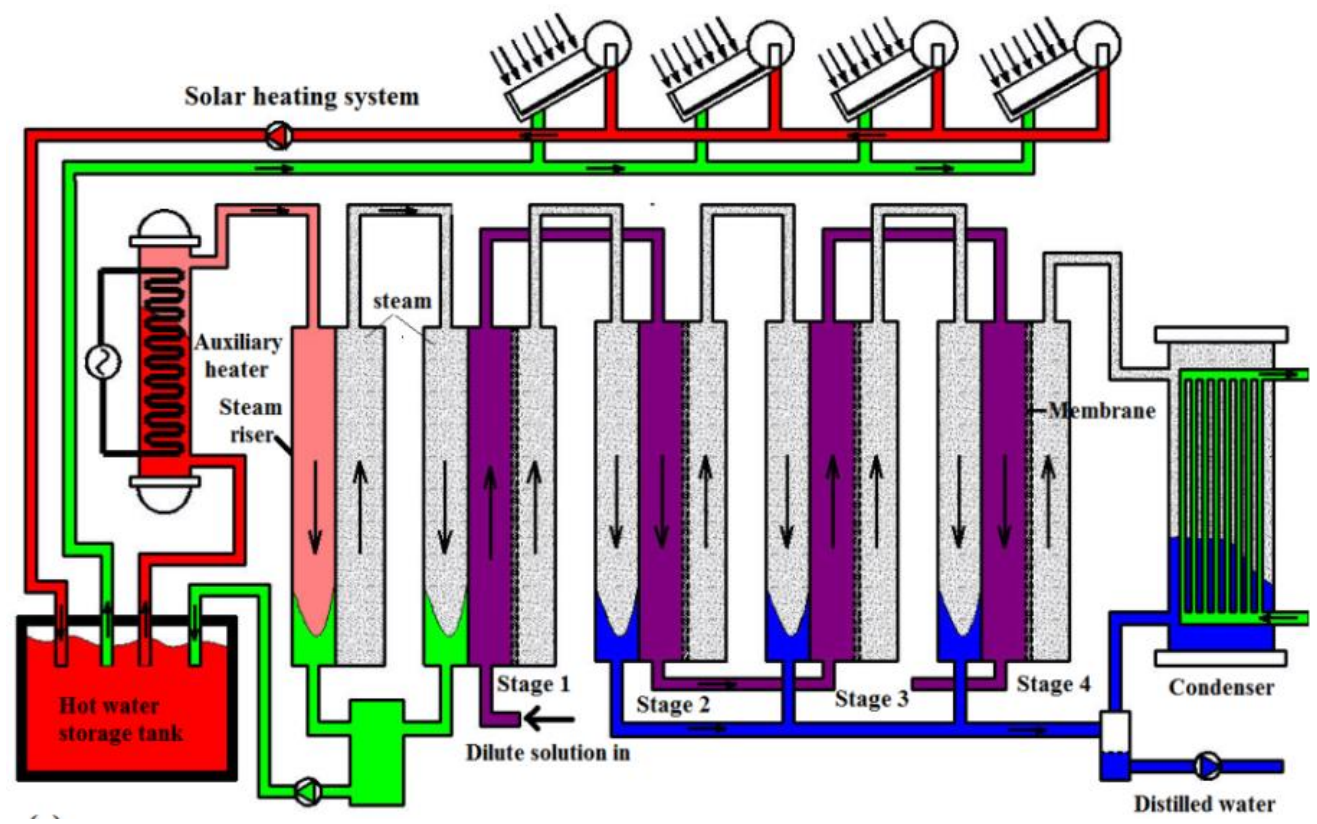

Figure 3.6: Schematic diagram of the conventional vacuum assisted multi-effect membrane distillation system (VMEMD) system. 
Hot water generating from the solar collector system or auxiliary heater flows through the heat exchanger, and a pump in the secondary loop of the heat exchanger circulates the hot water in the steam riser. The schematic of the conventional VMEMD is shown in Figure 3.6.

Due to the temperature and pressure gradient across the membrane, the frames operate under a vacuum environment, water vapour is produced and the generated steam crosses the PTFE membrane where it is channelled to the foil modules of the 1 st stage of the regenerator. The steam is condensed by the cooler feed solution flowing on the other side of the foil. In this regenerator, the condensate from the first stage is circulated back to the heat exchanger to top up the water loss due to the condensation. The temperature of the feed solution rises by capturing the latent heat of condensation at the foil. The temperature and pressure gradient across the membrane causes the steam to flow through the membrane and the steam is then channelled to the next stage. 


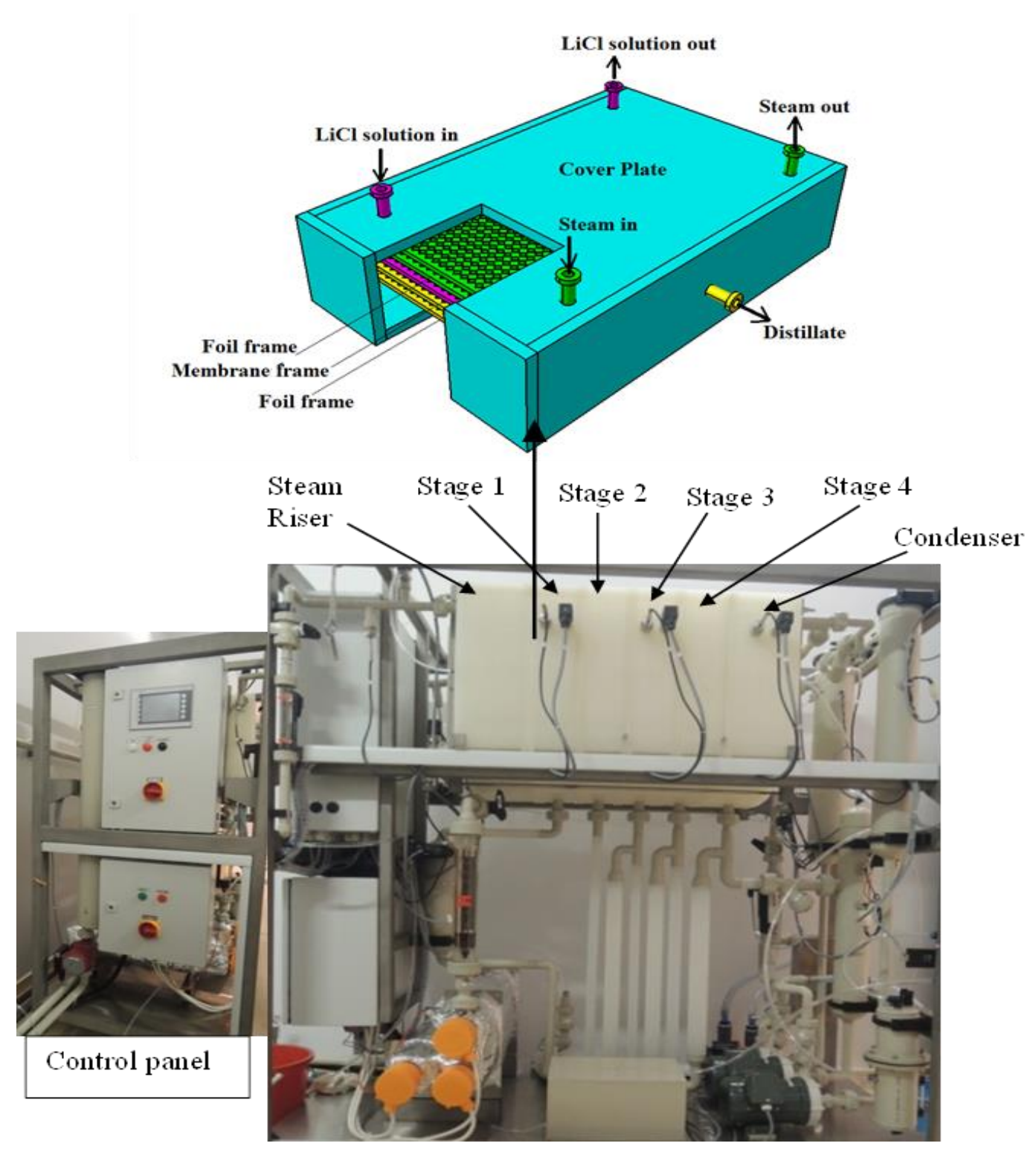

Figure 3.7: The pictorial view for the experimental setup of VMEMD system.

The vaporization causes the diluted feed solution to increase in concentration and the concentrated solution is channelled to the next stage for further concentration. In the next stage, the steam generated from the membrane frame of first stage flows into the foil frame of second stage, condensing into steam and at same time, the latent heat of condensation is recovered by the concentrated feed solution of the 
first stage. Finally, the steam generated from the fourth and last stage of this 4effect regenerator unit goes into the foil frames of the condenser. In this last stage, all the remaining steam is condensed. The pictorial view of the regenerator system is shown in Figure 3.7.

\subsection{Performance Indicators and effects of control parameters}

The parameters that influence the performances of the proposed desiccant regenerator for dehumidification purposes are feed desiccant (here LiCl) concentration, feed flow rates and the driving heat source temperatures. In this experiment (i) the feeding concentrations are ranged from $8 \%$ to $36 \%$, (ii) the feeding flow rates are varied from $0.15 \mathrm{litre} / \mathrm{min}$ to 1 litre/min, (iii) the hot water temperatures are set at 50, 55, 65 and $75^{\circ} \mathrm{C}$ with the cooling water inlet temperature of $28{ }^{\circ} \mathrm{C}$. The change in concentration $\Delta C$ (in \%) is calculated by $\Delta C$ $=C_{i}-C_{o}$, where $C_{i}$ and $C_{o}$ indicate the concentrations of aqueous lithium chloride solution at inlet and exit of the regenerator.

In this study, the performance of the multistage generator is calculated in terms of performance ratio (PR). The thermal performance ratio in terms of $\mathrm{kW}$ per $\mathrm{kW}$ can be expressed as the ratio of the heat generation for distillation process (water vapour separation from the salt solution) to the average heating energy. The PR is written as

$$
P R=\frac{m_{\text {dist }} \times h_{f g}}{H_{\text {in }}},
$$

Where,

$$
m_{\text {dist }}=\rho_{\text {sol }} V_{\text {sol }} \frac{C_{O}-C_{i}}{C_{O}},
$$


$H_{\text {in }}(\mathrm{kW})$ is the heat energy input to the system and is calculated by the hot water flow rate, and the temperature difference between the hot water flowing into and out of the steam riser. The heat input required for regeneration for all the VMEMD configurations is provided by a solar thermal system installed on the roof of the building.

\subsection{Solar thermal system and chemical energy storage system}

The solar thermal system is composed of evacuated solar collectors, energy storage tanks, collector side water circulation pump, load side water circulation pump, and a control panel. The area of the evacuated tube solar collector is $40 \mathrm{~m}^{2}$ and there are three solar collectors connected in series. The volume of the stratified storage tank is $1 \mathrm{~m}^{3}$ with four temperature sensors located at the four nodes; each node has a height of $0.75 \mathrm{~m}$. The stratified tank is divided into storage tank 1 and storage tank 2, and contains an auxiliary heater. The two tanks are connected with a pipe from the top of tank 1 to the bottom of tank 2. It is divided into two tanks due to height constraints and safety measure; ideally it should be one tank acting independently.

The solar energy harvesting time is shorter than the air-conditioning time, and both energy source and load-sink vary significantly over a period of time, hence energy storage system is an important area of concern for this research. The pictorial view of the solar thermal installation is provided in the appendix section.

In this work thermal energy is stored using water fluid medium and chemical energy is stored using desiccant salt solution medium. Initial experimental study has shown energy storage capacity of 29.1 Kilowatt hour is essential for 10 hours of operation without energy supply. Two plastic tanks of volume 300 litres each 
are used and $135.8 \mathrm{~kg}$ of $\mathrm{LiCl}$ is required to store 29.1 Kilowatt hour chemical energy. For the thermal energy storage, two water storage tanks of 5015.7 litres each with insulation is required to store this energy. Even though chemical energy storage tank is much smaller than thermal energy storage tank, foot print area is still large, and the cost of $\mathrm{LiCl}$ salt $(50 \$ / \mathrm{kg})$ leads to higher initial cost. The pictorial view of the desiccant storage tanks made of polypropylene (PP) is provided in the Appendix A section of this thesis.

In the next chapter the results and discussion of membrane based LDAC system will be discussed.

\section{References}

[1] W.P. Jones, Air conditioning engineering. 3rd ed. 1985, London: Edward Arnold. xiv, 577 p.

[2] E. Elsarrag,Performance study on a structured packed liquid desiccant regenerator. Journal of Solar Energy. Vol. 80, pages1624-163, 2006. 


\section{Chapter 4}

\section{Results and Discussion of LDAC}

\subsection{Introduction}

This chapter deals with the discussion of experimental results for the liquid desiccant air-conditioning system (LDAC) with multi-effect-membrane distillation (MEMD) process. This MEMD technology amalgamates the advantages of multieffect-evaporation and vacuum for highly efficient heat recovery [1-5]. In this experiment, solar-heat is used to drive the MEMD module. The detailed analysis of MEMD is discussed in the previous chapter. A good number of experiments were conducted to find the effects of various operating/controlled parameters on the performances of MEMD unit. Secondly, an attention is paid at minimizing the drawbacks associated with direct-contact dehumidification for e.g. aerosol formation, corrosion, scaling, fouling etc. Evidence from various studies in literature suggests that liquid desiccant concentration at the inlet of the dehumidifier is a critical parameter in the analysis of the absorber performance [69]. It is extremely difficult to accurately measure the concentration of the desiccant solution directly. Typically, the concentration is calculated from the measured conductivity or density values of liquid desiccant. During experimental investigation, the desiccant concentration is calculated on the basis of its density values as it offers greater accuracy. The effects of the controlled parameters such as air resident pressure and cooling temperatures on the system performances are discussed in the next section. This chapter also discusses the performances of vacuum graded MEMD in terms of performance ratio and concentration difference between the inlet and outlet of the MEMD module. 


\subsection{Effects of controlled parameters on the system performances}

Air resident pressure of the dehumidifier depends on the location of the fan installation. If the supply air fan is installed after the dehumidifier, it creates very low pressure in the dehumidifier. On the contrary, if the supply fan is installed before the dehumidifier, a high pressure is created in the dehumidifier. Therefore, it is important to conduct experiments and determine preferred position of the fan installation. A large set of experiments are carried out with various air inlet velocity ranging from $0.58 \mathrm{~m} / \mathrm{s}$ to $0.93 \mathrm{~m} / \mathrm{s}$, that creates a positive pressure from 180 to $1000 \mathrm{~Pa}$ when the fan is installed before the dehumidifier, and around 9 to $20 \mathrm{~Pa}$ when the fan is installed after the dehumidifier, in the same velocity range. The results are shown in Figure 4.1.

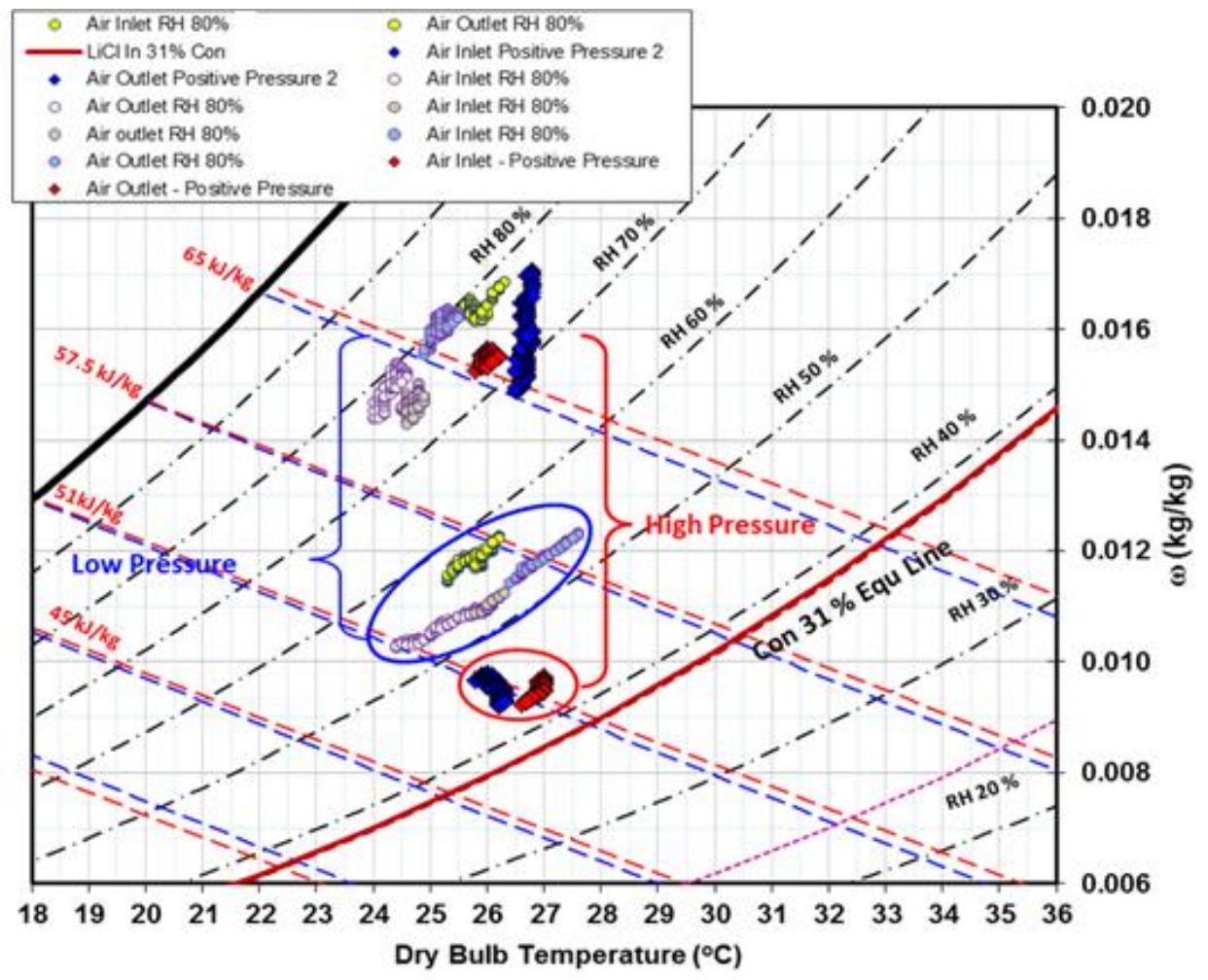

Figure 4.1: Humidity ratio $(\omega)$ for various air inlet and outlet velocities under air resident with high and low pressures. 
Figure 4.1 shows the humidity ratio of air at the inlet and outlet of the dehumidifier. The experiments are conducted under high pressures between 180$1000 \mathrm{~Pa}$, which indicate that the exit air humidity ratio is lower than the experimental runs at low pressure between 9-20Pa. The observation illustrates that under high pressure the dehumidifier can remove up to $12 \%$ more moisture than relatively low pressure. Hence for the proposed membrane based liquid desiccant dehumidifier the supply air fan should be installed before the dehumidifier.

The temperature of liquid desiccant increases due to moisture absorption which generates the enthalpy of dilution. Therefore, liquid desiccants are needed to be cooled. Cooling of the liquid desiccant can be achieved either by external cooling or internal cooling process. It is observed that the internal cooling exhibits better performance compared to external cooling of the dehumidifier. Hence the cooling of liquid desiccant is performed by the flowing of cooling water through the channels of LDAC absorber or dehumidifier unit.

The exothermic heat from the system is removed, while cooling the desiccant to just above $16^{\circ} \mathrm{C}$ to avoid condensation. The dehumidified air is cooled down to the desired supply temperature with the help of a separate fan coil unit. The objective of these set of experiments is to study the absorption performance when the cooling water temperature is higher than that of a conventional internal cooling desiccant dehumidifier. Figure 4.2 shows the recorded data of air-outlet temperature and humidity ratio, for cooling water temperature ranging from $16^{\circ} \mathrm{C}$ to $28^{\circ} \mathrm{C}$. The relative humidity $(\mathrm{RH})$ of inlet air, concentration, air velocity and flow rate of liquid desiccant are kept constant. 


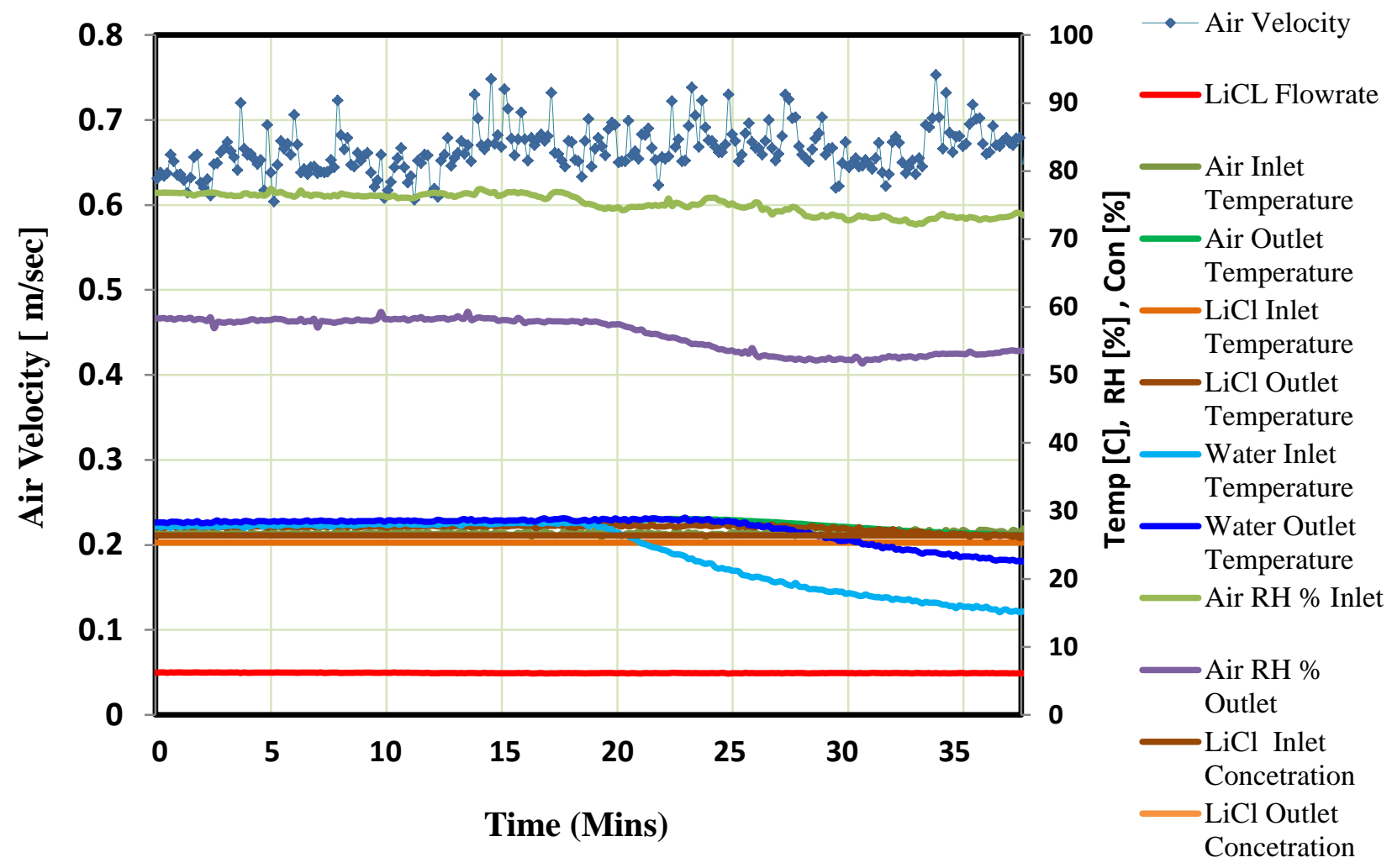

Figure 4.2: Air velocity, inlet-outlet air temperature, relative humidity, inlet-outlet water temperature, lithium chloride concentration and flow-rate, as a function of time for the LDAC dehumidifier system.

Figure 4.3 illustrates the experimental result, and it is observed that the moisture absorption rate is improved from 0.0115 to $0.014 \mathrm{~kg} / \mathrm{kg}$, when the cooling water temperature is reduced from $28^{\circ} \mathrm{C}$ to $16^{\circ} \mathrm{C}$. This is due to the vapour pressure properties of liquid desiccant solution, the vapour pressure decreases with the decrease in temperature, and at lower vapour pressure, the water absorption is higher. Hence, the performance is improved when the liquid desiccant is kept cooler. This is due to the vapour pressure properties of liquid desiccant solution, the vapour pressure decreases with decrease in temperature, and at lower vapour 
pressure the water absorption is higher. Figure 4.3 illustrates the variation in relative humidity with change in cooling water temperature.

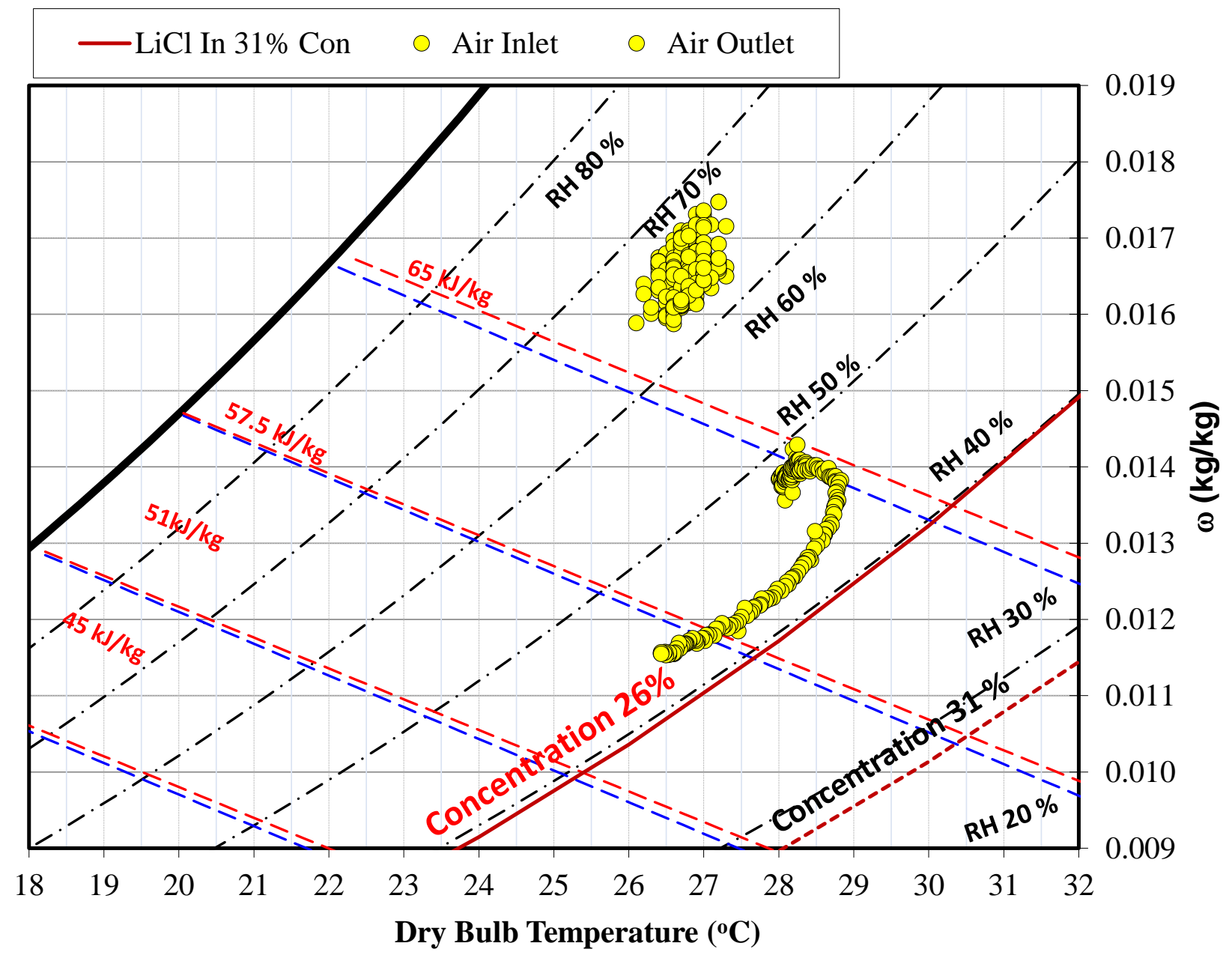

Figure 4.3: Humidity ratio of air inlet and outlet for the decrease in cooling water temperatures from $16^{\circ} \mathrm{C}$ to $28^{\circ} \mathrm{C}$. 


\subsection{Experimental Study of LDAC}

The performance of the dehumidifier is determined by the amount of moisture removed by the system. Hence, the outlet air condition, temperature and RH, can be used to determine the dehumidifier performance. In this experiment, six input parameters (Air temperature, RH, Air flow rate, Cooling water temperature, cooling water flow rate and Liquid desiccant concentration) and 4 output parameters (Air temperature, $\mathrm{RH}$, cooling water temperature and Liquid desiccant temperature) are handled, and these are shown in Figure 4.4.

The operating range of input parameters is determined by the maximum and minimum possible inlet air conditions that the dehumidifier is subjected to. The minimum possible air inlet condition is when the fresh air intake is $0 \%(100 \%$ return air from room exhaust) and is maximum, when the fresh air intake is $100 \%$ ( $0 \%$ return air from room exhaust). A total of 48 experiments are carried out at the two extreme air inlet conditions (as illustrated in Figure 4.5) to obtain the complete data.

The air inlet temperature and relative humidity are based on the design of the room and outdoor air conditions of Singapore. The operating ranges for room air inlet temperature and relative humidity are assigned to be $24^{\circ} \mathrm{C} \sim 26^{\circ} \mathrm{C}$ dry-bulb and $50 \%$ RH for 100\% return air (According to Singapore Standards, SS 553:2009, Section 7.1.6. for cold side). For the hot side, the outdoor air is assigned as $30^{\circ} \mathrm{C} \sim 32^{\circ} \mathrm{C}$ dry-bulb and $80 \%$ RH (According to National Environment Agency, Singapore). 


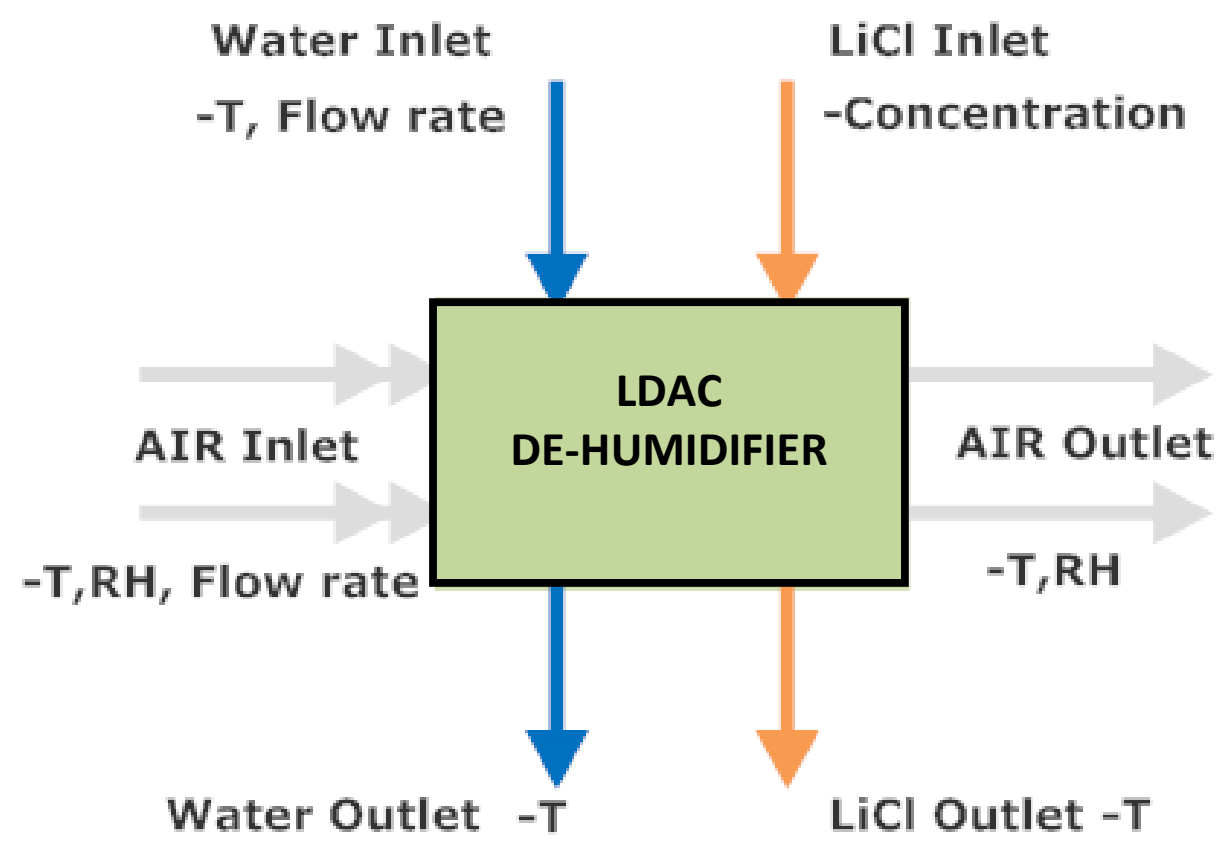

Figure 4.4: Six inlet parameters and three outlet parameters of membrane based dehumidifier, where $\mathrm{T}$ is the temperature, and $\mathrm{RH}$ indicates relative humidity.

The Preliminary experiments are conducted within the air-loop system. During experiments, the air flow velocity and the static pressures at different designated points along the ducts are observed. The experimental data show that air velocity below $0.22 \mathrm{~m} / \mathrm{s}$ demonstrates the inaccuracy in velocity measurements due to the limitation of the velocity sensors used in the experimental set-up. Air velocity exceeding $1.24 \mathrm{~m} / \mathrm{s}$ leads to a high static pressure drop of $939.54 \mathrm{~Pa}$ across the dehumidifier, which raises concern about the design and performance of the dehumidifier. Moreover, due to the limitation of the sensors used, it is unable to measure any static pressure over $1000 \mathrm{~Pa}$. Hence, three distinct air flow velocities of $0.6 \mathrm{~m} / \mathrm{s}, 0.9 \mathrm{~m} / \mathrm{s}$ and $1.2 \mathrm{~m} / \mathrm{s}$ are selected to run the experiments. 
From experimental observations, the cooling water temperature below $18^{\circ} \mathrm{C}$ exhibits condensation on the outer surface of the dehumidifier, which causes the energy loss to the surroundings. Thus, in one aspect, the cooling water minimum temperature was set at $18^{\circ} \mathrm{C}$ for the purpose of solely cooling the desiccant solution and the air stream inside the dehumidifier. On the other hand, the cooling water temperature above $28^{\circ} \mathrm{C}$ provides ineffective cooling in the desiccant solution. Hence the cooling water inlet temperatures are separated into two extremes, one for cold water experiments at $18^{\circ} \mathrm{C}$ inlet temperature and the other for warm water experiments at $28^{\circ} \mathrm{C}$.

Lithium chloride ( $\mathrm{LiCl})$ is used as the desiccant salt for these experiments. The inlet concentration is divided into two distinct low and high feed concentration by mass of $26 \%$ and $40 \%$ respectively. The minimum concentration of $26 \%$ is suitable for experimental run with cold water temperature maintained at $18^{\circ} \mathrm{C}$. The desired dehumidification is achieved between $26 \%$ and $40 \% \mathrm{LiCl}$ concentration at the inlet, and beyond $40 \%$ feed concentration, $\mathrm{LiCl}$ solution starts to crystallize, which is completely undesirable. Therefore, the maximum inlet concentration is fixed at $40 \%$. 


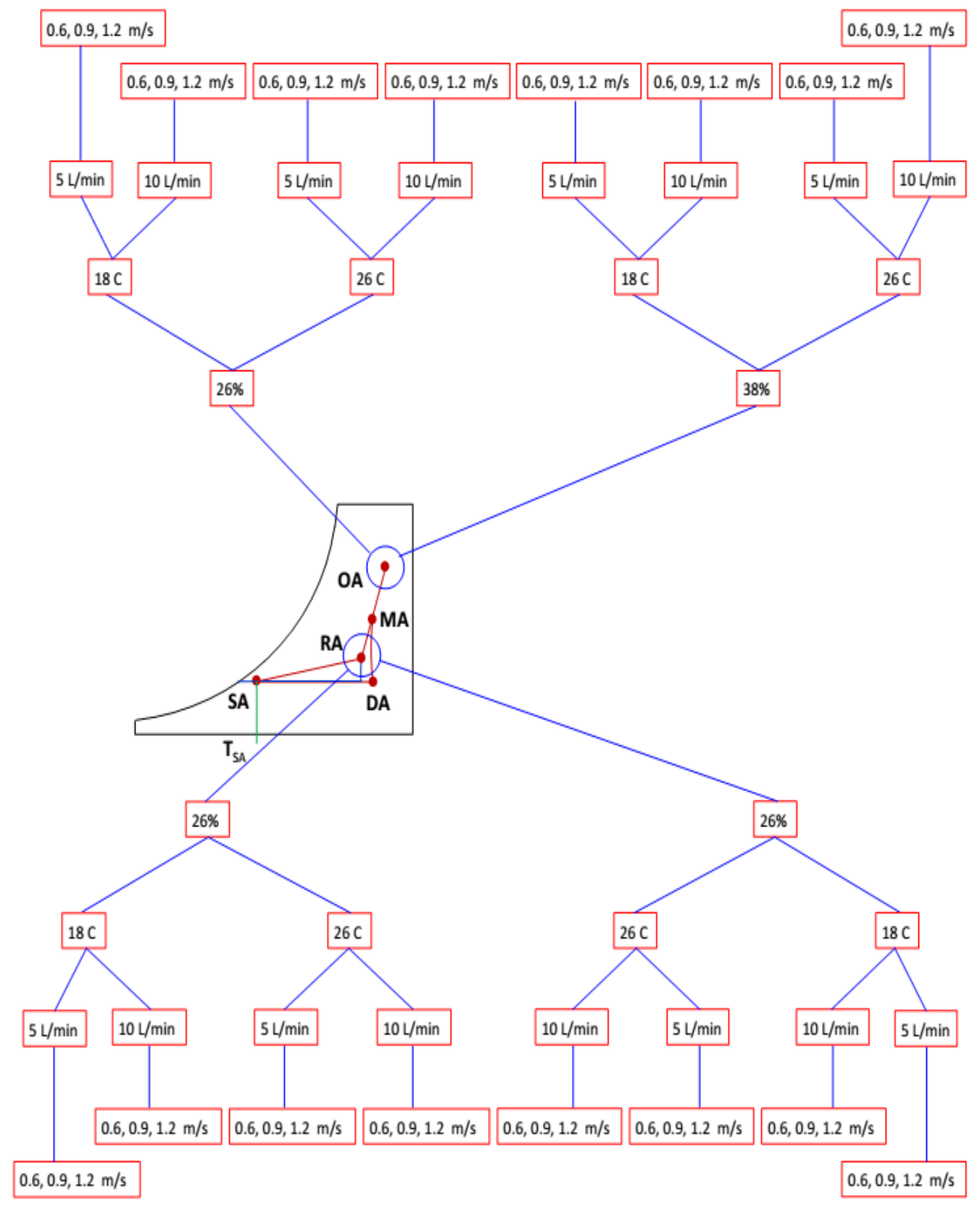

Figure 4.5: The flow chart illustrating 48 experiments conducted at minimum and maximum possible Inlet air conditions of LDAC dehumidifier. Here OA indicates outdoor air, MA is mixed air, RA defines return air, DA is Dehumidified air and SA stands for supply air. 


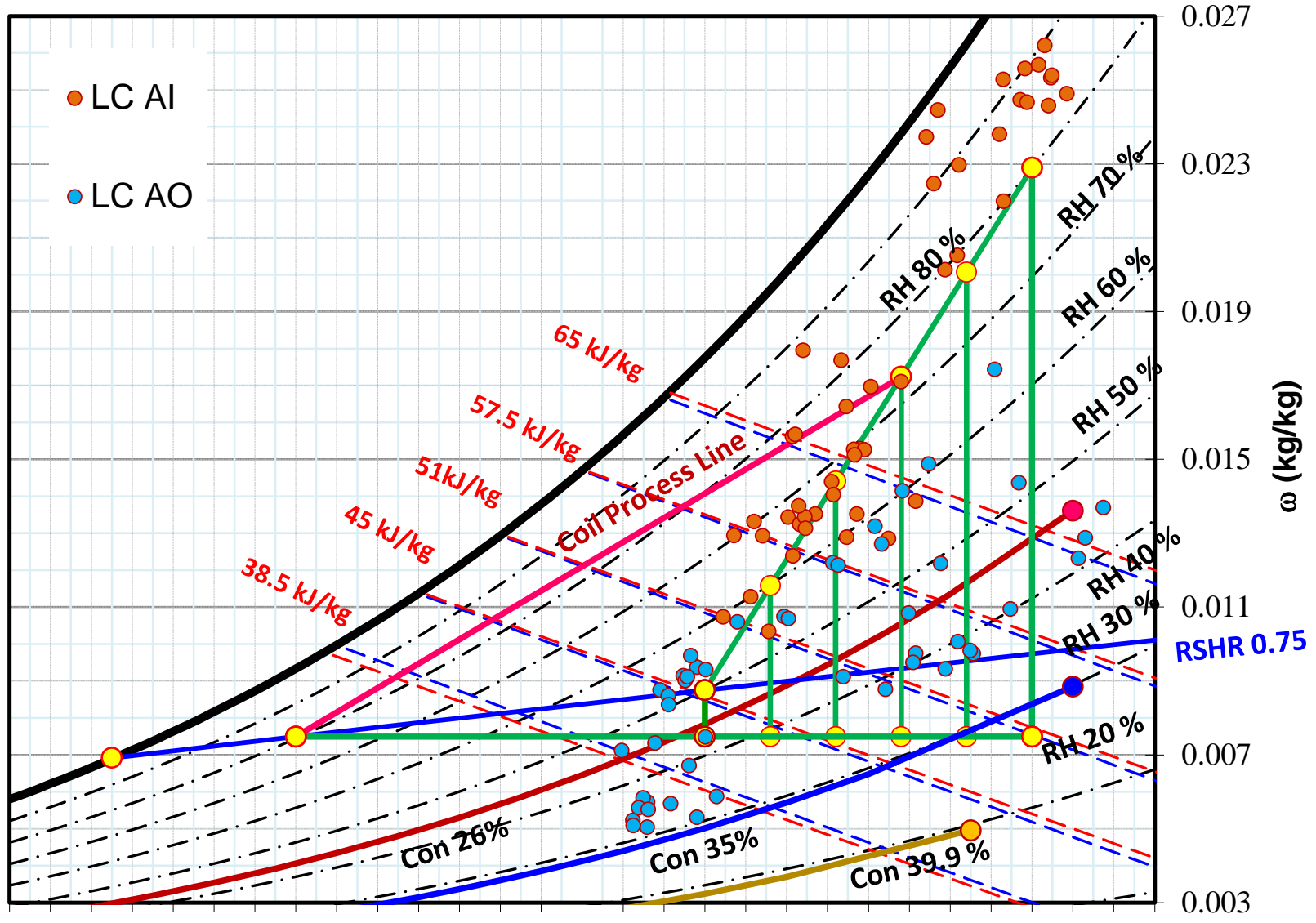

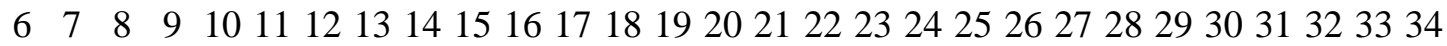

Dry Bulb Temperature $\left({ }^{\circ} \mathrm{C}\right)$

Figure 4.6: Coverage range of air inlet conditions and resulted air outlet conditions. Here LC AI and LC AO indicate air inlet and air outlet conditions.

Figure 4.6 illustrates the coverage range of air inlet conditions (indicated by brown circles), for $\mathrm{LiCl}$ feed concentrations between $26 \%$ and $36 \%$ under Singapore outdoor air conditions. The outlet air conditions are indicated by blue circles. This psychometric chart indicates that the dehumidification capacity of the liquid desiccant varies with the concentration of the desiccant solution. The dehumidification is higher when the inlet desiccant concentration is higher and its 
absorption rate is significantly reduced at lower inlet concentrations. The blue dots show air outlet conditions, and indicate that the dehumidifier is able to achieve the desired dehumidification depending on various cooling water inlet temperatures.

\subsection{LDAC-Dehumidifier Performances}

The performances of the dehumidifier for various moist air flow rates are presented in Table 4.1. These are relative humidity, humidity ratio, outlet temperature, concentration. Hence, the air flows through the channel of $0.23 \mathrm{~m} \times 0.5 \mathrm{~m}$ cross sectional area. Due to the flow of air through the channel, the $\mathrm{LiCl}$ solution absorbs water vapour from the moist air. Finally the dehumidified air with $\mathrm{RH}_{\text {out }}$ exits through the outlet of the system. The temperature and humidity are measured by RTD temperature sensor (error $\pm 0.25^{\circ} \mathrm{C}$ ) and humidistat sensor (error $\pm 2 \% \mathrm{RH}$ ). When the air flows through the channel, turbulent flow may be created. Therefore, the contact time between the air and $\mathrm{LiCl}$ flow results in more water vapour flow through the membrane pores, and more water vapour is absorbed by $\mathrm{LiCl}$ solution. Experimentally the $\mathrm{LiCl}$ concentration level is found up to $36 \%$ (Table 4.1). The moisture removal rate per is calculated by:

$$
\text { Removal Rate }=\dot{\mathrm{m}}_{\text {air }}\left(\omega_{\text {air,in }}-\omega_{\text {air }, \text { out }}\right)
$$

where $\dot{\mathrm{m}}_{\text {air }}(\mathrm{kg} / \mathrm{hr})$ is the mass flow rate of air and $\omega_{\text {air,in }}(\mathrm{kg} / \mathrm{kg})$, $\omega_{\text {air,out }}(\mathrm{kg} / \mathrm{kg})$ is the relative humidity of air at inlet and outlet of the dehumidifier respectively.

After absorption, the concentrated $\mathrm{LiCl}$ solution enters into the regenerator for desorption of water from $\mathrm{LiCl}$ salt solution. In the next section, we will investigate the performance of conventional VMEMD regenerator. 
Table 4.1: Performance analysis of the LDAC Dehumidifier

\begin{tabular}{|c|c|c|c|c|c|c|c|c|c|c|}
\hline \multicolumn{2}{|c|}{ Area $0.23 \mathrm{~m} \times 0.5 \mathrm{~m} \times 1 \mathrm{Channel}]$} \\
\hline $\begin{array}{c}\mathrm{T}_{\text {in }} \\
{\left[{ }^{\circ} \mathrm{C}\right]}\end{array}$ & $\begin{array}{c}\text { Relative } \\
\text { humidity } \\
{[\%]}\end{array}$ & $\begin{array}{c}\omega_{\text {in }} \\
{[\mathrm{kg} / \mathrm{kg}]}\end{array}$ & $\begin{array}{c}\mathrm{T}_{\text {out }} \\
{\left[{ }^{\circ} \mathrm{C}\right]}\end{array}$ & $\begin{array}{c}\mathrm{Rh}_{\text {out }} \\
{[\%]}\end{array}$ & $\begin{array}{c}\omega_{\text {out }} \\
{[\mathrm{kg} / \mathrm{kg}]}\end{array}$ & $\begin{array}{c}\text { Con } \\
{[\%]}\end{array}$ & $\begin{array}{c}\text { Vel } \\
{[\mathrm{m} / \mathrm{sec}]}\end{array}$ & $\begin{array}{c}\text { Airflow } \\
\mathrm{CMH} \\
\left.\mathrm{m}^{3} / \mathrm{Hr}\right)\end{array}$ & $\begin{array}{c}\text { Removal } \\
\text { Rate } \\
{[\mathrm{kg} / \mathrm{Hr}]}\end{array}$ & $\begin{array}{c}\text { Removal } \\
\text { Rate per } \\
{\left[\mathrm{kg} / \mathrm{Hr} / \mathrm{m}^{2}\right]}\end{array}$ \\
\hline 24.4 & 94.4 & 0.018237 & 26 & 47.3 & 0.00992 & 36.0 & 0.4 & 45.2 & 0.38 & 3.29 \\
\hline 23.1 & 95.0 & 0.016938 & 24.2 & 54 & 0.01018 & 33.0 & 0.5 & 56.5 & 0.38 & 3.34 \\
\hline 22.5 & 95.1 & 0.016334 & 24.5 & 51.9 & 0.00996 & 33.0 & 0.31 & 35.0 & 0.22 & 1.95 \\
\hline
\end{tabular}

\subsection{Experimental investigation of VMEMD regenerator}

The regenerator employs hydrophobic membrane to separate water vapour from $\mathrm{LiCl}$ solution with higher evaporation rates. The main aim of this study is to reduce energy consumption by the use of membrane based multistage regenerator, which possesses an acceptable performance ratio (PR) at the heat source temperatures ranging from $50^{\circ} \mathrm{C}$ to $73^{\circ} \mathrm{C}$. The working principles of the VMEMD regenerator are discussed in the previous chapter. The objectives are to conduct the experimental investigation of VMEMD (re-generator of LDAC system) to analyse the effects of various operating parameters on change in concentration $(\Delta C)$ as well as the thermal performance ratio (PR). The PR is calculated by [10],

$$
P R=\left(m_{\text {dist }} \times h_{f g}\right) / H_{\text {in }},
$$

where the rate of distillation $m_{\text {dist }}$ is calculated as,

$$
\dot{\mathrm{m}}_{\text {dist }}=V_{S} \rho_{S} \frac{\Delta C}{C_{\text {out }}}
$$


where $V_{S}$ (litre/hour) is the volumetric flow rate of the solution, $\rho_{S}$ is the feed inlet density and $(\Delta C),\left(C_{\text {out }}\right)$ are the change in concentration and the feed outlet concentration respectively.

$H_{\text {in }}(\mathrm{kW})$ is the heat energy input to the system and is calculated as,

$$
H_{\text {in }}=\dot{\mathrm{m}}_{H}\left(T_{H}^{\text {in }}-T_{H}^{\text {out }}\right) / 4.18 \text {, }
$$

where $\left(T_{H}^{\text {in }}-T_{H}^{\text {out }}\right)$ is the temperature difference between hot water inlet and outlet, and $\dot{\mathrm{m}}_{H}$ is the mass flow rate of hot water.

Hence, an experimental investigation was carried out to measure the performance factor of the regenerator using $\mathrm{LiCl}$ desiccant solution with the feed concentrations varying from $8 \%$ to $22 \%$ and feed flow rates between $0.15 \mathrm{litre} / \mathrm{min}$ and 1 litre $/ \mathrm{min}$. The heating source temperatures are ranged from $50{ }^{\circ} \mathrm{C}$ to $80{ }^{\circ} \mathrm{C}$. The temperature chart of the conventional VMEMD system is shown in Figure 4.7.

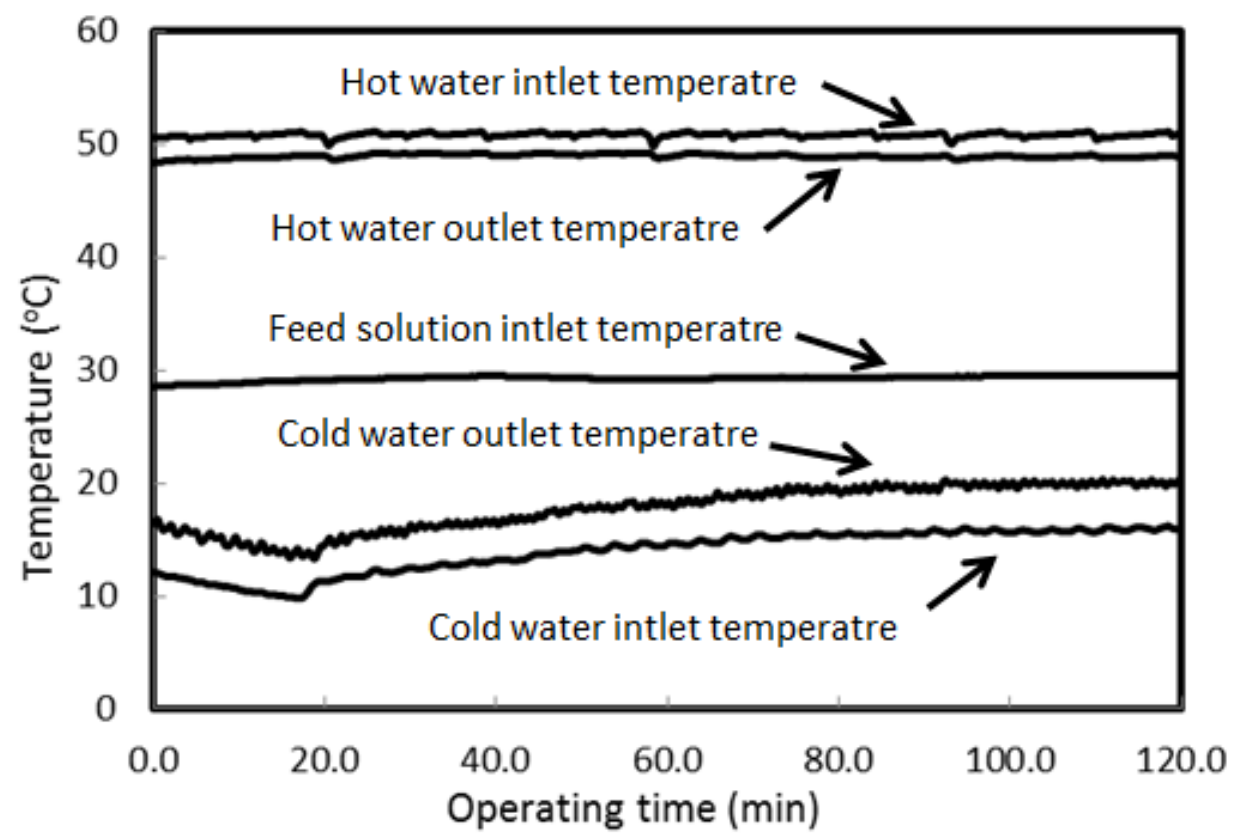

Figure 4.7: Temperature profiles against time of 4-stage VMEMD regenerator under steady state conditions for feed concentration $8 \%$ and $55{ }^{\circ} \mathrm{C}$ heating temperature. 
The variations of thermal performance ratio (PR) with feed flow rate and heating temperature are illustrated in Figures 4.8(a), 4.8(b) and 4.8(c) for the inlet salt concentrations of $8 \%, 15 \%$ and $22 \%$. These results show that at $8 \%$ feed concentration (similar to sea water); the PR varies from 2 to 2.5 depending on the heating temperature and feed flow rate. These PR values are comparable with that of the conventional multi-effect evaporator for desalination purposes [11].
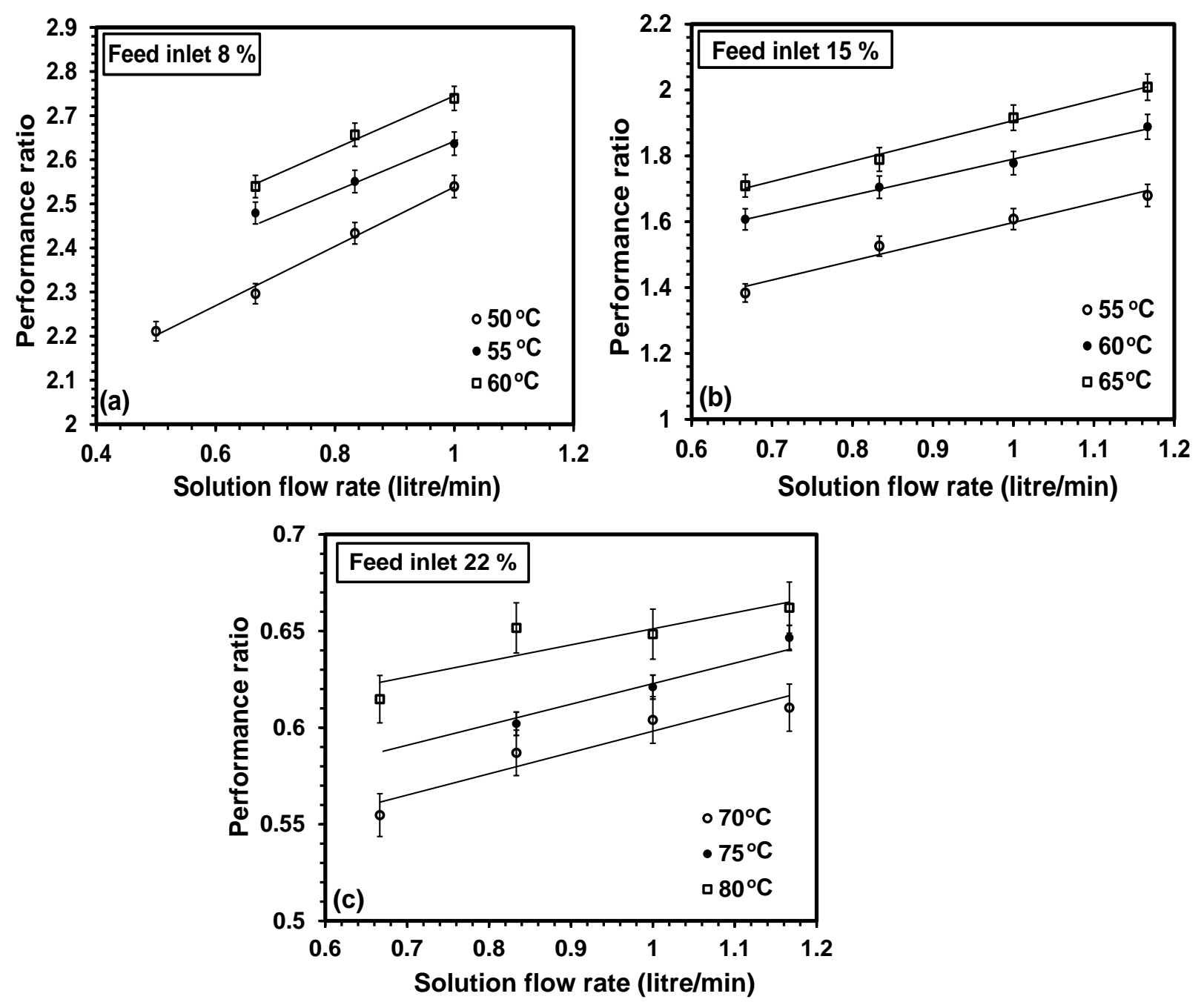

Figure 4.8: Performance ratio against solution flow rates for (a) inlet feed concentration of $8 \%$ at $50-60{ }^{\circ} \mathrm{C}$, (b) inlet feed concentration of $15 \%$ at $55-65{ }^{\circ} \mathrm{C}$, and (c) inlet feed concentration of $22 \%$ at $70-80{ }^{\circ} \mathrm{C}$. 
The change in concentration between inlet and outlet of the regenerator module $(\Delta C)$ as a function of feed flow rates and regeneration temperatures for various inlet feed concentrations are shown in Figures 4.9(a), 4.9(b) and 4.9(c).

It should be noted here that at higher concentrations of $30 \%$ or higher, the performance ratio drops drastically and the VMEMD system stopped performing.
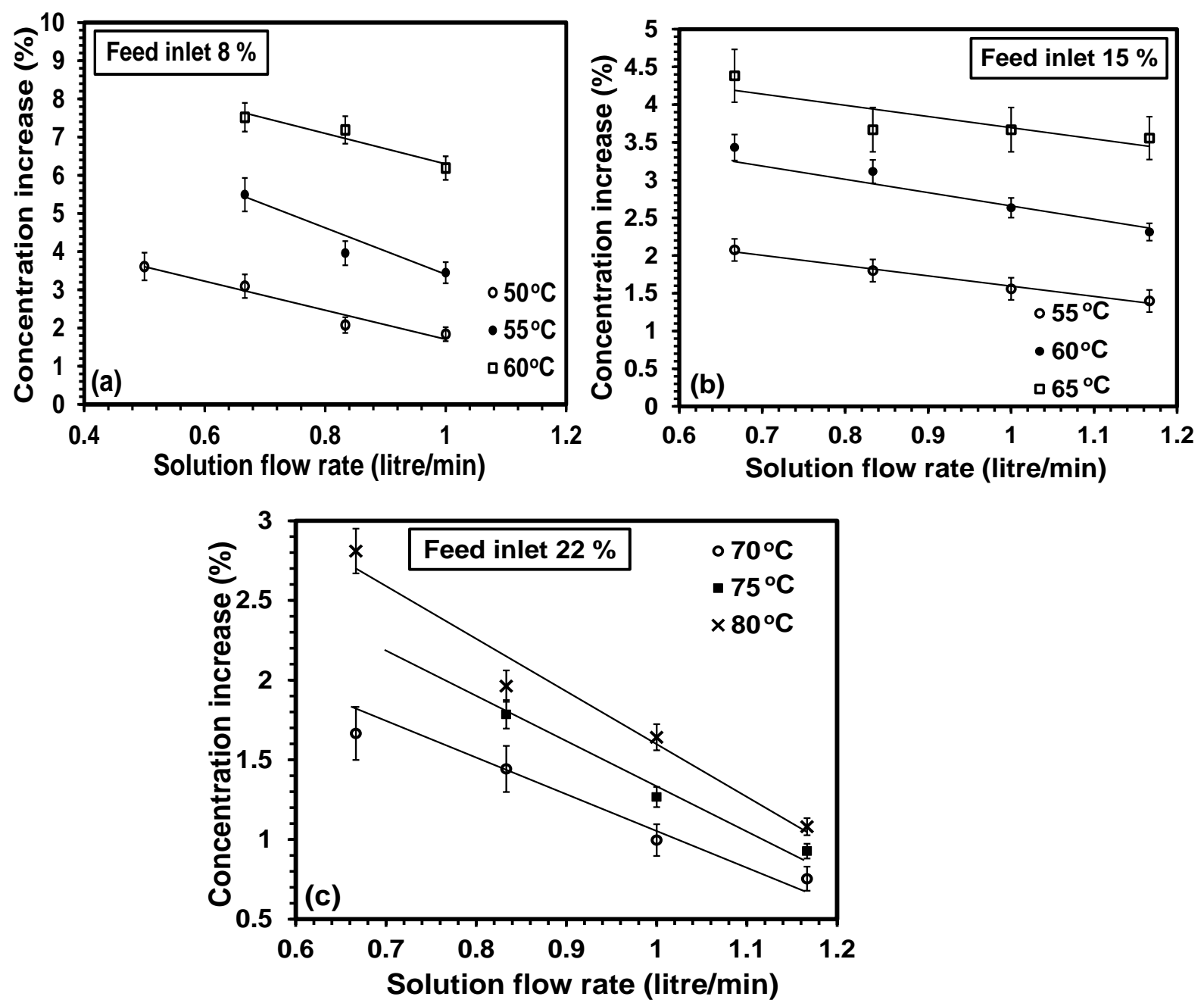

Figure 4.9: Concentration increase against solution flow rates for (a) inlet feed concentration of $8 \%$ at $50-60{ }^{\circ} \mathrm{C}$, (b) inlet feed concentration of $15 \%$ at $55-65$ ${ }^{\circ} \mathrm{C}$, and (c) inlet feed concentration of $22 \%$ at $70-80{ }^{\circ} \mathrm{C}$. 
At higher concentration and flow rates, the concentration difference $(\% \Delta C)$ becomes smaller. The sharp decrease in PR at higher concentrations can be attributed to the vapour pressure characteristics of aqueous $\mathrm{LiCl}$ solutions. The vapour pressure of liquid desiccants is inversely related to the desiccant concentration. As the concentration increases, the vapour pressure drops. Therefore, the amount water vapour from liquid desiccant decreases and the PR drops. On the other hand, the driving heat source temperature plays a significant role on the increase in PR of LDAC regenerator. This is due to the fact that the vapour pressure is directly related to the temperature of desiccant solution, and at higher heating temperatures, the solution absorbs more heat with the increase of vapour pressure, which in turn increases its ability to lose more water. It should also be noted here that the overall heat transfer coefficient are also decreased due to the lower thermal conductivity at higher feed concentration.

This Chapter shows that the conventional 4-stage VMEMD system performs very well under the regeneration temperature of $50{ }^{\circ} \mathrm{C}$ with $8 \%$ feed concentration. However, at higher concentration (22\% or higher), the overall performance drops drastically. Therefore, the conventional 4 stage VMEMD is not suitable for dehumidification purposes. Although, it is good for desalination purposes [10,11].

\subsubsection{Conclusions}

Vacuum multi-effect-membrane-distillation (VMEMD) system amalgamates the advantages of multi-effect evaporation and the merit of the membrane's mass transfer process. Since this product is designed for the desalination and water treatment industry, it works very well when the feed concentration is as low as sea water concentration (\% Concentration in mass is less than 10\%). However, the minimum operation concentration of the regeneration process for liquid desiccant air-conditioning (LDAC) system is $26 \%$. According to the experimental 
investigation, a conventional 4 stages VMEMD system fails to provide satisfactory performance above $22 \%$ feed concentration. Therefore, for dehumidification

purposes, the conventional 4 stage VMEMD system should be modified from the heat transfer and energy utilization viewpoints, for operating the LDAC with high feed concentration $(26 \sim 40 \%)$. Therefore VMEMD system should be modified. The next chapter analyses the modelling and simulation of vacuum graded multieffect distillation system, which can handle the de-humidification process.

\section{References}

[1] K. Gommed and G. Grossman, "A liquid desiccant system for solar cooling and dehumidification," Journal of solar Energy Engineering, vol. 126, pp. 879 - 885, 2004.

[2] K. Gommed and G. Grossman, "Experimental investigation of a liquid desiccant system for solar cooling and dehumidification," Solar Energy, vol. 81, pp. 131 - 138, 2007.

[3] Y. Yin, X. Zhang, and Z. Chen, "Experimenatl study on dehumidifier and regenerator of liquid desiccant cooling air conditioning system," Building and Environment, vol. 42, pp. 2505-2511, 2007.

[4] X. H. Liu, Y. Jiang, and K. Y. Qu, "Heat and mass transfer model of cross flow liquid desiccant air dehumidifier/regenerator.," Energy Conservation and Management, vol. 48, pp. 546 - 554, 2007.

[5] G.A. Longo and A. Gasperella, "Experimental and theoretical analysis of heat and mass transfer in a packed column dehumidifier/regenerator with liquid desiccant," Int J. Heat and Mass Tranfer, vol. 48, pp. 5240-5254, 2005. 
[6] R. M. Lazzarin, A. Gasparella, and G. A. Longo, "Chemical dehumidification by liquid desiccants: theory and experiment," International Journal of Refrigeration, vol. 22, 1996.

[7] N. Fumo and D. Y. Goswami, "Study of an aqueous lithium chloride desiccant system: Air dehumidification and desiccant regeneration," Solar Energy, vol. 72, pp. 351-361, 20022002.

[8] L. Z. Zhang and S. M. Huang, "Coupled heat and mass transfer in a counter flow hollow fiber membrane module for air humidification," nternational Journal of Heat and Mass Transfe, vol. 54, 2011.

[9] Yin. Yonggao, Zhang. Xiaosong, Wang. Geng, and Luo. Lei, "Experimental study on a new internally cooled/heated dehumidifier/regenerator of liquid desiccant systems," International Journal of Refrigeration, vol. 31, p. 857, 2008.

[10] F. H. Choo, M. Kumja, K. Zhao, A. Chakraborty, E. Mohan Dass, and M. Prabu, "Experimental study on performance of membrane base multi-effect dehumidifier regenerator powered by solar energy," Energy Procedia, vol. 48, pp. 535 - 542, 2013.

[11] T. Hisham, El-Dessouky, and H. M. Ettouney, "Multiple-effect evaporation desalination systems," Thermal ananlysis, Desalination 125, pp. 259-276, 1999. 


\section{Chapter 5: Thermodynamic Study of LDAC Regenerator System}

\section{$5.1 \quad$ Introduction}

The two most important components of the LDAC system are the absorber and the regenerator. The LDAC working condition is affected by the performance of the regenerator. The reason being the energy input to the LDAC is mostly utilized in the regenerator and so the focus of this research is the VMEMD regenerator, with the scope of improving its performance. The conventional VMEMD is widely used for desalination and water treatment processes, and the aim is to use the membrane assisted unit for desiccant regeneration in a LDAC system.

A thermodynamic framework of the LDAC regenerator is required to develop for understanding the heat and mass transfer processes in fluids and solutions through the membrane, which allows one to optimise the system performances in terms of various heat source temperatures and solution flow rates. The thermodynamic study helps to identify various parameters needed for designing the desiccant regenerator system and conducting parameter optimization for performance enhancement. Several research activities on theoretical modelling and simulation on liquid desiccant regeneration systems are available in literature. Fumo and Goswami [1] studied the heat and mass transfer processes of a packed-bed regenerator using finite difference method. They concluded that the desiccant temperature and concentration provides the most significant impact on the desiccant regenerator. Factor and Grossman [2] conducted simulation studies of regenerator performance using $\mathrm{LiBr}$ and $\mathrm{MEG}$ in a packed bed air-liquid contactor. They achieved satisfactory regeneration at $80{ }^{\circ} \mathrm{C}$ and concluded that the computer model yields higher temperature due to the ideal adiabatic design. Liu et al. [3] 
developed a theoretical model using number of transfer units (NTU) and Lewis number to predict air and solution parameters inside the packed-module regenerator for cross-flow arrangement. The theoretical model was able to predict the temperature and concentration distributions inside the regenerator. Longo and Gasparella [4] carried out theoretical analysis and computer coding for heat and mass transfer studies. Their study exhibited that the regeneration efficiency increases from $20 \%$ to $75 \%$ with change in flow rate ratio from 0.3 to 0.35 . Abdel Salam et al. [5] studied a LAMEE (Liquid-air-membrane energy exchanger) under different control parameters in 2013. They found that the performance of the system significantly improves when NTU (number of transfer units) was increased up-to 10, and when NTU was increased beyond this $(\mathrm{NTU}=10)$ the performance slightly improved only. It was recommended to set the solution inlet temperatures to the regenerator at $45-55{ }^{\circ} \mathrm{C}$, to achieve the best performance. Several research works on desiccant regeneration and membrane based distillation have already been discussed in Chapter 2.

The conventional 4-stage VMEMD utilizes the benefits of multi-effect distillation and vacuum pressure in the module with high thermo-pressure gradient for mass transfer across the membrane. However, the preliminary experimental results suggest that the 4-stage regenerator does not perform well during higher desiccant concentration treatments $(<22 \%)$ and hence not suitable for LDAC applications. Suitable modifications are made to the design and working principles of conventional VMEMD system. Based on thermodynamic study, a novel MEMD regenerator can be developed for handling high concentration desiccant solutions. The novel design is capable of operating over a wide range of fluid concentration, temperature, pressure and flow rates. The next section describes the working principles of the proposed one-steam-three-solution (1S-3L) VMEMD system. 


\subsection{One Steam-Three-Solution (1S-3L) VMEMD systems}

The VMEMD regenerator consists of a steam riser, a condenser and regeneration modules. For continuous regeneration, the hot water is generated in the steam riser and is supplied to the multiple modules of the regenerator. The thermal source required for driving the steam riser is available from solar thermal collectors in the form of hot water. The dilute desiccant solution $(\mathrm{LiCl})$ delivering from the absorber is fed into the first regenerator module, where it is separated from the hot water channel by non-porous poly-propylene (PP) foil on one side and poly-tetra-fluoroethylene (PTFE) membrane on the other side. The schematic diagram of the regenerator is shown in Figure 5.1. The energy transmitted to the solution channel by the hot water through convection raises its temperature. Therefore the vapour pressure of the desiccant solution increases, and it starts desorbing the watervapour. The system is operated under vacuum conditions. The temperature and pressure gradients across the membrane drive the water-vapour from the solution channel into the vapour channel. The vapour moves on to the condenser for distillation. The solution from the first module is sent into the second module for further regeneration, and the same process is repeated up to the final module. The steam/water vapours generated in the modules are moved to the condenser for distillation. The warm and concentrated desiccant solution exiting from the final module is stored in the concentrated desiccant tank. The condenser in internally cooled with cooling water.

All these phenomena are expressed mathematically employing the energy and mass balances between the major components of the regeneration unit as shown schematically in Figure 5.1. 


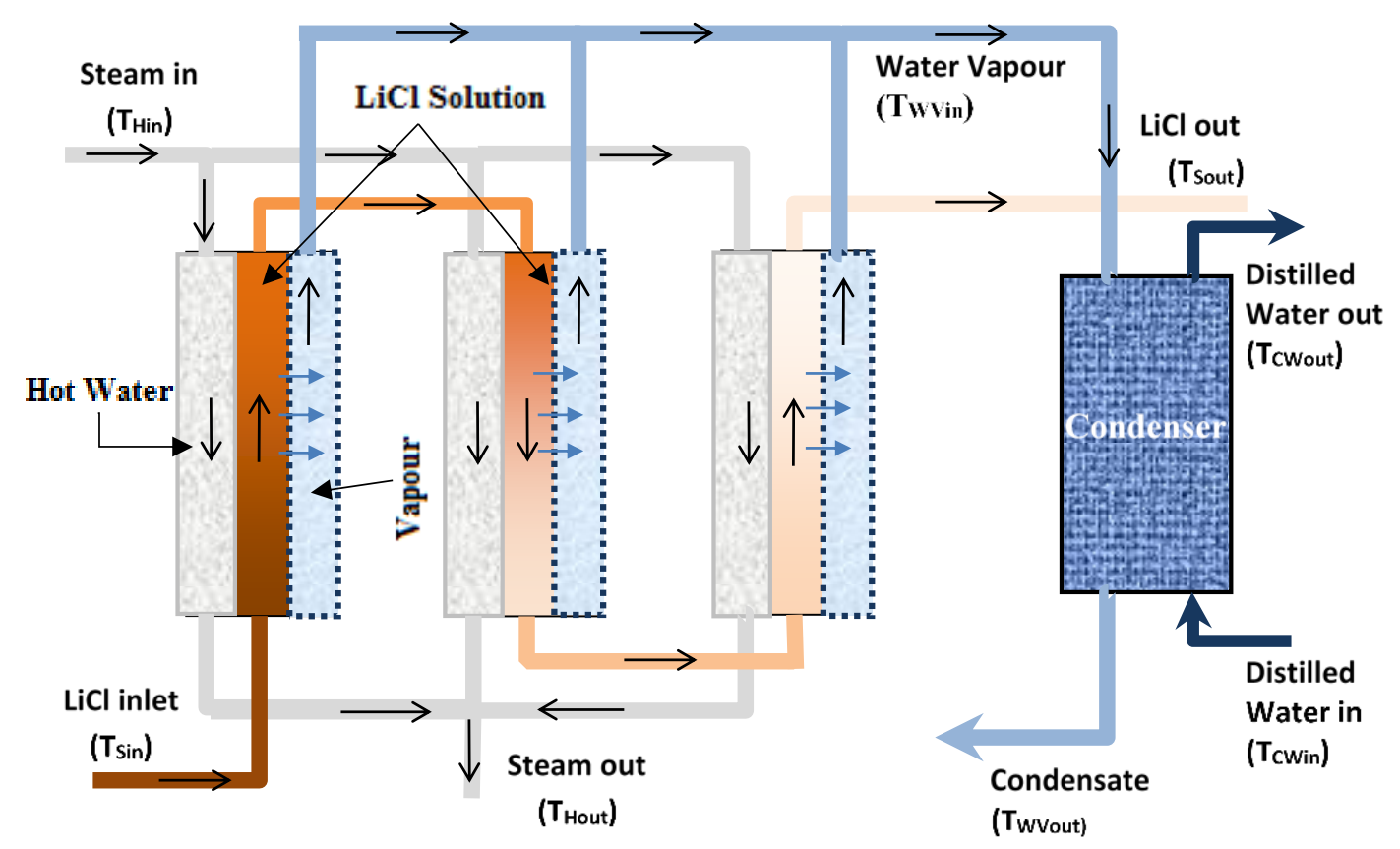

Figure 5.1: Schematic model of 1S-3L VMEMD regenerator

\subsection{Modelling of 1S-3L VMEMD systems}

A thermodynamic framework of the proposed MEMD regenerator system is developed from the rigor of heat and mass transfer model. The model is classified into three components representing individual modules (Figure 5.1), and each module is operated simultaneously using nested iterations. Using iterative calculations, the outlet parameters of all fluids under different design and operating conditions can be obtained. Similarly, the energy balance of the regenerator and its thermal performance can be assessed using this model.

Various theoretical models have been proposed and developed in the recent past for better understanding of Vacuum Membrane Distillation, especially in the desalination sector. The main outcome of these models are to predict the effects of 
the membrane design, module design, and control parameters on the permeate flux. The present model considers Knudsen, molecular, and Poiseuille flow transport mechanisms as proposed by many researchers [6-12].

The proposed LDAC-regenerator model is based on the following thermodynamic view points, and these are:

a) The process of vapour permeating through the membrane consists of three components: Knudsen diffusion, molecular diffusion and Poiseuille flow.

b) Negligible heat loss through the membrane.

c) Effects of liquid desiccant concentration are incorporated in model in the form of activity coefficient of water in solution.

d) The effect of liquid desiccant flow rate is also included in the model in terms of hydrodynamics as well as energy transfer.

e) The entire surface area separating the fluids is assumed to be the area for heat and mass transfer.

The system is optimized based on PR (performance ratio), and the effects of various parameters are examined. To verify the model, the simulation results are compared with the experimental data. The experimental investigation of $1 \mathrm{~S}-3 \mathrm{~L}$ VMEMD will be provided in the next chapter

\subsubsection{Thermodynamic model of desiccant regeneration unit}

For continuous regeneration operations, firstly a low-pressure refrigerant (hence water) is evaporated at the steam riser and supplied to the foil frame of all the three stages. The desiccant flowing in the desiccant channel is heated up and the water vapour removed from the desiccant travels across the membrane due to temperature and pressure differential acting across the membrane. The regeneration 
process results in the liberation of the heat of dilution at the desiccant channel providing useful thermal heat energy which can be recovered at the condenser. Secondly, the mass transfer across the polymer membrane is critical to the functioning of the regenerator. All the parameters pertaining to membrane material and liquid desiccant properties guide the mass transfer process. And all such properties are included in the mass flux equations. Finally, the water vapour removed from the desiccant goes to the condenser for condensation by pumping cold water through the environment. The distillate (water) is pumped back to the steam riser for re-use. The concentrated liquid desiccant is pumped back to the storage tank and thus completing the regeneration closed loop.

These phenomena are expressed mathematically using the mass and energy balances between major components of the $1 \mathrm{~S}-3 \mathrm{~L}$ regeneration system. The equations used for modelling are generic in nature but the application of these equations to our process is novel and unique. A lumped parameter modelling is carried out based on various assumptions are as follows:

\section{Assumptions:}

i) The heat losses in the piping are assumed to be negligible throughout the system.

ii) The flow rates of hot water and liquid desiccant are assumed to be constant throughout the channel. The change in flow rate due to bubbling is assumed to be negligible.

iii) The heat transfer area is assumed to be constant along the length and breadth of the foil frame separating hot water and desiccant channels.

iv) The physical and chemical properties of the Polypropylene remain unchanged throughout the operating range of temperature.

v) Errors due to pressure fluctuations are considered negligible. 
vi) In the open channels all the fluid properties are calculated under standard temperature and pressure (STP).

vii) Mass transfer across the membrane is considered to be uniform throughout the length, breadth and depth of the membrane.

viii) Phenomenon of pool boiling and surface film formation at heat and mass transfer surfaces are not considered in this modelling.

The schematic diagram of the system modelling is shown in Figure 5.2. In this Figure, $i$ indicate the number of heat transfer element in one direction that ranges from 1 to $x$. From Figure 5.2, one could find the connections of heat and mass transfer between (i) hot water and solution and (ii) solution and vapour through the membrane.

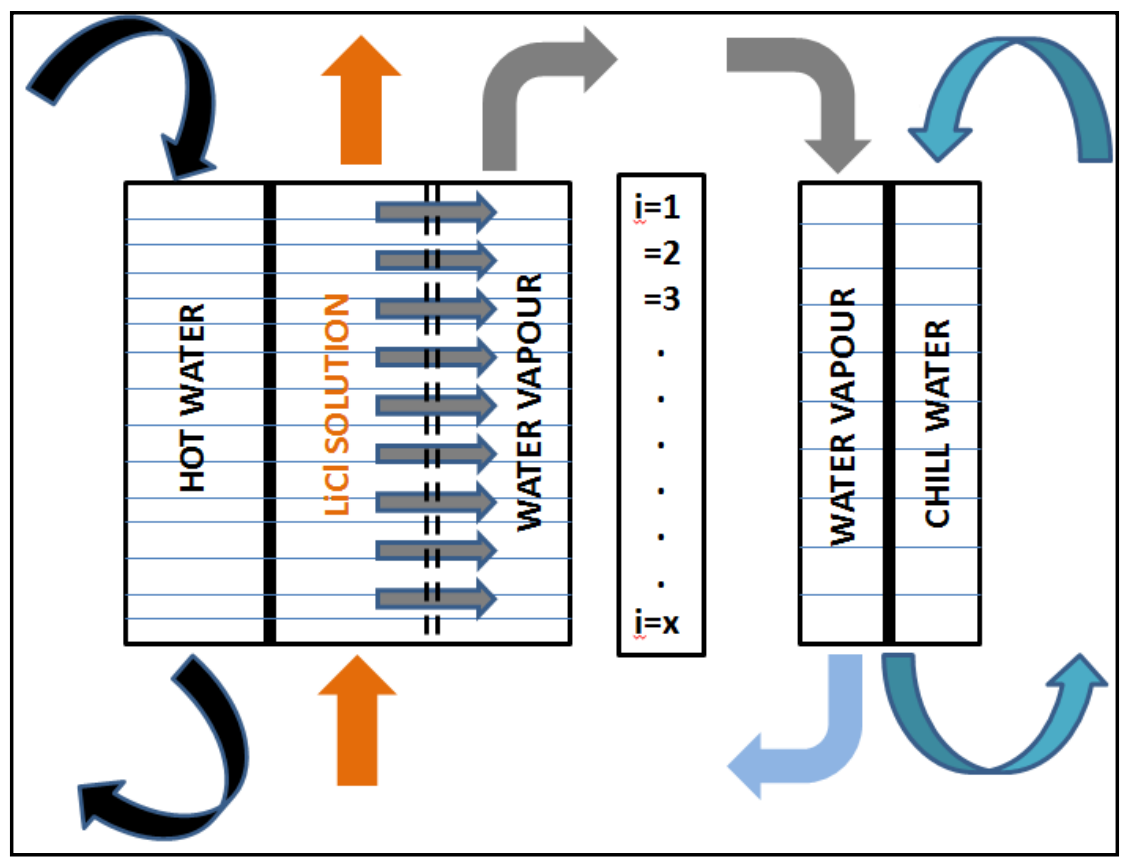

Figure 5.2: Schematic diagram of the system modelling 


\section{Hot water channel:}

The hot water channel is connected with the solution channel by Polypropylene foils, and the heat is transferred to the solution. The energy balance of the hot water, ranging from inlet to outlet is given by,

$$
\begin{aligned}
\left(\rho C_{P} V\right)_{C h}^{H o t} \frac{d T_{H}^{i}}{d t} & =\left(\dot{\mathrm{m}} C_{P}\right)_{H}\left(T_{H}^{i}-T_{H}^{i-1}\right)-U_{H-S} A_{H}\left(T_{H}^{i}-T_{S}^{i}\right) \\
& -U_{\text {LosS }}^{H} A_{H}\left(T_{H}^{i}-T_{\text {ambient }}\right)
\end{aligned}
$$

where, $\left(\rho C_{P} V\right)_{C h}^{H o t}$ is the summation of all the mass and specific heat capacities of the hot water channel. The first term on the right hand side defines the energy change due to the mass flow rate within the hot water channel. The second term indicates the convectional heat transfer to the solution channel across the foil frame, and the third term indicates the heat loss to the surrounding.

\section{Solution channel:}

Due to the transfer of heat energy from the hot water, the solution channel is heated up, and the water vapour is desorbed from $\mathrm{LiCl}$ solution. The energy balance across aqueous $\mathrm{LiCl}$ solution is expressed as,

$$
\begin{aligned}
\left(\rho C_{P} V\right)_{C h}^{S o l} \frac{d T_{S}^{i}}{d t} & =\left(\dot{\mathrm{m}} C_{P}\right)_{S}\left(T_{S}^{i}-T_{S}^{i-1}\right)+U_{H-S} A_{S}\left(T_{H}^{i}-T_{S}^{i}\right) \\
& -U_{S-W V} A_{S}\left(T_{S}^{i}-T_{W V}^{i}\right)-\frac{\dot{\mathrm{m}}_{W V} h_{w v}^{f g}}{X_{n}} \\
& -U_{\text {LosS }}^{S} A_{S}\left(T_{S}^{i}-T_{\text {ambient }}\right),
\end{aligned}
$$

where $\left(\rho C_{P} V\right)_{C h}^{S o l}$ is the summation of all the heat capacities of the desiccant channel. The first term on the right hand side defines the change in heat energy due to the solution flow within the channel. The second term indicates the transfer of 
heat between the solution channel and the foil frame. The third term defines the transfer heat energy from the solution channel to the water vapour channel across the PTFE membrane. The fourth term indicates the mass transfer of water vapour through the membrane, and the last term shows the heat loss.

\section{Water vapour channel:}

Water vapour generated from the solution flows in the water vapour channel. Therefore, heat is transferred from the solution to water vapour channel. The energy balance is given by,

$$
\begin{aligned}
\left(\rho C_{P} V\right)_{C h}^{W V} \frac{d T_{w v}^{i}}{d t} & =\left(\dot{\mathrm{m}} C_{P}\right)_{W V}\left(T_{W V}^{i}-T_{W V}^{i-1}\right)+U_{S-W V} A_{W V}\left(T_{S}^{i}-T_{W V}^{i}\right) \\
& +\frac{\dot{\mathrm{m}}_{W V}\left(h_{w v}^{f g}-h_{w v}^{g}\right)}{X_{n}}-U_{\text {LosS }}^{W V} A_{W V}\left(T_{W V}^{i}-T_{\text {ambient }}\right),
\end{aligned}
$$

The first term on the right hand side defines energy exchange due to the vapour flow rate within the channel. The second term is the heat energy transfer from solution channel across the PTFE membrane into the water vapour channel and the final term indicates the heat loss from the vapour channel into the surrounding.

\section{Condenser:}

The water vapours are collected in the condenser and the water vapour is condensed. The energy balance becomes,

$$
\begin{aligned}
\left(\rho C_{P} V\right)^{\text {Cond }} \frac{d T_{S}^{i}}{d t} & =\sum_{k=1}^{3}\left(\left(\dot{\mathrm{m}}_{w v} A_{W V}\right)\left(h_{\text {Cond }}^{f g}-h_{\text {Cond }}^{f}\right)\right)^{k} \\
& -\dot{\mathrm{m}}_{c w}\left(h_{C w_{\text {out }}}^{f}-h_{C w_{\text {in }}}^{f}\right)
\end{aligned}
$$


Where, $\left(\rho C_{P} V\right)^{\text {Cond }}$ is the heat capacities of the condenser and ' $k$ ' indicates the regeneration stages. The first term on the right hand side defines the thermal energy carried by the distillate in the condenser with the latent heat of condensation. The second term indicates the heat energy carried away from the condenser by the chilled water flow.

In the equations above ' $\boldsymbol{i}$ ' indicates the temperature of the fluid elements ranging from 1 to $X_{n}$, where $X_{n}$ is the total number of fluid elements along the length (L) of the module. The $1^{\text {st }}$ boundary condition for fluid flow is defined as $\boldsymbol{T}_{\text {fluid }}^{\boldsymbol{i}}(\mathbf{j}, \mathbf{i}=\mathbf{1})$ $=T_{\text {fluid }}^{\text {in }}$, where the subscript "fluid" refers to the material flowing in the corresponding module or the condenser. And $2^{\text {nd }}$ boundary condition is $\frac{d T_{f l u i d}}{d x}=\mathbf{0}$ at $\boldsymbol{T}_{\text {fluid }}(\mathbf{j}, \mathbf{i}=\mathbf{L})$.

The initial condition for the regeneration system is defined by $\boldsymbol{T}^{\boldsymbol{j}}{ }_{\text {fluid }}(\mathbf{j}=\mathbf{0}, \mathbf{i})$ $=\boldsymbol{T}^{\text {ambient }}$, where $\mathbf{j} \mathbf{j}$ ' indicates the time of operation ranging from 1 to $t_{n}$. Hence, $t_{n}$ is the total time of operation and $\mathrm{x}$ indicates any fluid element between 1 and $X_{n}$.

\section{Equations for distillation modelling:}

The distillation modelling comprises the Knudsen and molecular diffusions with the transport of mass according to Poiseuilli mechanism [12].

The diffusion due to Knudsen mechanism is given by,

$$
N_{K}=\left(\frac{4}{3}\right) d \frac{\varepsilon}{\tau \delta} \sqrt{\frac{1}{2 \Pi M R T}} \Delta P
$$


where $N_{K}$ is the Knudsen diffusion in, $\tau$ is the tortuosity of the membrane, $\varepsilon$ is the porosity of the PTFE membrane, $\mathrm{R}$ is the universal gas constant, $\delta$ is the membrane thickness, $d$ is the average pore diameter, $\mathrm{M}$ is the molecular weight of water and $\Delta P$ is the trans-membrane pressure difference.

The Poiseuilli mechanism for mass transport is written as,

$$
N_{P}=\frac{d^{2}}{32 \eta} \frac{\varepsilon}{\tau \delta} C \Delta P
$$

where $N_{P}$ is the flux due to Poiseuilli mechanism, $\eta$ is the kinematic viscosity, $\tau$ is the tortuosity of the membrane, $\varepsilon$ is the porosity of the PTFE membrane, $\delta$ is the membrane thickness, $d$ is the average pore diameter, $\mathrm{C}$ is the gas concentration and $\Delta P$ is the trans-membrane pressure difference.

The Molecular diffusion is given by,

$$
N_{M}=\frac{1}{1-Y_{A}} \frac{\varepsilon}{\tau \delta \mathrm{RT}} D_{A B} \Delta P
$$

where $N_{M}$ is the molecular diffusion flux, $\left(1-Y_{A}\right)$ is the mole fraction of air, $\tau$ is the tortuosity of the membrane, $\varepsilon$ is the porosity of the PTFE membrane, $\mathrm{R}$ is the universal gas constant, $\delta$ is membrane thickness, $d$ is the average pore diameter, $D_{A B}$ is the diffusivity and $\Delta P$ is the trans-membrane pressure difference.

The total flux related to Knudsen and molecular diffusion is given by:

$$
\frac{1}{N_{M-K}}=\frac{1}{N_{K}}+\frac{1}{N_{M}}
$$


The combined trans-membrane flux is calculated with respect to the mass transport of Poiseuilli mechanism as well as combined effects of Knudsen and molecular diffusion.

$$
N_{M-K-P}=N_{M-K}+N_{P}
$$

Employing equation (5.5) - (5.9), the total mass flux across the membrane is given by,

$$
\begin{aligned}
N_{M-K-P} & =\frac{\varepsilon}{\tau \delta \mathrm{RT}}\left\{\frac{1-Y_{A}}{D_{A B}}+\frac{3}{4 d} \sqrt{\frac{2 \Pi M}{R T}}\right\}^{-1} \Delta P \\
& +\frac{\varepsilon r^{2}}{\tau \delta \mathrm{RT}} \frac{\mathrm{P}_{s o l} M}{8 \eta \mathrm{RT}} \Delta P
\end{aligned}
$$

The partial pressure of water on the feed side membrane surface:

$$
P_{\text {sol }}=(1-x) \gamma P_{\text {sol }}^{\circ}
$$

where $x$ is the mole fraction of the salt $\mathrm{LiCl}, \gamma$ is the activity of water in lithium chloride solution and $P_{\text {sol }}^{\circ}$ is the saturation pressure of water in the solution.

According to Lawson and Lloyd [13],

$$
\gamma=1-0.5 x-10 x^{2}
$$

From Antoine Equation, the value of $P_{\text {sol }}$ is calculated as:

$$
P_{\text {sol }}=23.194-\frac{3816.44}{T_{\text {sol }}-46.13}
$$


The parameters for the simulation study include the volumetric flow rates of hot water, cold water and feed solution. The temperature and density of the desiccant at inlet are also fed as input parameters. Aqueous $\mathrm{LiCl}$ solution properties are calculated based on equations as provided by Conde and Petit [14]. The density of the feed solution is calculated as a function of temperature and concentration of the feed solution. The detailed simulation parameters are furnished in Table 5.1.

Table 5.1: Parameters for simulating LDAC-regenerator system (1S-3L), based on experimental test-facility.

\begin{tabular}{|l|c|}
\hline Length of the module (mm) & 430 \\
\hline Breadth of the module (mm) & 360 \\
\hline Width of the channel (mm) & 9 \\
\hline Thickness of the membrane $(\mathrm{mm})$ & $2.4 \mathrm{x} 10^{(-5)}$ \\
\hline$D_{A B}$, diffusivity $\left(\mathrm{m}^{2} / \mathrm{s}\right)[12]$ & 0.22 \\
\hline $\mathrm{d}$, membrane pore diameter $(\mu \mathrm{m})$ & $1-10^{(-5)}$ \\
\hline$Y_{A}$, mole fraction of air [12] & 8.314 \\
\hline $\mathrm{R}$, Universal gas constant $(\mathrm{kJ} / \mathrm{kmolK})$ & 18 \\
\hline $\mathrm{M}$, Molecular weight of water $(\mathrm{kg} / \mathrm{kmol})$ & $0.673 \mathrm{e}-3$ \\
\hline viscosity $(\mathrm{kg} / \mathrm{m}-\mathrm{s})[12]$ & \\
\hline
\end{tabular}


Table 5.1

\begin{tabular}{|l|c|}
\hline porosity [12] & 70 \\
\hline tortuosity[12] & 1 / porosity \\
\hline $\mathrm{V}^{\mathrm{Hot}}=\mathrm{V}^{\mathrm{Sol}}=\mathrm{V}^{\mathrm{WV}}=\mathrm{V}^{\mathrm{Cond}}$, Volume $\left(\mathrm{m}^{3}\right)$ & 0.014 \\
\hline $\mathrm{A}^{\mathrm{Hot}}=\mathrm{A}^{\text {Sol }}=\mathrm{A}^{\mathrm{WV}}$, Area $\left(\mathrm{m}^{2}\right)$ & 0.1548 \\
\hline $\mathrm{T}_{\text {ambient }}(\mathrm{K})$ & 0.6 \\
\hline $\begin{array}{l}\mathrm{U}_{\mathrm{H}-\mathrm{S}}, \text { Overall heat transfer coefficient between hot water } \\
\text { channel and solution channel. }\left(\mathrm{kW} / \mathrm{m}^{2} \mathrm{~K}\right)\end{array}$ & 0.9 \\
\hline $\begin{array}{l}\mathrm{U}_{\mathrm{S}-\mathrm{wV}}, \text { Overall heat transfer coefficient between solution } \\
\text { channel and water vapour channel, }\left(\mathrm{kW} / \mathrm{m}^{2} \mathrm{~K}\right)\end{array}$ & 0.04 \\
\hline \begin{tabular}{l}
$\mathrm{U}^{\mathrm{H}}{ }_{\text {loss }}$, Heat loss coefficient to the surrounding $\left(\mathrm{kW} / \mathrm{m}^{2} \mathrm{~K}\right)$ \\
\hline $\mathrm{U}_{\text {loss }}^{\mathrm{S}}$, Heat loss coefficient to the surrounding $\left(\mathrm{kW} / \mathrm{m}^{2} \mathrm{~K}\right)$
\end{tabular} & 0.04 \\
\hline $\mathrm{U}^{\mathrm{WV}}{ }_{\text {loss }}$, Heat loss coefficient to the surrounding $\left(\mathrm{kW} / \mathrm{m}^{2} \mathrm{~K}\right)$ & 0.045 \\
\hline
\end{tabular}

\section{$5.4 \quad$ Results and Discussions}

A membrane based multi effect regenerator has been designed and simulated in MATLAB platform. The function of steam riser and condenser is same as that of conventional VMEMD regenerator system. Only the configurations of steam and solution stages are modified to improve the performance of regenerator system for higher salt concentrations. The hot water from the steam riser enters all of the three modules independently and the desiccant solution enters the regenerator in the first 
module. The ambient temperature is considered to be $301 \mathrm{~K}$ for calculation purposes.

Thermal performance ratio is a key parameter for measuring the regeneration performance.

$$
P R=\left(m_{\text {dist }} \times h_{f g}\right) / H_{\text {in }},
$$

The flux across the membrane from the three modules is sent to the condenser for cooling and is removed as distillate. The rate of distillate generation is also an important indicator of the system performance. The rate of distillation $m_{\text {dist }}$ is calculated as,

$$
\dot{\mathrm{m}}_{\text {dist }}=V_{S} \rho_{S} \frac{\Delta C}{C_{\text {out }}}
$$

where $V_{S}$ (litre/hour) is the volumetric flow rate of the solution, $\rho_{S}$ is the feed inlet density and $(\Delta C),\left(C_{\text {out }}\right)$ are the change in concentration and the feed outlet concentration respectively. $H_{\text {in }}(\mathrm{kW})$ is the heat energy input to the system and is calculated as,

$$
H_{\text {in }}=\dot{\mathrm{m}}_{H}\left(T_{H}^{\text {in }}-T_{H}^{\text {out }}\right) / 4.18 \text {, }
$$

where $\left(T_{H}^{\text {in }}-T_{H}^{\text {out }}\right)$ is the temperature difference between hot water inlet and outlet, and $\dot{\mathrm{m}}_{H}$ is the mass flow rate of hot water.

A simulation study was carried out to measure the performance factor of the regenerator using $\mathrm{LiCl}$ desiccant solution with the feed concentrations varying from $26 \%$ to $36 \%$ and feed flow rates between 10 litre/hour to 50 litre/hour. The heating source temperatures are varied from $50{ }^{\circ} \mathrm{C}$ to $80{ }^{\circ} \mathrm{C}$. Figure 5.2 (a-c) shows the temperature variation of the fluids with time at the outlet of three modules respectively. It is observed from simulation results that the steady state occurs after $2000 \mathrm{~s}$, which is quite close to the experimental data. 

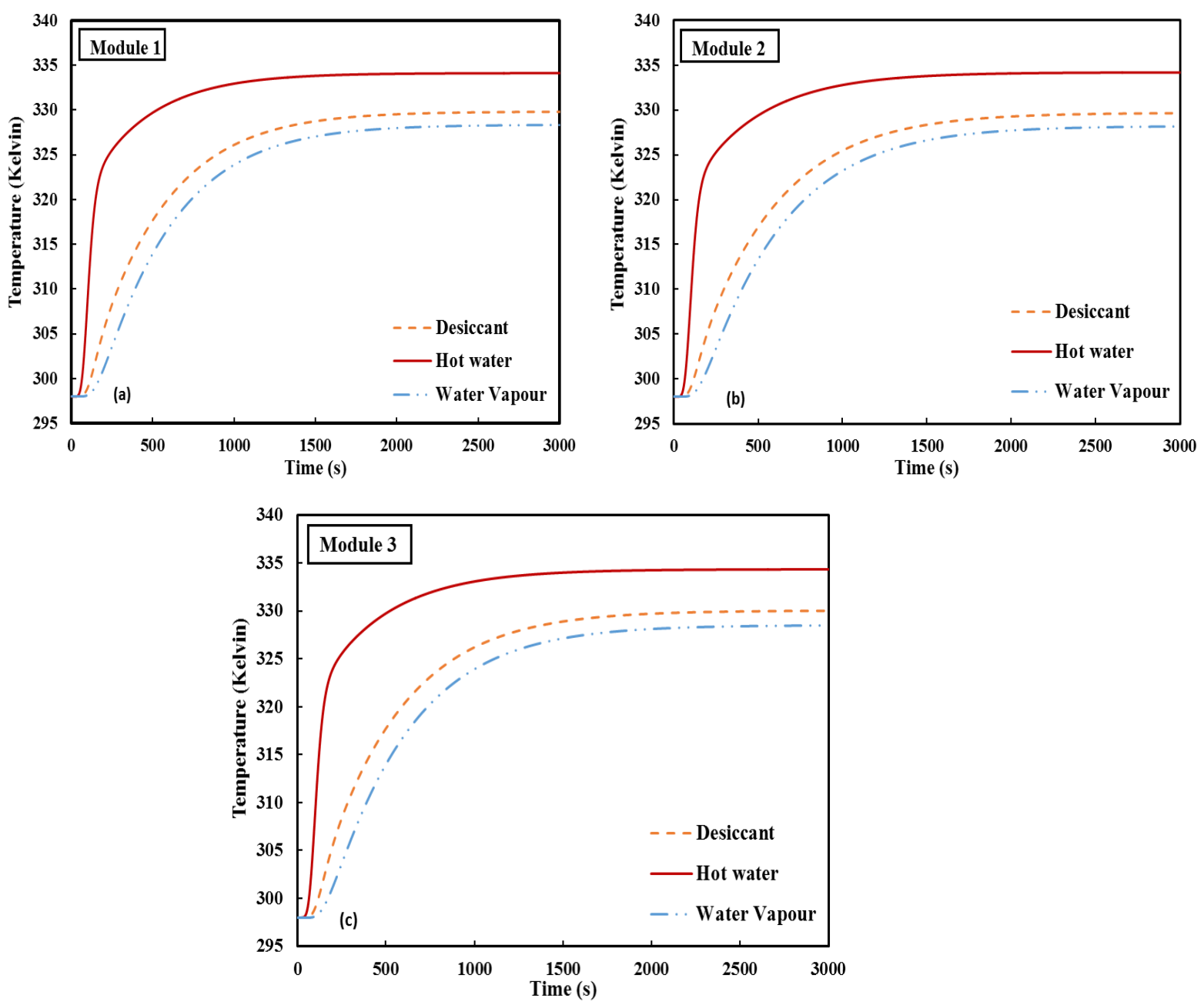

Figure 5.3: Temperature profile of the fluids at the outlet of (a) Module 1, (b) Module 2 and (c) Module 3 of the 1S-3L LDAC regenerator; inlet concentration $32 \%$, heating temperature $65^{\circ} \mathrm{C}$.

The variations of thermal performance ratio (PR) with respect to feed flow rates and heating temperature are illustrated in Figures 5.3(a-d) for the solution with feed concentration of $27 \%, 32 \%, 34 \%$ and $36 \%$. 

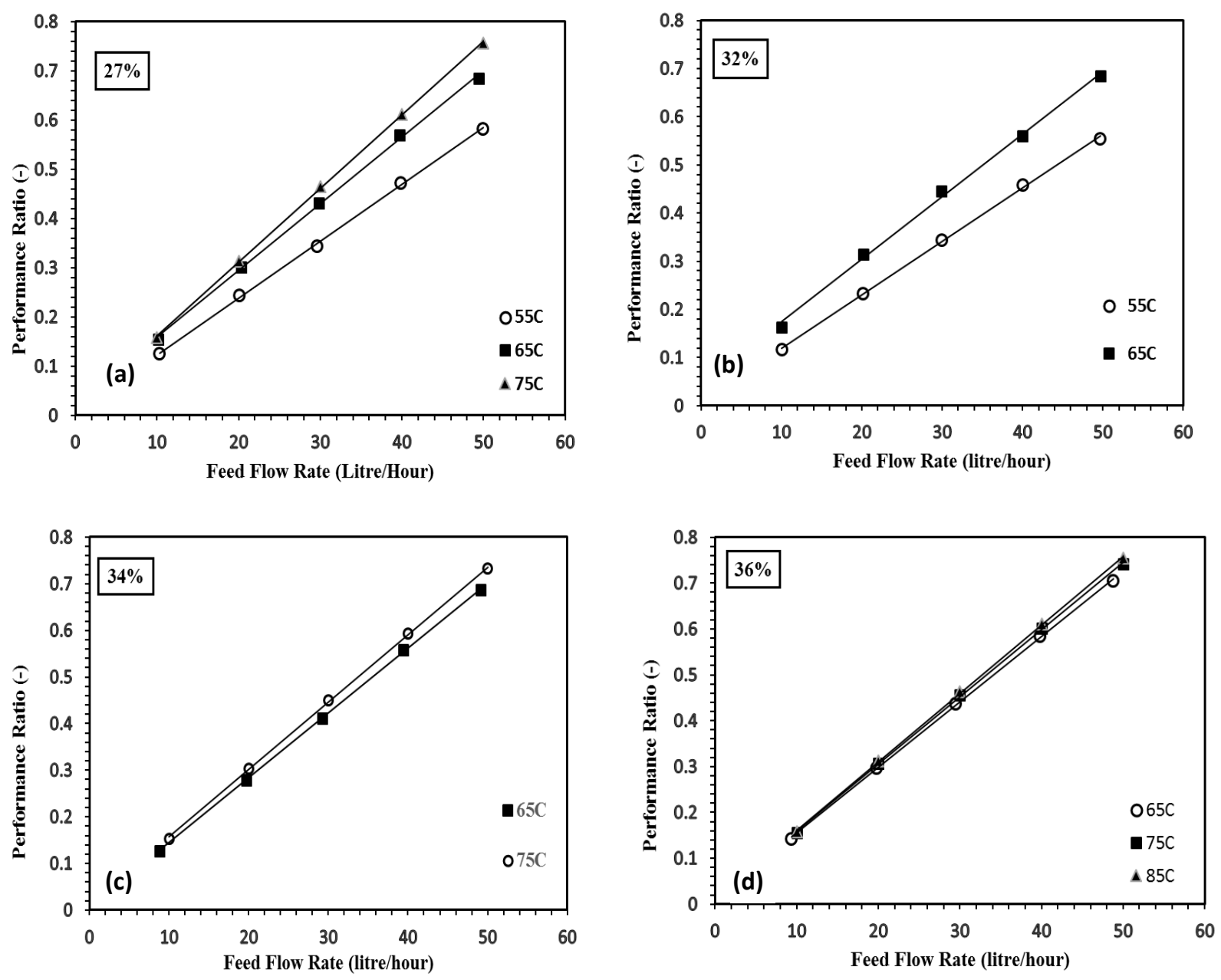

Figure 5.4: Performance ratio (PR) against solution flow rates of one-steam-threesolution regenerator configuration for the inlet feed concentrations of (a) $27 \%$ (b) $32 \%$ (c) $34 \%$ and (d) $36 \%$ for different heating temperatures.

From the graphs 5.3(a-d), it is observed that the PR increases with the increase in feed flow rates. The maximum performance ratio is achieved when the flow rate is highest for any salt concentration. The PR of the system also increases with increase of heating temperature this is due to the increased amount of heating energy. However the increase in PR with temperature is decreased at higher 
concentration and is extremely low at $36 \%$ feed concentration. This shows that at higher concentration the effect of feed flow rate is significantly more than the heating temperature. This can be attributed to the vapour pressure of the desiccant which becomes saturated at higher concentrations and thus doesn't affect the PR significantly.

The PR of the experimental results is lower as compared to the simulation results. This may be due heat loss from the system and flow rate variations. The heat losses may be occurred due poor insulation and welding of the modules, and heat losses in distribution pipes. The change of membrane geometry with temperature and pressure variations over time can also affect the performance during the experimental study. The heat transfer between the solution and hot water is also affected due to trapped air bubbles in the flow stream during experimental runs. Hence the surface area available for heat and mass transfer is lower during experimental study.

The design of the 1S-3L system can be improved by increasing the heat and mass transfer surface area, and by installing membranes with better mass transfer properties. The overall heat loss can be minimized by better insulation of the piping and the regeneration modules.

The rate of distillate production (gm/hour) with feed flow rate and heating temperature are illustrated in Figures 5.4(a-d) for the solution with feed concentration of $27 \%, 32 \%, 34 \%$ and $36 \%$. It can be observed from the distillate versus feed flow rate graphics that both temperature and feed flow rate have significant effects on the rate of distillate generation. 

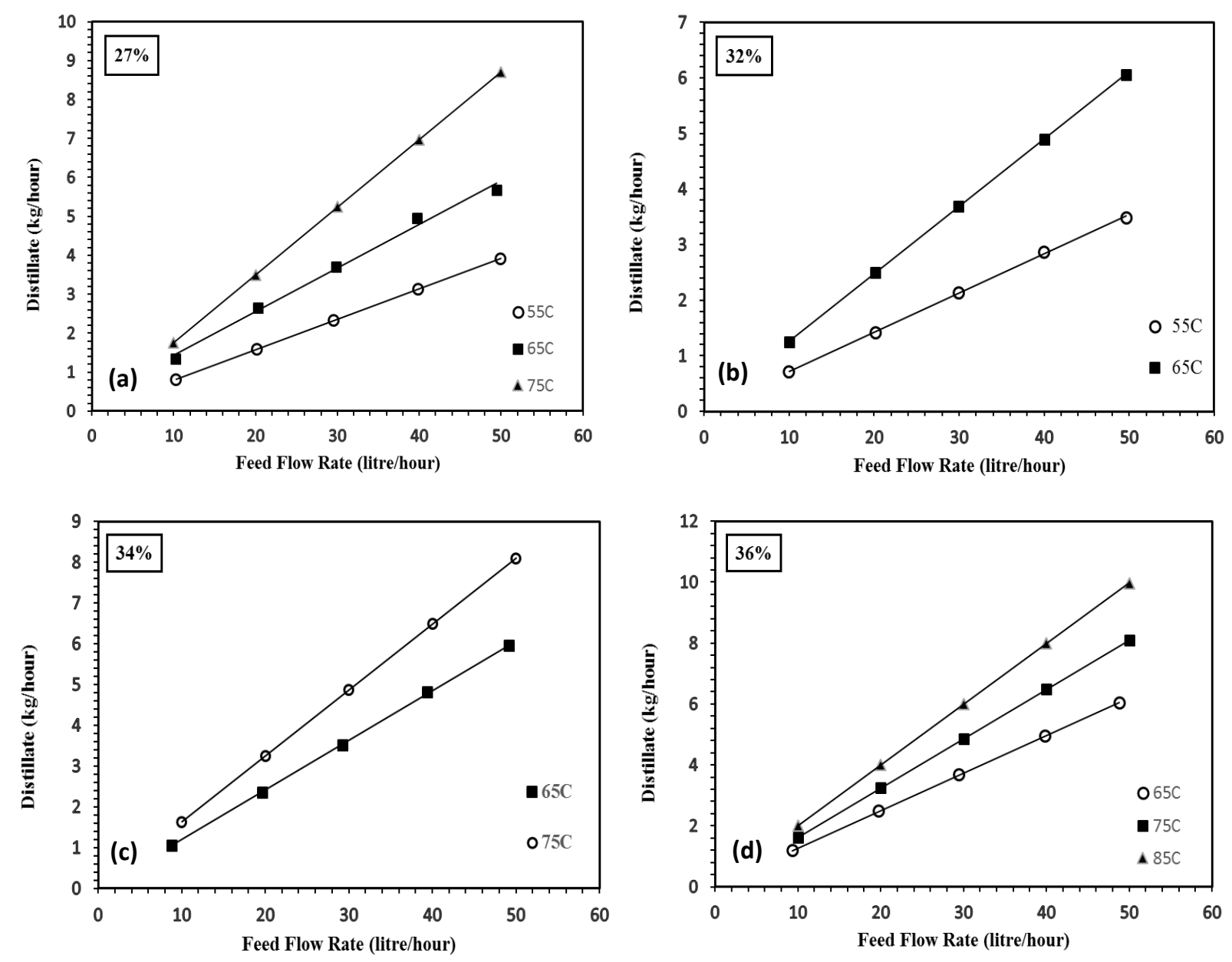

Figure 5.5: Distillate against solution flow rates of one-steam-three-solution regenerator configuration for the inlet feed concentrations of (a) $27 \%$ (b) $32 \%$ (c) $34 \%$ and (d) $36 \%$ for different heating temperatures.

At higher heating temperature, the rate of distillate generation is increased. This is due to increase in solution temperature, and as a result it desorbs more water vapour. The distillate production increases with the increase in flow rate, this can be attributed to the increases in mass transfer at high flow rates and leads to a faster desorption process. At higher concentration feed solution inlet, the rate of distillate 
generation is not significantly affected by the inlet concentration. This is due to the vapour pressure of the liquid desiccant which is saturated at higher concentrations.

\subsection{Conclusions}

In this chapter, the working principles of the regenerating module are modified with the combinations of steam and $\mathrm{LiCl}$ solution flows in each module for handling high concentration feed for dehumidification applications. The thermal performances (in terms of $\mathrm{kW}$ distillation per $\mathrm{kW}$ heat input) of a single-stage (1S3L) VMEMD are simulated for various inlet feed concentrations ranging from $27 \%$ to $36 \%$ and flow rates up to 1 litre/min. The configuration deals with steam flows in single stage and liquid desiccant flows in three stages where the low grade energy is recovered. The PR is found to attain a maximum value of 0.75 for the heating temperature of $75^{\circ} \mathrm{C}$ with $27 \%$ inlet feed concentration. This configuration also works well for higher feed concentration of up to $36 \%$. However at $36 \%$ solution concentration the PR is not significantly affected the heating temperature, as the effect of solution vapour pressure prevents any effect of heating temperature. As can be observed from simulation data, this system provides acceptable performance ratio even at higher desiccant concentrations. From the present analysis, it is concluded that VMEMD module, which is generally designed for desalination purposes, can also be employed for desiccant regeneration

applications. Based on this study the new configuration is proposed for experimental study, to analyse the practical utility of the $1 \mathrm{~S}-3 \mathrm{~L}$ system. 


\section{References}

[1] N. Fumo and D. Y. Goswami, "Study of an aqueous lithium chloride desiccant system: Air dehumidification and desiccant regeneration," Solar Energy, vol. 72, pp. 351-361, 20022002.

[2] H. M. Factor and G. Grossman, "A Packed-Bed Dehumidifier-Regenerator For Solar Air-Conditioning With Liquid Desiccants," Solar Energy, vol. 24, pp. 541-550, 19801980.

[3] X. H. Liu, Y. Jiang, and K. Y. Qu, "Heat and mass transfer model of cross flow liquid desiccant air dehumidifier/regenerator.," Energy Conservation and Management, vol. 48, pp. 546 - 554, 2007.

[4] G.A. Longo and A. Gasperella, "Experimental and theoretical analysis of heat and mass transfer in a packed column dehumidifier/regenerator with liquid desiccant," Int J. Heat and Mass Tranfer, vol. 48, pp. 5240-5254, 2005.

[5] A. salam, "Performance analysis of a membrane liquid desiccant airconditioning system, pp. 559-569, ," Energy Build., vol. 62, pp. 559-569, 2013.

[6] C. K. Chiam and R. Sarbatly, "Vacuum membrane distillation processes for aqueous solution treatment - A review," Chem. Eng. Process, vol. 74, pp. 27-54, 2013.

[7] M. Gryta, "Effectiveness of water desalination by membrane distillation process," Membranes (Basel), vol. 2, pp. 415-29, Jul 172012.

[8] M. Khayet, M. P. Godino, and J. I. Mengual, "Modelling Transport Mechanism Through A Porous Partition.," Journal of Non-Equilibrium Thermodynamics, vol. 26, pp. 1-14, 2001. 
[9] ZHANG Xiuli, ZHANG Weidong, and H. Xinmin, "Mathematical Model of Gas Permeation Through PTFE Porous Membrane and the Effect of Membrane Pore Structure," Chin.J.Chem.Eng., vol. 11, pp. 383-387, 2003.

[10] J. G. Lee, Y. D. Kim, W. S. Kim, L. Francis, G. Amy, and N. Ghaffour, "performance modelling of direct contact membrane distillation (DCMD) seawater desalination process using a commercial composite membrane," Journal of Membrane Science, vol. 478, pp. 85 - 95, 2015.

[11] M. Kumja, F. H. Choo, B. Li, A. Chakraborty, E. Mohan Dass, K. Zhao, et al., "Two Dimensional Numerical Analysis of Membrane-based Heat and Mass Cross Flow Exchanger," Heat Transfer Engineering.

[12] Sushant Upadhyaya, Kailash Singh, S.P. Chaurasia, R. K. Dohare, and M. Agarwal, "Mathematical and CFD modeling of vacuum membrane distillation for desalination," Desalination and Water Treatment, vol. 57, pp. 11956-11971, 2016.

[13] K. W. Lawson and D. R. Lloyd, "Membrane Distillation," Journal of Membrane Science, vol. 124, pp. 1-25, 1997.

[14] M. Conde, "Properties of aqueous solutions of lithium and calcium chlorides: formulations for use in air conditioning equipment design," International Journal of Thermal Sciences vol. 43, pp. 367-382, 2004. 


\section{Chapter 6}

\section{Experimental Investigation of 1S-3L VMEMD System}

\subsection{Introduction}

The conventional VMEMD is designed for the desalination and water treatment industry, it works very well when the feed concentration is as low as sea water concentration (\% Concentration in mass is less than 10\%) [1]. However, the minimum operation concentration of the regeneration process for liquid desiccant air-conditioning (LDAC) system is $26 \%$. According to the preliminary test, a conventional 4 stages VMEMD system [2], which is shown in Figure 3-7 (a) of Chapter 3, fails to provide satisfactory performance above $22 \%$ feed concentration. Therefore, for dehumidification purposes, the conventional 4 stage VMEMD system should be modified. Based on simulation study, 1S-3L VMEMD system has been designed, developed and fabricated.

This chapter deals with the experimental study of the proposed 1S-3L VMEMD system. Experimental investigation of the modified configurations is conducted to analyse the effects of control parameters on the change in concentration $(\Delta \mathrm{C})$ and thermal performance ratio (PR).

\subsection{Experiments}

The objective of the experimental investigation is to reduce energy consumption by the use of membrane based multistage regenerator, which possesses an acceptable performance ratio (PR) at the heat source temperatures ranging from 50 to $80{ }^{\circ} \mathrm{C}$. The $\triangle \mathrm{C}$ and $\mathrm{PR}$ of the modified configurations of VMEMD distillation are 
investigated experimentally under various feed flow rates, feed concentrations and heating temperatures. The pictorial view of the test-facility of 1S-3L VMEMD system is shown in Figure 6.1, and the schematic of the 1S-3L is shown in figure 6.2 .
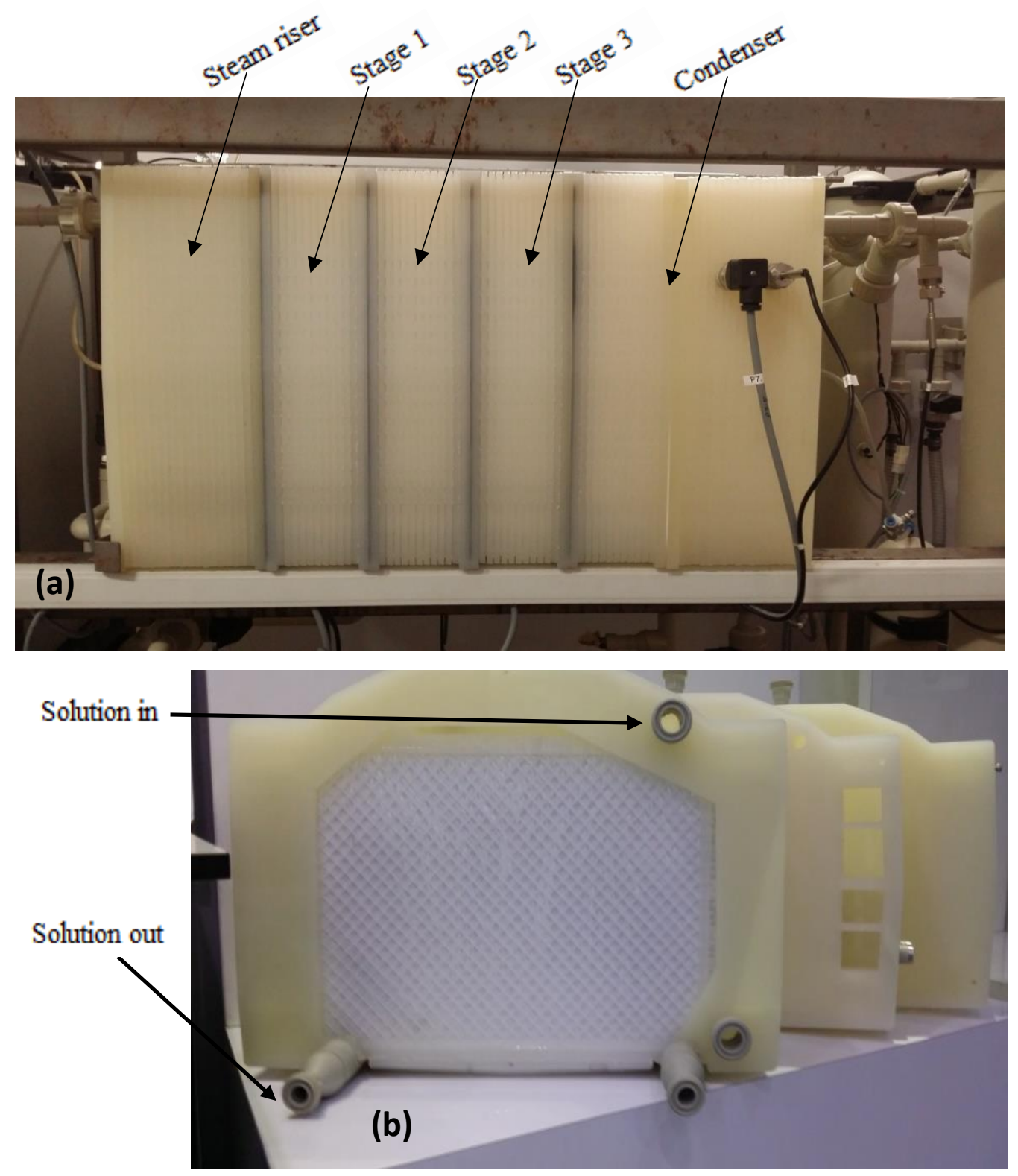

Figure 6.1: Pictorial view of (a) 1S-3L VMEMD Regenerator and (b) 1S-3L Regeneration modules 


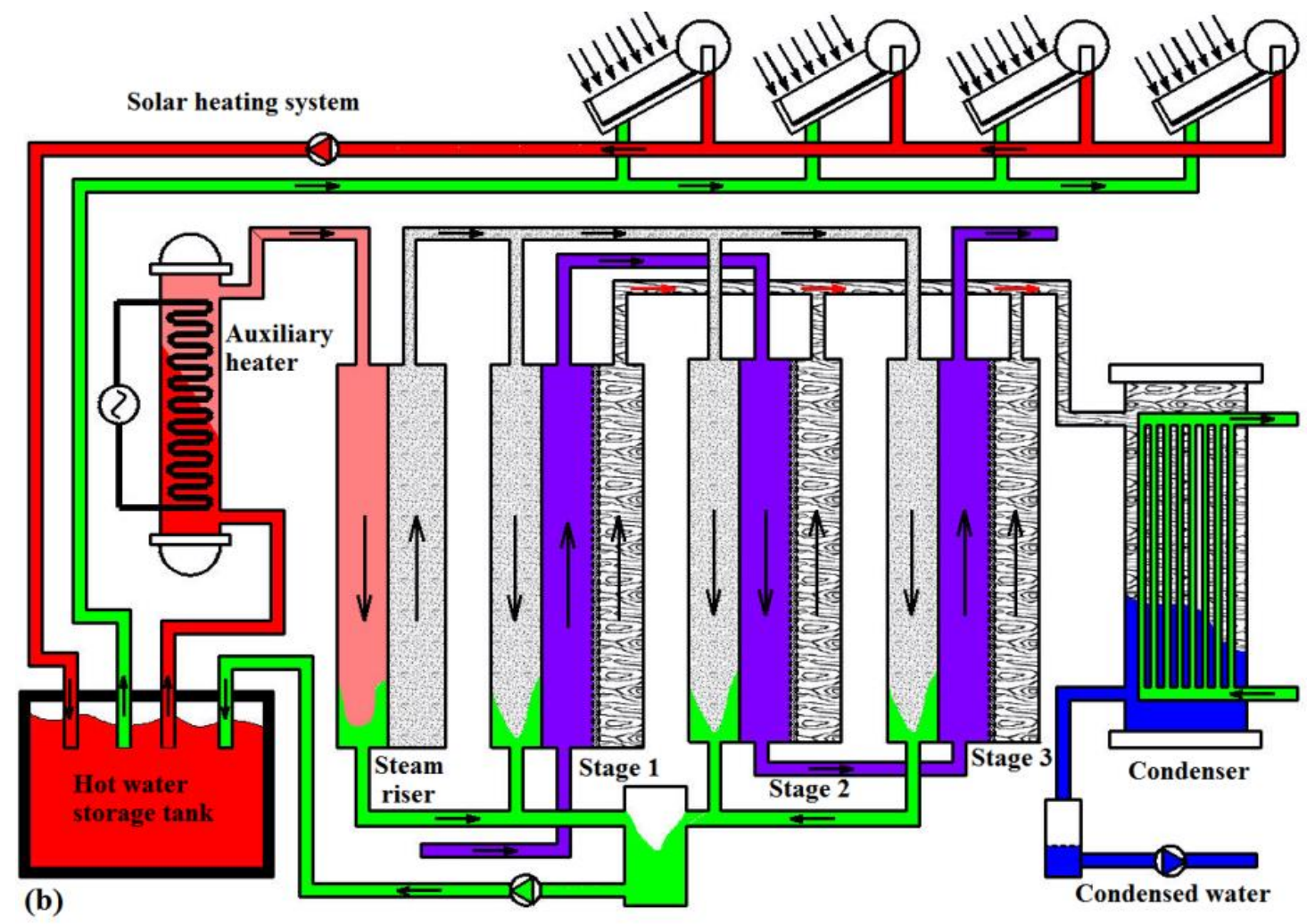

Figure 6.2: Schematic of the 1S-3L VMEMD regenerator

\subsubsection{Performance parameters}

The parameters that influence the performances of the proposed desiccant regenerator for dehumidification purposes are feed desiccant (here $\mathrm{LiCl}$ ) concentration, feed flow rates and the driving heat source temperatures. In this experiment (i) the feeding concentrations are ranged from $27 \%$ to $36 \%$, (ii) the feeding flow rates are varied from $0.15 \mathrm{litre} / \mathrm{min}$ to 1 litre/min, (iii) the hot water temperatures are set at $55,65,75$ and $85^{\circ} \mathrm{C}$ with the cooling water inlet temperature of $28{ }^{\circ} \mathrm{C}$. The performance of the multistage generator is calculated in terms of performance ratio (PR). The thermal performance ratio in terms of $\mathrm{kW}$ per $\mathrm{kW}$ can be expressed as the ratio of the heat generation for distillation process (water vapour separation from the salt solution) to the average heating energy. The 
change in concentration $\Delta C$ (in \%) and the $\mathrm{PR}$ is calculated using the same procedure as that of the conventional VMEMD regenerator.

\subsection{RESULTS: Single stage steam-three stages desiccant (1S-3L)}

The functions of steam riser and condenser of the proposed $1 \mathrm{~S}-3 \mathrm{~L}$ are same as those of conventional VMEMD regenerator system. Only the configurations of steam and solution stages are modified to improve the performance of regenerator system for higher salt concentrations. The solution with feed concentration of $27 \%$, $32 \%$ and $34 \%$ are applied at different feed flow rates and different hot water temperature in the steam riser.

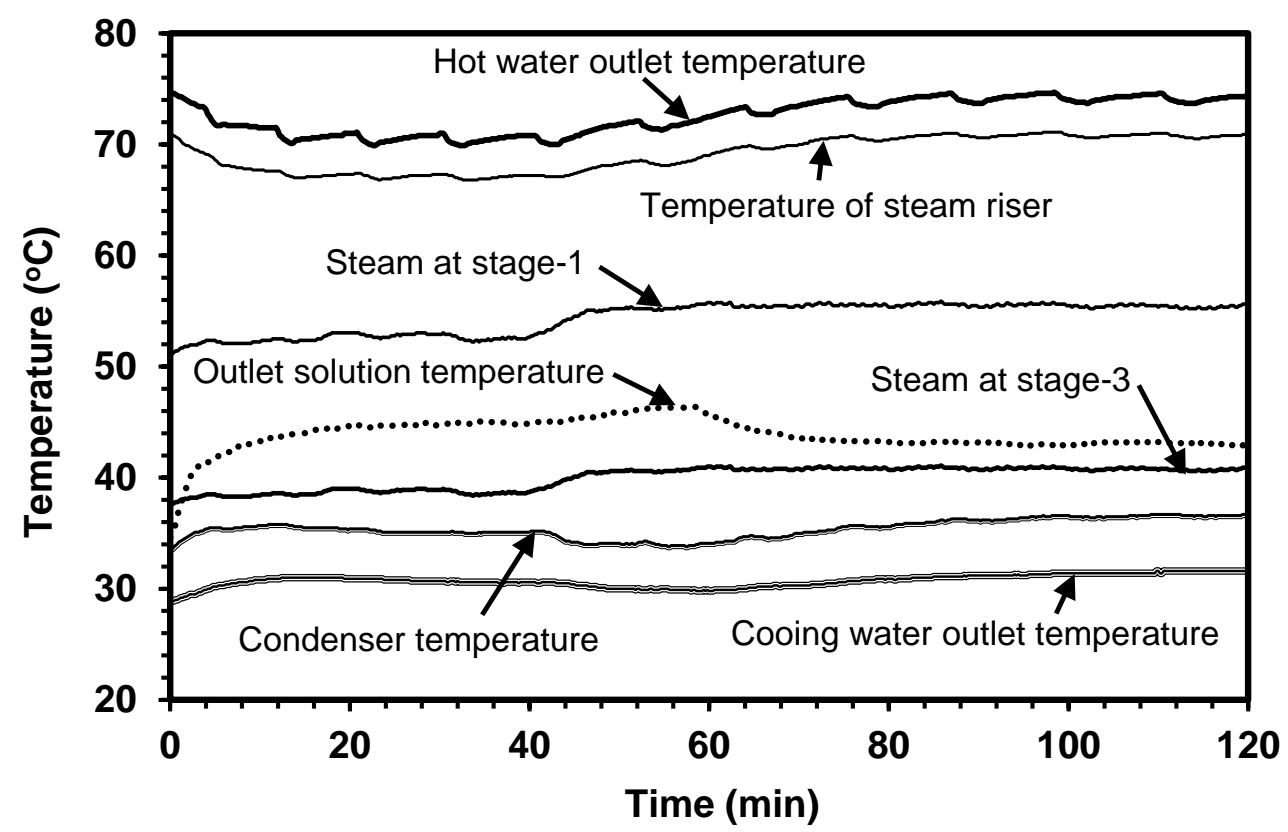

Figure 6-3: Temperature profiles of various components of $1 \mathrm{~S}-3 \mathrm{~L}$ regenerator under steady state conditions.

The temperature charts of 1S3L system are shown in Figure 6-3. Due to energy utilization and heat losses to the ambient, the temperature of steam at stage 3 is lower than that at stage 1. 
The test results related to change in concentration $(\Delta C)$ and $\mathrm{PR}$ of the $1 \mathrm{~S}-3 \mathrm{~L}$ regenerator system at the salt concentration level of $27 \%, 30 \%$ and $32 \%$ for the hot water temperature of $55^{\circ} \mathrm{C}$ with feed flow rates ranging from 0.17 to $1 \mathrm{litre} / \mathrm{min}$ are shown in Figures 6-4 (a) and 6-4 (b). It is found that the PR increases with the increase in feed flow rates. At $27 \%$ inlet feed concentration and the solution flow rate of 0.17 litre $\min ^{-1}$, the $\Delta \mathrm{C}$ shows the highest value and decreases gradually with the increase in feed flow rates up to 1 litre $\min ^{-1}$, due to insufficient heat to remove the moisture from salt. Here the change in concentration is varied from $5 \%$ to $2 \%$. However, at the inlet feed concentration of $32 \%, \Delta C$ is increased, which is nearly constant at about $0.8 \%$. The maximum performance ratio is achieved 0.6 at $27 \%$ salt concentration and 0.83 litre $\min ^{-1}$ feed flow rate. At higher concentrations, the performance ratio drops significantly.
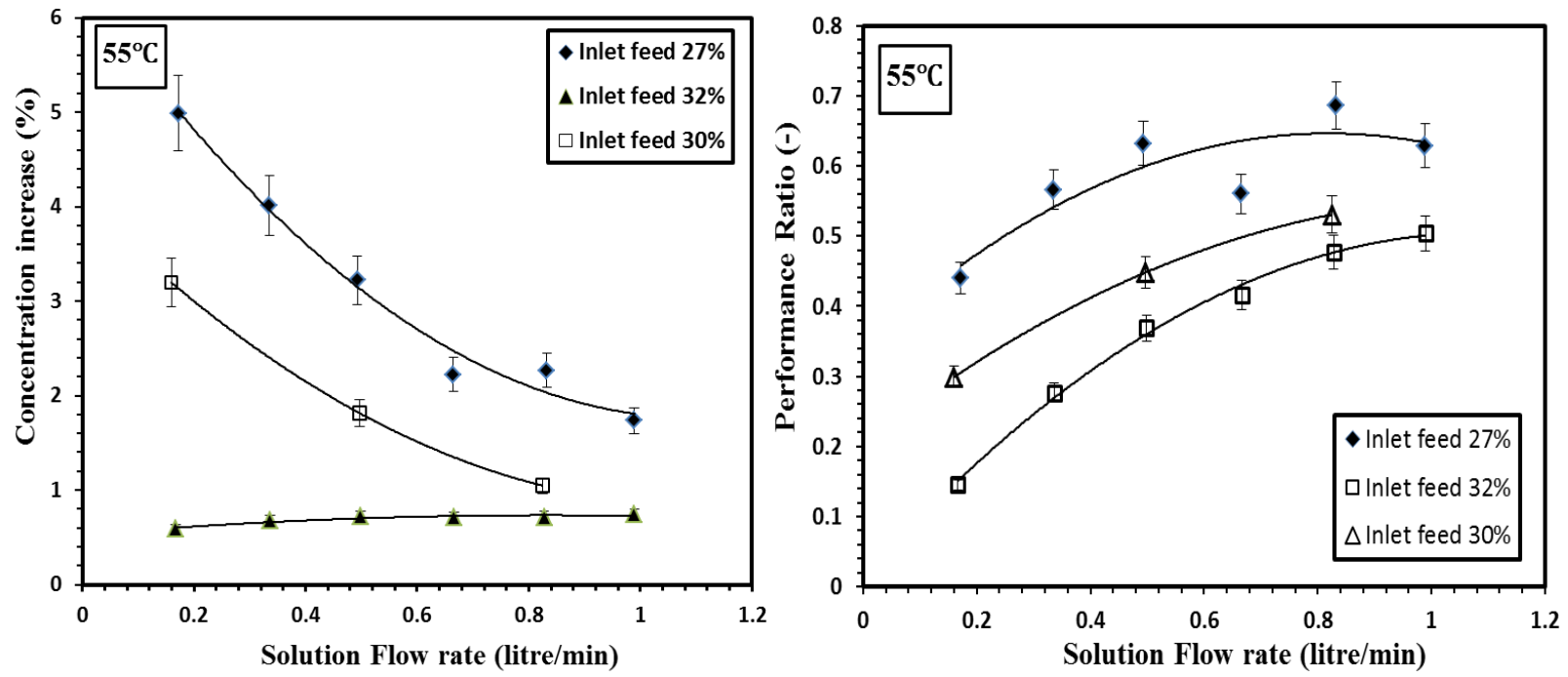

Figure 6-4: (a) Increase in concentration, (b) Performance ratio (PR) against solution flow rates of $1 \mathrm{~S}-3 \mathrm{~L}$ regenerator configuration for the inlet feed concentrations of $27 \%, 30 \%$ and $32 \%$ at $55^{\circ} \mathrm{C}$. 
At higher concentrations, the performance ratio drops significantly. Figures 6-5(a) and 6-5(b) show the variations of $\Delta C$ and PR at $65{ }^{\circ} \mathrm{C}$ for the feed concentrations of $27 \%, 30 \%, 34 \%$, and $38 \%$, where the feed flow rates are varied from 0.15 litre/min to 1 litre/min.
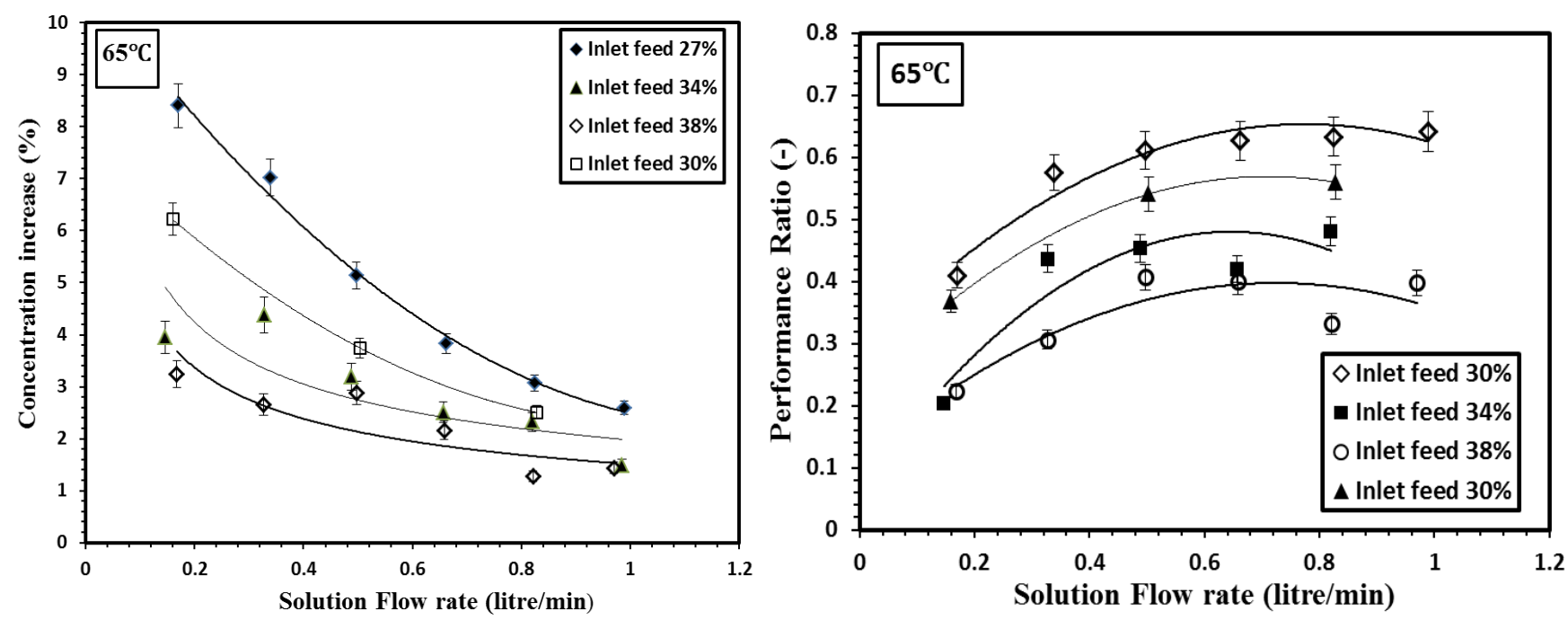

Figure 6-5: (a) Increase in concentration and (b) Performance ratio (PR) against solution flow rates of one-steam-three-solution regenerator configuration for the inlet feed concentrations of $27 \%, 30 \%, 34 \%$ and $38 \%$ at $65{ }^{\circ} \mathrm{C}$.

It is found that the change in $\Delta C$ drops with the feed flow rate. The highest $\Delta C$ are found $9 \%, 4 \%$, and $3 \%$ for the inlet feed concentration of $27 \%, 34 \%$, and $38 \%$ at the solution flow rate of 0.17 litre $\mathrm{min}^{-1}$. At feed flow rate of 1 litre $\mathrm{min}^{-1}$, the values of $\Delta \mathrm{C}$ are measured to be $3 \%, 2.2 \%$, and $2 \%$ (Figure $6.5 \mathrm{a}$ ). The maximum PRs are calculated as $0.65,0.45$, and 0.35 at $27 \%, 34 \%$, and $38 \%$ inlet feed concentration for the solution flow rates of 0.83 litre $\min ^{-1}, 0.67$ litre $\min ^{-1}$ and 0.67 litre $\min ^{-1}$, respectively. All these results are furnished in Figure 6-5(b). 
Figures 6-6(a) and 6-6(b) show the concentration increase and performance ratio at $31 \%, 34 \%$ and $38 \%$ feed concentration with the hot water temperature of $75^{\circ} \mathrm{C}$. At the feed concentration of $31 \%$, the maximum and minimum increases in concentrations are $6.7 \%$ and $3.2 \%$ for feed flow rate of 0.17 litre $\mathrm{min}^{-1}$ and 0.76 litre $\min ^{-1}$, respectively.
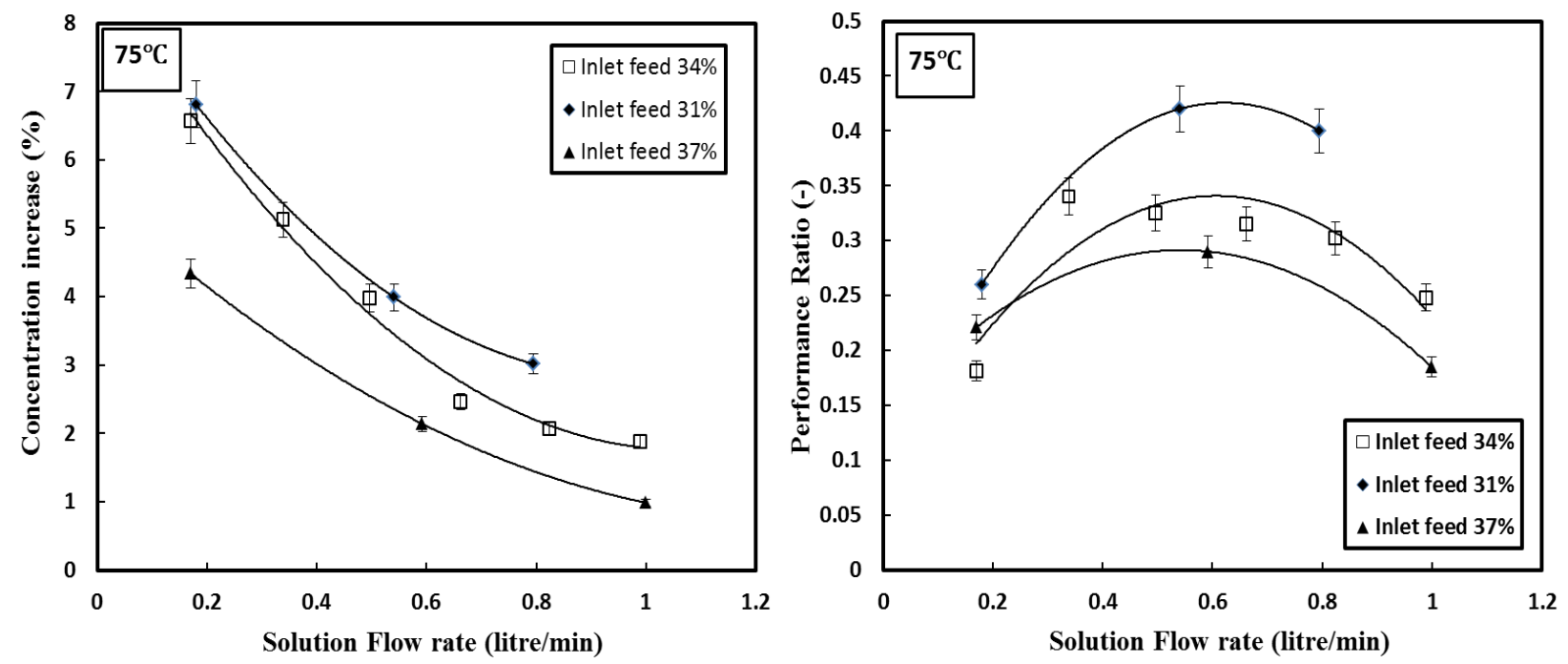

Figure 6-6: (a) Increase in concentration and (b) Performance ratio (PR) against solution flow rates of one-steam-three-solution regenerator configuration for the inlet feed concentrations of $31 \%, 34 \%$ and $37 \%$ at $75^{\circ} \mathrm{C}$.

The maximum performance ratio is achieved as 0.4 at the feed flow rate of 0.55 litre $\min ^{-1}$. At the feed concentration of $38 \%$, the highest and lowest $\Delta C$ are calculated to be $4 \%$ and $1 \%$ for feed flow rates of 0.17 litre $\min ^{-1}$ and 1 litre $\mathrm{min}^{-1}$. The maximum PR is calculated to be 0.28 for the feed low rate of 0.56 litre $\mathrm{min}^{-1}$. At the feed concentration of $38 \%$, the highest and lowest $\Delta C$ are calculated to be $4 \%$ and $1 \%$ for feed flow rates of 0.17 litre $\min ^{-1}$ and 1 litre $\min ^{-1}$. The maximum PR is calculated to be 0.28 for the feed low rate of 0.56 litre $\mathrm{min}^{-1}$. 


\subsection{Discussions}

For all cases, the $\Delta C$ is found greater at higher heating temperatures, and this is due to the temperature difference between the hot water and the feed desiccant solution separated by the polymer foil which may provide a greater driving force for the removal of water vapour from the feed solution across the membrane. Figures 64(a), 6-5(a) and 6-6(a) also reveal that the increase in concentration $(\Delta C)$ is significantly lower for higher inlet concentrations $\left(C_{i}\right)$ even at higher heating temperatures and decreases even more at a higher feed flow rate. At higher inlet concentrations, the solution provides higher resistance to the removal of water vapour from the solution due to its higher vapour pressure. It is observed from the test results that the PR increases with the increase in temperature for both the low and high concentration feed solution. This occurs due to the fact that the higher heating temperature increases the pressure difference and as a result the vapour pressure of the salt solution in a partial vacuum condition increases the water vapour separation rate from the liquid desiccant, which also enhances the thermal performance ratio. It should also be noted here that the resident time of the salt solution in the membrane module is lessened due to its higher flow rates, and the proper desorption of water vapour from the salt solution is not achieved. Therefore the reduction in $\Delta \mathrm{C}$ and $\mathrm{PR}$ can be obtained.

At higher concentrations $(>29 \%)$ feed inlet, the value of $\Delta C$ is low for lower feed velocity. Therefore, an optimum feed flow rate exists for maximizing the concentration increment and $\mathrm{PR}$, which can be attributed to the requirement of an optimum residence period for the feed solution to utilize the latent heat of vaporization essential for effective regeneration. In 1S3L system operation, the performance ratio is not significantly improved with the increase in heating water temperature for the feed concentrations higher than 30\%, which may be occurred 
due to heat loss from the regenerating module. It should be noted here that the regenerator system can also be modified by introducing more stages of steam and desiccant solution such as two stages steam and four stages desiccant solution but these are complex and are not cost effective.

\subsection{Conclusions}

The 4-stage VMEMD which is suitable for desalination applications shows an increase in PR at higher feed inlet temperature. However, at higher feed concentrations, the PR decreases significantly. For desiccant dehumidification conditions (concentration $>22 \%$ ), the PR drops drastically with the heating water temperature of $65{ }^{\circ} \mathrm{C}$ and the system does not perform even with the source temperature of $55{ }^{\circ} \mathrm{C}$. The conventional VMEMD is not suitable for desiccant dehumidification. Hence the working principles of the regenerating module are modified with the combinations of steam and $\mathrm{LiCl}$ solution flows in each module such that the system can handle high concentration feed for dehumidification applications.

Experiments are conducted on the modified configurations for a wide range of operating parameters which includes feed flow rate, feed concentration at inlet and heating temperature, and the results are recorded. The $1 \mathrm{~S}-3 \mathrm{~L}$ configuration deals with steam flows in single stage and liquid desiccant flows in three stages where the low grade energy is recovered. The PR is found to be 0.7 for the heating temperature of $55^{\circ} \mathrm{C}$ with $27 \%$ inlet feed concentration. This configuration also works well for the feed concentration of $32 \%$ at $55{ }^{\circ} \mathrm{C}$. At the higher heating temperature of $75^{\circ} \mathrm{C}$, the PR drops due to heat loss from the system. 


\section{References}

[1] S. Wang, Y. Wang, Investigation of the through plane effective oxygen diffusivity in the porous media of PEM fuel cells: Effects of the pore size distribution and water saturation distribution, International Journal of heat and Mass Transfer, Vol. 98, pp. 541 - 549, 2016.

[2] N. Datta, A. Chakraborty, S.M. Ali., Experimental Investigation of Multi-Effect Rgenerator for Desiccant Dehumidifier: Effects of various regeneration stages on system performances, International Journal of Refrigeration, Volume 76, April 2017, Pages 7-18. 


\section{Chapter 7}

\section{Conclusion and Recommendations}

The issues addressed in this thesis include (a) the carry-over of desiccant solution droplets into the air-stream (b) the experimental investigation of multi-effect membrane based LDAC system and VMEMD (Vacuum multi-effect membrane distillation) regeneration systems (c) the design of 1S-3L VMEMD regeneration with transient modelling and simulations and (d) the experimental testing of $1 \mathrm{~S}-3 \mathrm{~L}$ VMEMD system as the most effective regeneration for LDAC process.

A novel liquid desiccant assisted air-conditioning (LDAC) system is proposed which can overcome the limitations of direct-contact $\mathrm{LiBr}$ solution based LDAC systems. The proposed LDAC system utilizes membrane technology to design the absorber and regenerator to improve the efficiency of air-conditioning system and to prevent carry-over of desiccant solution droplets into the air-stream which leads to corrosion and affects the longevity of the system [1]. The experimental set-up of the membrane based LDAC system has been described and discussed in Chapter 3.

An Experimental investigation of membrane-based LDAC de-humidifier is carried out and the effects of various controlled parameters such as air, solution and heat exchange fluid flow rates etc. on air-dehumidification are reported in Chapter 4. Lithium chloride $(\mathrm{LiCl})$ is used as the desiccant salt for these experiments. The absorber performance is affected by air-resident pressure, cooling temperature and inlet concentration of desiccant solution. The desired dehumidification is achieved between $26 \%$ and $40 \% \mathrm{LiCl}$ concentration at inlet of the re-generator or at the outlet of the absorber under Singapore outdoor air conditions. 
The regeneration of the liquid desiccant takes place in the regenerator of the LDAC unit. The multi-effect-membrane-distillation (MEMD) is used in water treatment industry for desalting the sea-water. Vacuum-multi-effect-membrane distillation (VMEMD) system amalgamates the advantages of multi-effect evaporation and the merit of membrane's mass transfer process. The experimental investigation of the conventional VMEMD system for regenerating aqueous lithium chloride $(\mathrm{LiCl})$ is described in Chapter 4.

The performance of the regeneration process is evaluated on two fronts (1) thermal performance ratio (PR) and (2) percentage change in concentration of the desiccant $(\Delta \mathrm{C})$. The control parameters are varied in order to find a balance between the PR and $\Delta \mathrm{C}$ which exhibits the optimum working performance. The system is studied using $\mathrm{LiCl}$ desiccant solution with the feed concentrations varying from $8 \%$ to $22 \%$ and feed flow rates between $0.15 \mathrm{litre} / \mathrm{min}$ and 1 litre/min. The heating source temperatures are ranged from $50{ }^{\circ} \mathrm{C}$ to $80{ }^{\circ} \mathrm{C}$. The performance ratio for $8 \%$ feed concentration is found to be between 2.0-2.5, depending on the heating temperature and feed flow rate. These PR values are comparable with that of the conventional multi-effect evaporator for desalination purposes [2]. At higher inlet concentration of $15 \%$, the PR value varies between 1.4 and 2.0. The PR value falls sharply to 0.65 at the concentration of $22 \%$. The experimental results illustrate that the conventional VMEMD system is suitable for regeneration of lower concentration solutions for desalination applications. However the operating range of desiccant concentration for LDAC application is higher (>26\%) and the conventional VMEMD is not found suitable for air-conditioning applications. 
The working principles of the conventional regenerating module are modified with the combinations of steam and $\mathrm{LiCl}$ solution flows in each module of the VMEMD system for handling high concentration feed for dehumidification applications. A single-stage-steam-three-stages-liquid (1S-3L) regenerator is a modified form of the conventional 4-stages VMEMD. Theoretical studies include the development of heat and mass transfer equations from the rigors of thermodynamics and are capable of simulating the working of the regenerator under different configurations. These findings are reported in Chapter 5. The system is simulated for various inlet feed concentrations ranging from $27 \%$ to $36 \%$ and flow rates up to 1 litre/min. The thermal performance ratio (PR) is found to attain a maximum value of 0.75 for the heating temperature of $75{ }^{\circ} \mathrm{C}$ with $27 \%$ inlet feed concentration. The proposed configuration also works well for higher feed concentration up to $36 \%$. The results obtained by the transient simulation exhibit higher accuracy as compared with the experimental data with the errors ranging from $5 \%$ to $10 \%$.

The experimental investigation of the proposed 1S-3L regenerator with lithium chloride as desiccant salt is reported in Chapter 6. The performance of the regenerator is studied with respect to various controlled parameters. The inlet feed concentrations are ranged from $27 \%$ to $36 \%$. The feed flow rates are varied from $0.15 \mathrm{litre} / \mathrm{min}$ to $1 \mathrm{litre} / \mathrm{min}$ and the hot water temperatures are set at 55, 65, 75 and $85^{\circ} \mathrm{C}$ with the cooling water inlet temperature of $28{ }^{\circ} \mathrm{C}$. The PR is found to be 0.7 for the heating temperature of $55{ }^{\circ} \mathrm{C}$ and $27 \%$ inlet feed concentration. This configuration also works well for the feed concentration of $32 \%$ at $55{ }^{\circ} \mathrm{C}$. The difference in performance between theoretical model and experimental set-up is occurred due to heat losses from the system. 
From the present analysis, it is concluded that VMEMD module, which is generally designed for desalination purposes, can also be employed for desiccant regeneration applications. Based on theoretical and experimental analysis 1S-3L system is considered as the efficient design for dehumidification purposes.

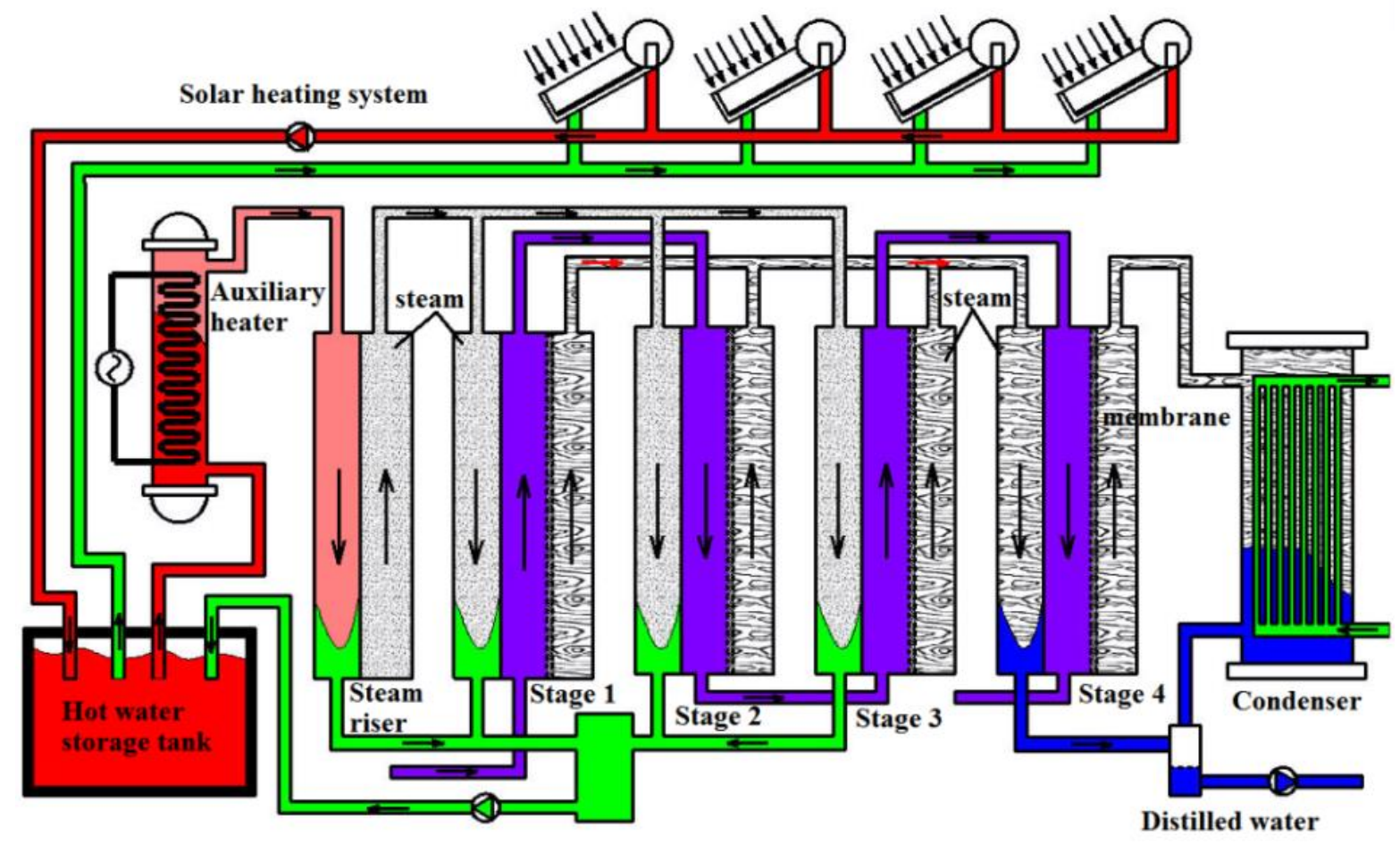

Figure 7.1: Schematic of hybrid 2S-4L VMEMD system (steam flows in two stages and liquid desiccant flows in four stages). 
In future, attention will be paid to study the effects of pressure variations on the behaviour for each module of the regenerator unit and efforts will be made to reduce heat loses from the system by employing better insulation features. Another modification of the conventional VMEMD system based on steam flows in two stages and liquid desiccant flows in four stages $(2 \mathrm{~S}-4 \mathrm{~L})$ is proposed for future studies. A schematic of the proposed 2S-4L VMEMD configuration is shown in Figure 7.1. The better heat recovery at the fourth stage is expected and it is hoped that the two-stages-steam-four-stages-solution $(2 \mathrm{~S}-4 \mathrm{~L})$ system may exhibit better performances for high concentration desiccant operations. More research activities and experimental studies are needed to be developed for $2 \mathrm{~S}-4 \mathrm{~L}$ system.

\section{References}

[1] Manuel C. Petit, Liquid Desiccant Based Air-conditioning systems- LDAC. in 1st European Conference on Polygeneration 2007. Tahoma.

[2] S. Wang and Y. Wang, "Investigation of the through plane effective oxygen diffusivity in the porous media of PEM fuel cells: Effects of the pore size distribution and water saturation distribution," International Journal of Heat and Mass Transfer, vol. 98, pp. 541 - 549, 2016. 


\section{APPENDICES}

\section{Appendix A}

\section{Components of LDAC plant, Energy Research Institute at NTU (ERI@N), Singapore}

The experimental study of liquid desiccant air-conditioning reported in Chapter 3 . The pictorial views of the different components of the LDAC plant are shown in this section.

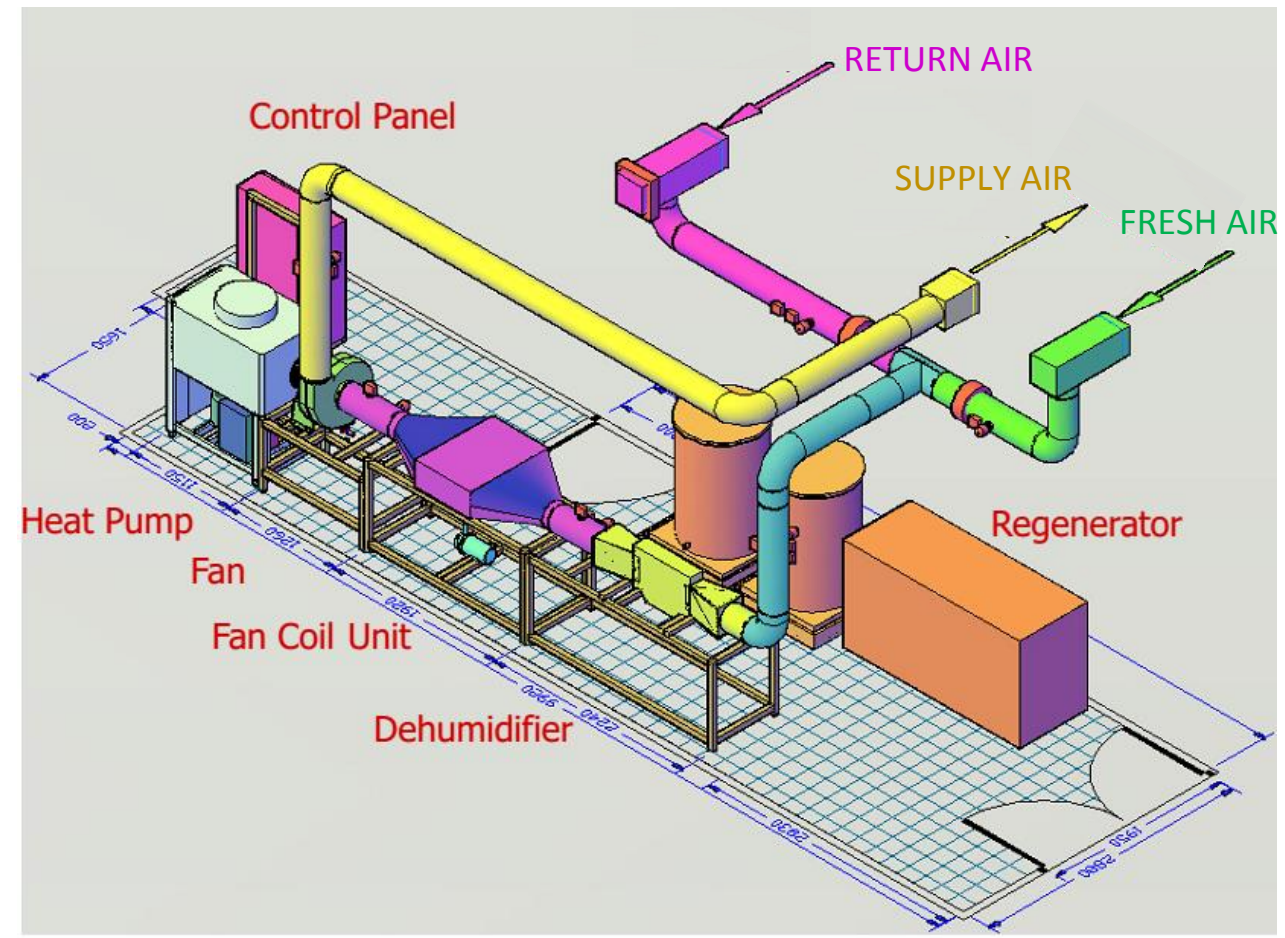

Figure A.1: Layout drawing of the LDAC test bed 


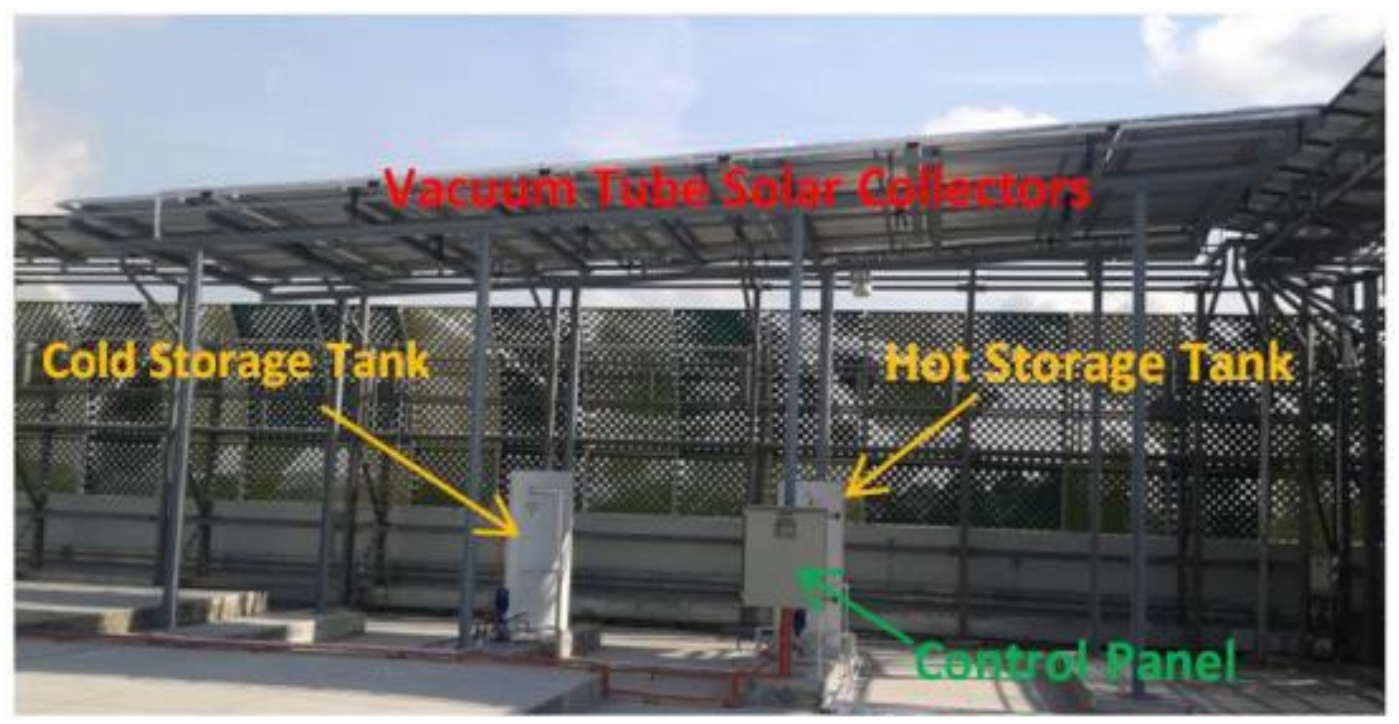

Figure A.2: Solar Thermal system installed on the roof of the building for driving the LDAC regeneration unit

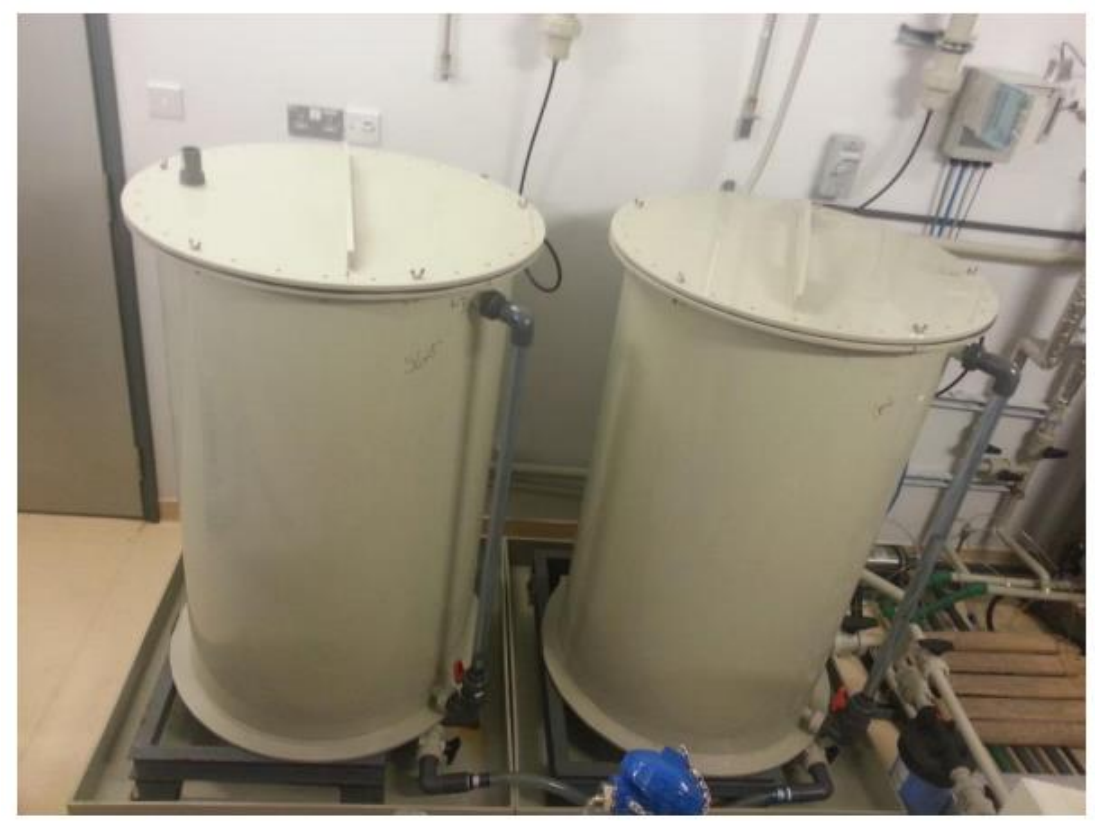

Figure A.3: Chemical energy storage tanks for dilute and concentrated aq. Lithium chloride solution made of Polypropylene. 


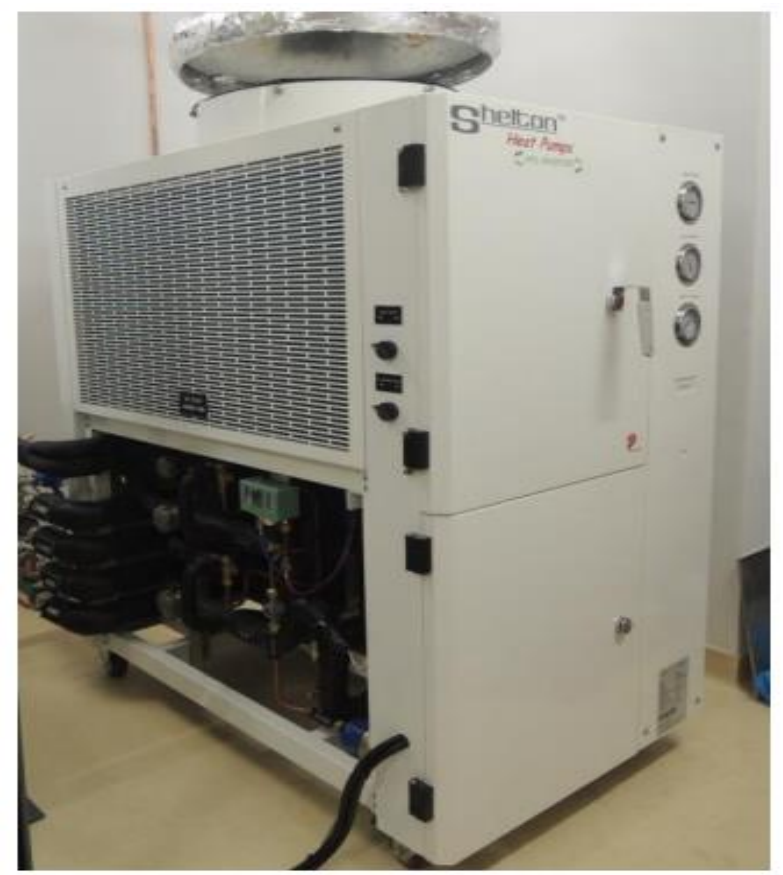

Figure A.4: Pictorial view of the VFD Inverter with two evaporator refrigeration system.

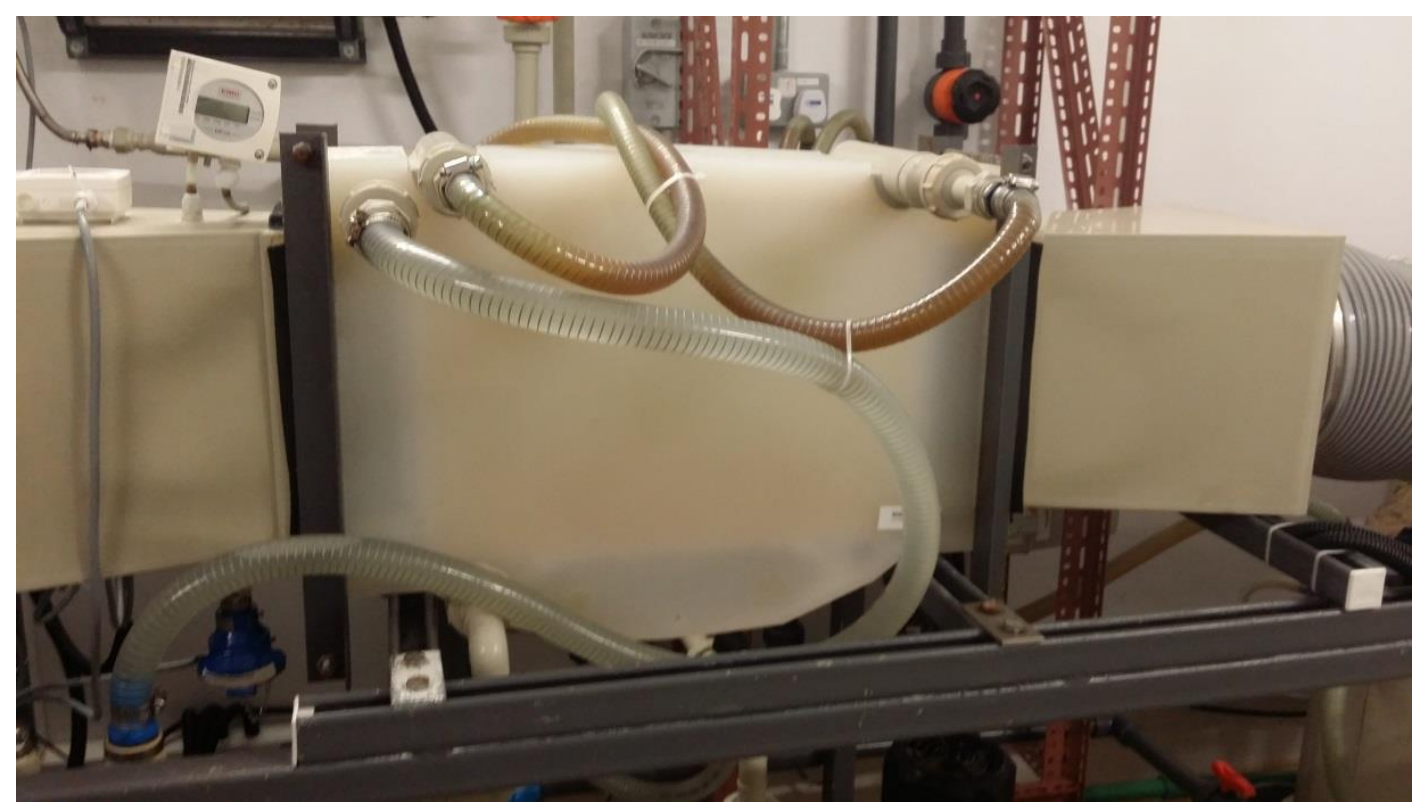

Figure A.5: Pictorial view of the membrane assisted dehumidifier. 


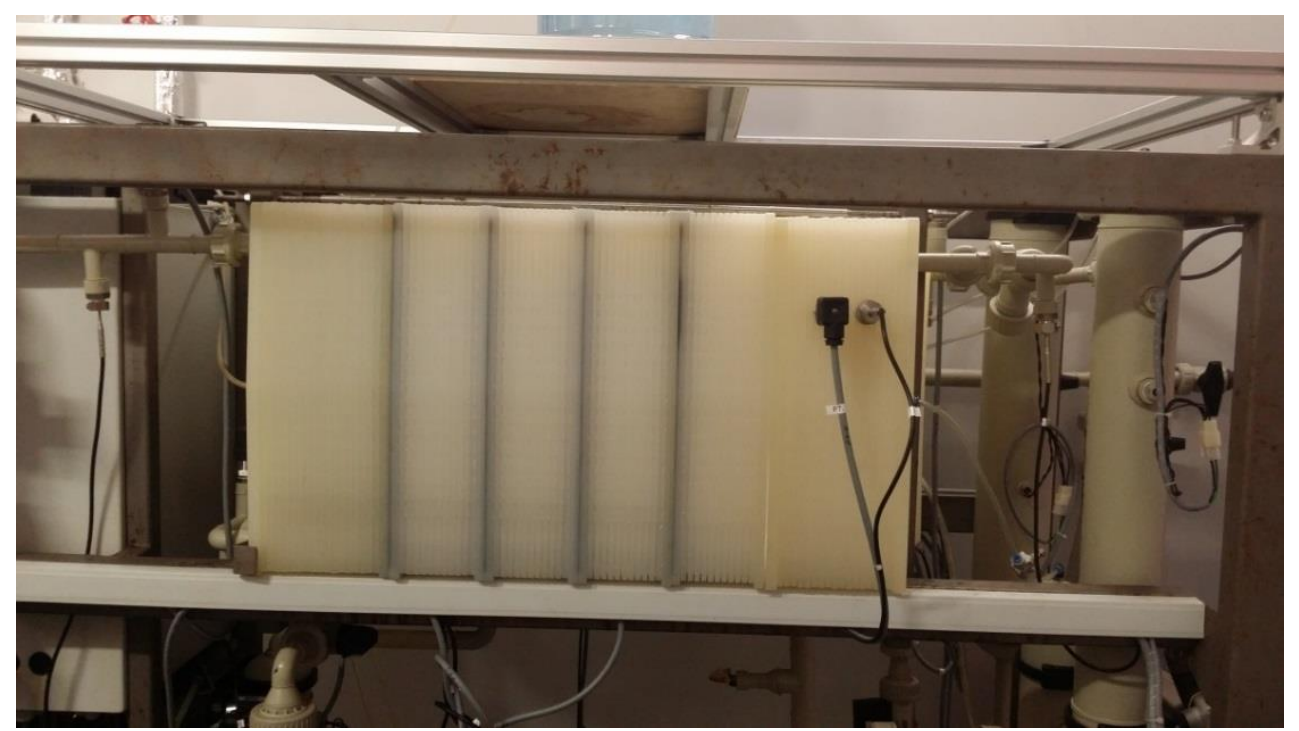

Figure A.6: Pictorial view of the VMEMD regenerator

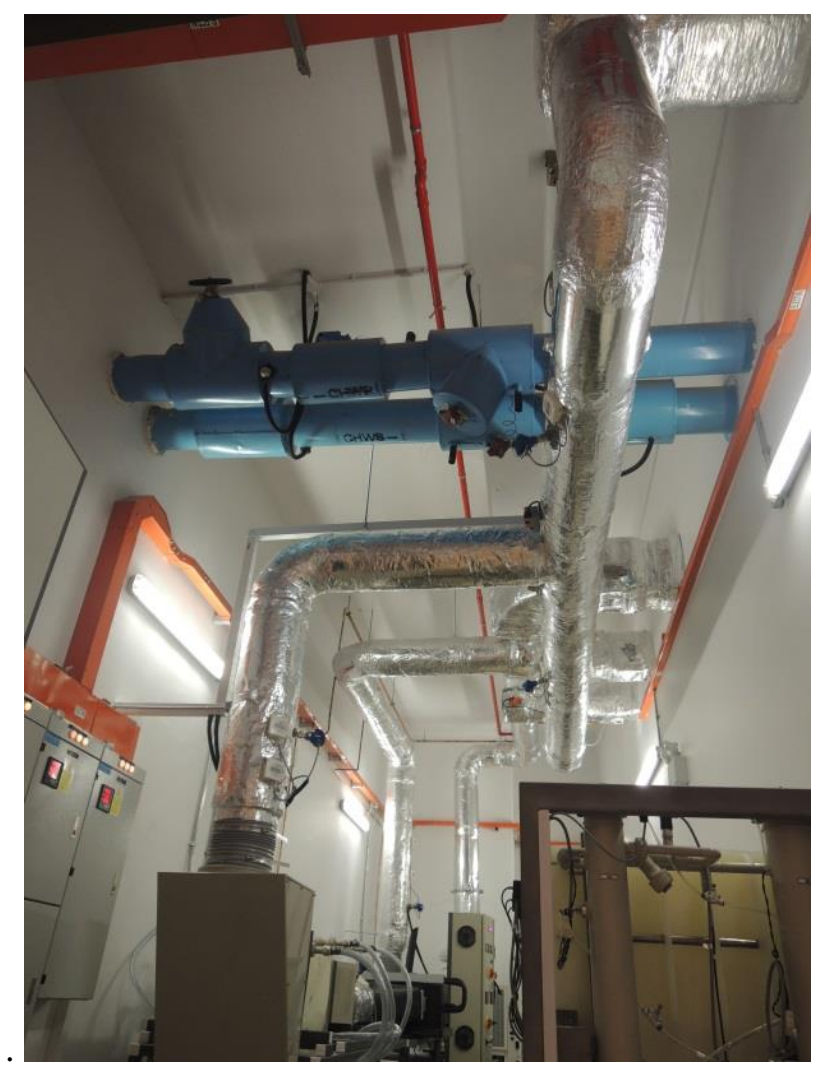

Figure A.7: Air duct channels for supply air, mixed air and return air. 

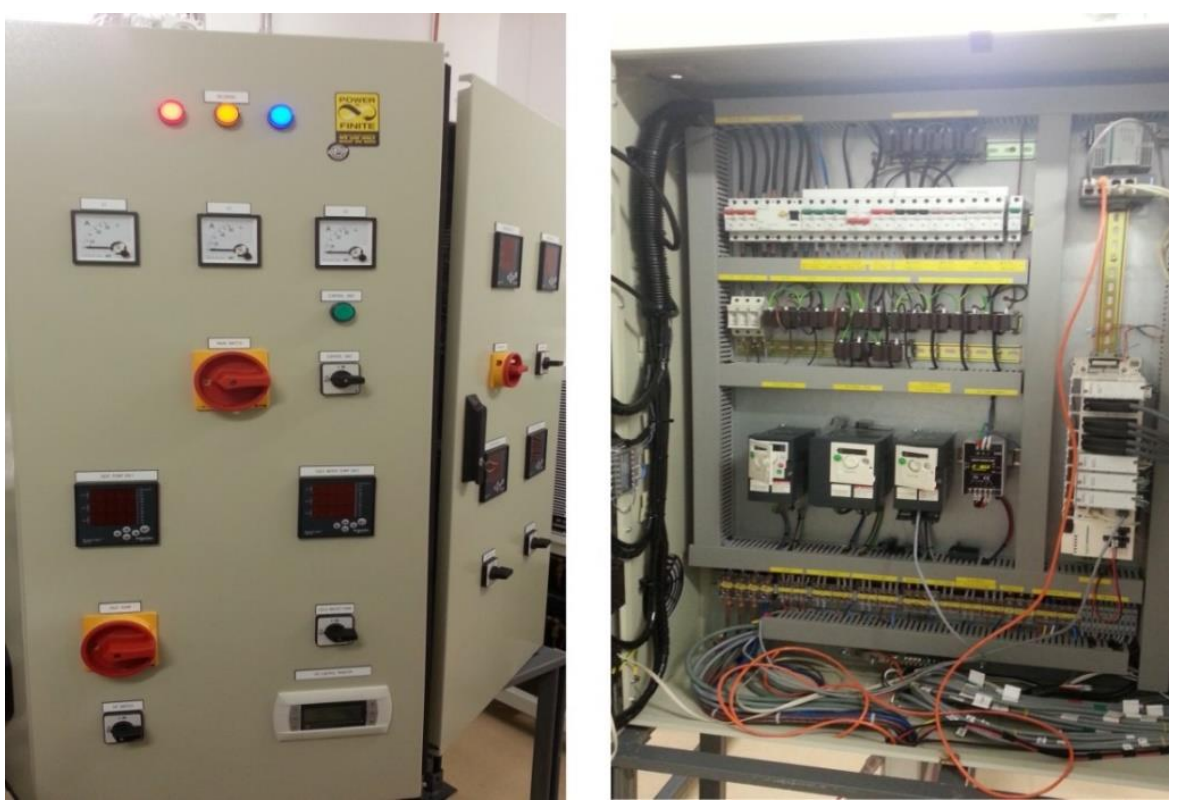

Figure A.8: Control unit and Data logger 


\section{Appendix B}

\section{Experimental Data of conventional VMEMD regenerator operations}

The experimental investigation reported in Chapter 4 of this thesis. The experimental data for conventional VMEMD regenerator are reported in this section.

Table B.1: Four-stage VMEMD experimental data for $8 \% \mathrm{LiCl}$ concentration at different heating temperatures and flow rates. Cooling water temperature is $28{ }^{\circ} \mathrm{C}$.

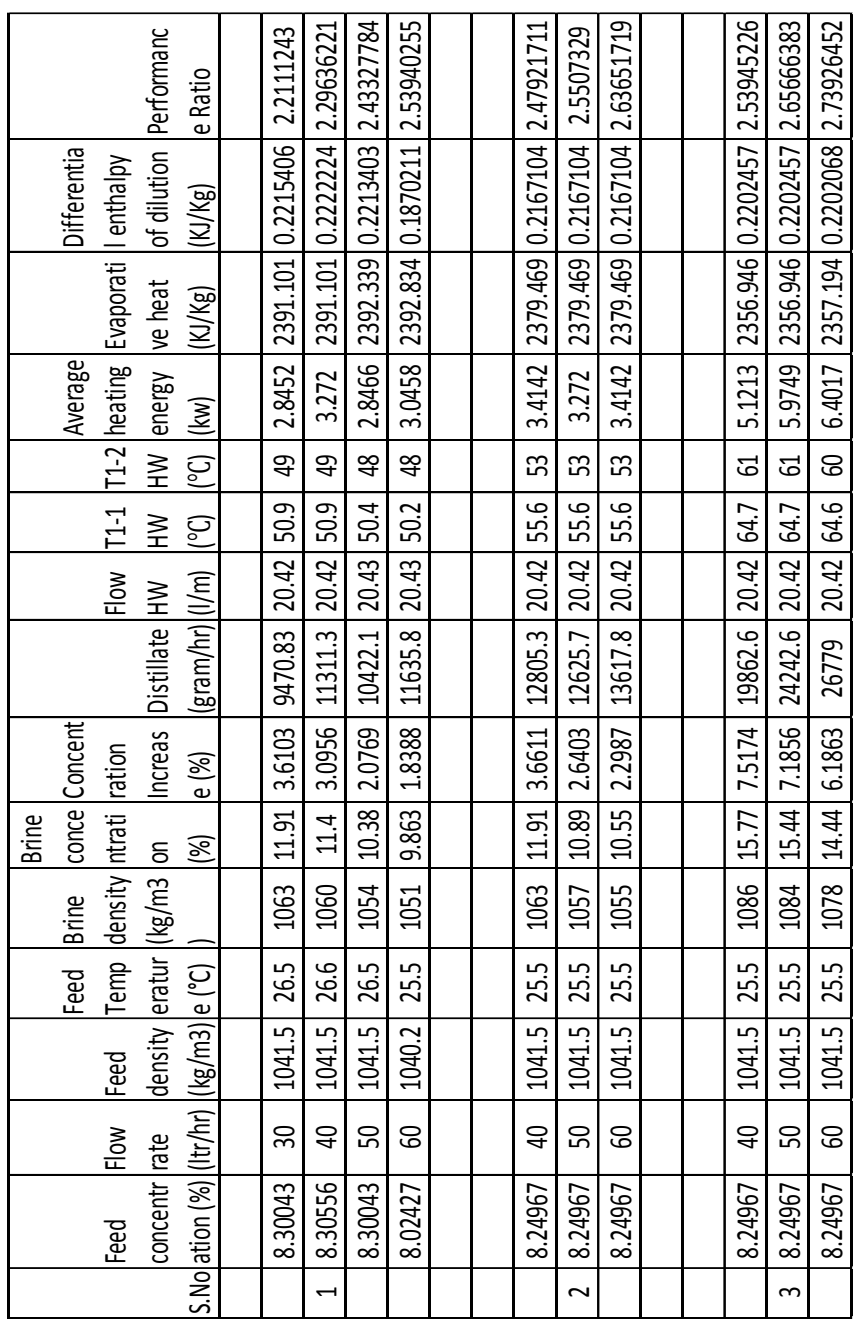


Table B.2: Four-stage VMEMD experimental data for $15 \% \mathrm{LiCl}$ concentration at different heating temperatures and flow rates. Cooling water temperature is $28{ }^{\circ} \mathrm{C}$.

\begin{tabular}{|c|c|c|c|c|c|c|c|c|c|c|c|}
\hline 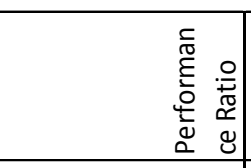 & 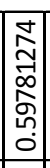 & 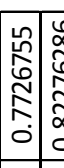 & 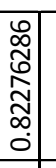 & 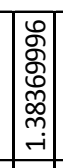 & 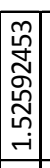 & $\begin{array}{r}\infty \\
\infty \\
0 \\
0 \\
0 \\
0 \\
0 \\
-i \\
\end{array}$ & 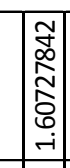 & 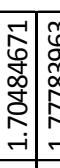 & & 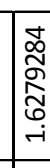 & 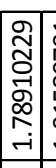 \\
\hline 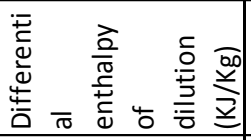 & 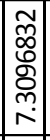 & 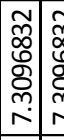 & 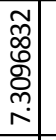 & 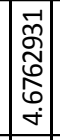 & 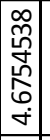 & \begin{tabular}{|l|}
$\vec{p}$ \\
$\grave{D}$ \\
$\grave{0}$ \\
$\dot{+}$ \\
\end{tabular} & 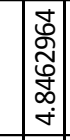 & 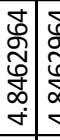 & & 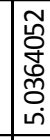 & 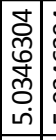 \\
\hline 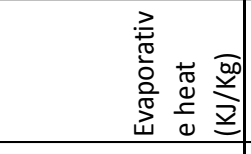 & 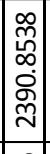 & 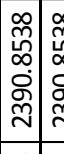 & 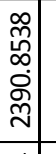 & 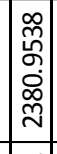 & 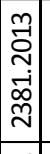 & 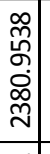 & 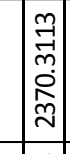 & 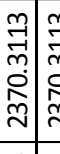 & & 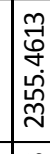 & 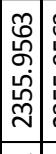 \\
\hline 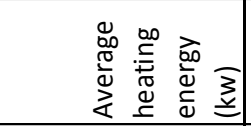 & 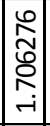 & 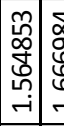 & \begin{tabular}{|c|} 
\\
0 \\
0 \\
0 \\
0 \\
-1 \\
\end{tabular} & 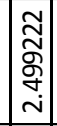 & 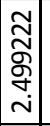 & 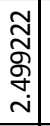 & 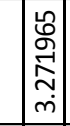 & 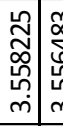 & & 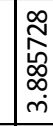 & 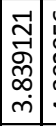 \\
\hline 点主可 & \begin{tabular}{|l|}
$\infty$ \\
$\dot{q}$ \\
\end{tabular} & \begin{tabular}{|l|l|} 
& $\alpha$ \\
$\dot{q}$ & 0 \\
\end{tabular} & $\begin{array}{l}\infty \\
\dot{q} \\
\end{array}$ & $\begin{array}{l}n \\
\tilde{n} \\
\end{array}$ & \begin{tabular}{|l|}
\multirow{n}{n}{} \\
กิ
\end{tabular} & $\begin{array}{l}\sim \\
\tilde{n} \\
\\
\end{array}$ & in & 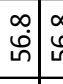 & & นn & 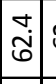 \\
\hline $\begin{array}{l}\vec{I} \\
\vec{F}\end{array}$ & in & $\vec{n}$ & nิ & กิ & \begin{tabular}{|l|}
\multirow{2}{*}{} \\
กิ \\
\end{tabular} & 缉 & \begin{tabular}{|l|}
$m$ \\
in \\
\end{tabular} & 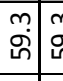 & & $\begin{array}{ll}m \\
\text { in } \\
\end{array}$ & \begin{tabular}{|l|l|}
$\vec{i}$ \\
$\dot{0}$
\end{tabular} \\
\hline 은 & 孛 & 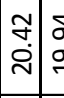 & $\begin{array}{l}\text { ने } \\
\text { ने }\end{array}$ & 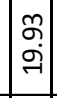 & $\begin{array}{l}\text { م. } \\
\text { ने }\end{array}$ & $\begin{array}{l}\text { ळ. } \\
\text { } \\
\end{array}$ & \begin{tabular}{l}
7 \\
\multirow{2}{*}{} \\
\multirow{2}{*}{}
\end{tabular} & ণ̊. & & ๙ू. & 吾 \\
\hline 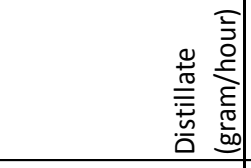 & 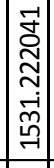 & 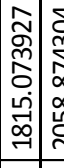 & 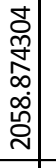 & 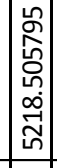 & 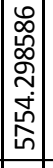 & 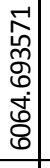 & 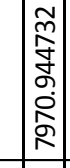 & 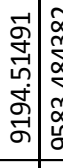 & & 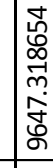 & 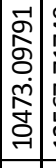 \\
\hline 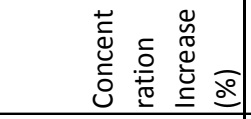 & $\begin{array}{l}-1 \\
0 \\
0 \\
0 \\
0 \\
0\end{array}$ & 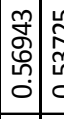 & $\mid \begin{array}{c}\stackrel{2}{N} \\
\hat{N} \\
\\
0\end{array}$ & $\mid$\begin{tabular}{l}
$\infty$ \\
\multirow{1}{1}{} \\
0 \\
$\mathbf{i}$ \\
\end{tabular} & 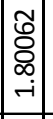 & $\begin{array}{c}0 \\
\infty \\
0 \\
\\
-i \\
\end{array}$ & \begin{tabular}{|l|}
$\stackrel{9}{9}$ \\
$\stackrel{3}{7}$ \\
n் \\
\end{tabular} & 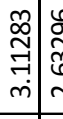 & & $\begin{array}{l}\vec{j} \\
\stackrel{9}{\infty} \\
m \\
\dot{+}\end{array}$ & \begin{tabular}{|c|} 
\\
$\hat{6}$ \\
0 \\
$\dot{n}$
\end{tabular} \\
\hline 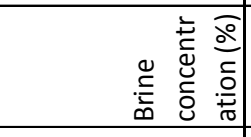 & 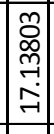 & 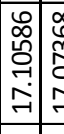 & \begin{tabular}{|l|}
0 \\
0 \\
0 \\
0 \\
\\
\\
\end{tabular} & 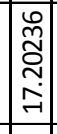 & \begin{tabular}{|c|}
2 \\
0 \\
2 \\
6 \\
\\
\end{tabular} & \begin{tabular}{|l|} 
\\
0 \\
0 \\
0 \\
$\underline{0}$ \\
\end{tabular} & 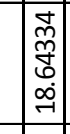 & 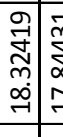 & & 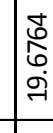 & \begin{tabular}{|l|l|} 
& \\
-1 \\
8 \\
$\infty$ \\
$\infty$ \\
-1
\end{tabular} \\
\hline 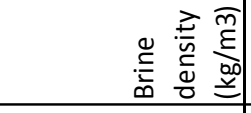 & - & 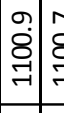 & $\begin{array}{l}1 \\
\vdots \\
\vdots \\
-1 \\
\end{array}$ & 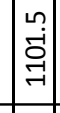 & $\begin{array}{l}\infty \\
0 \\
\text { Oे } \\
\text { ने } \\
\end{array}$ & $\begin{array}{l}m \\
\infty \\
0 \\
0 \\
-1 \\
\end{array}$ & 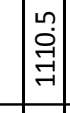 & 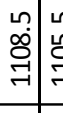 & & $\exists$ & 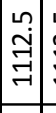 \\
\hline 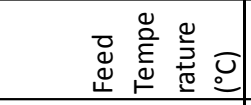 & $\begin{array}{l}\text { ก̊ } \\
\text { ஸे }\end{array}$ & 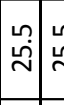 & $\begin{array}{l}\stackrel{n}{\sim} \\
\stackrel{\leftrightarrow}{N}\end{array}$ & 足 & 亗 & 芫 & 古 & 岗| & & 亗 & $\mid$ \\
\hline 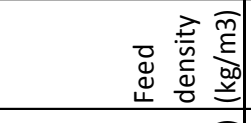 & 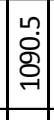 & 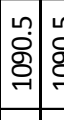 & \begin{tabular}{l|} 
\\
0 \\
0 \\
0 \\
\\
\end{tabular} & $\mid$ & 各 & 点 & \begin{tabular}{|l|}
$n$ \\
in \\
0 \\
$\rightarrow$ \\
\end{tabular} & 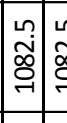 & & 赵 & $\left|\begin{array}{l}\infty \\
0 \\
\hdashline \\
-1\end{array}\right|$ \\
\hline 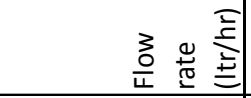 & 아 & 只 6 & : & $q$ & in & 8 & $q$ & 인 & & 우 & in \\
\hline 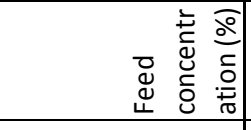 & 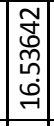 & 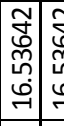 & 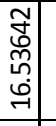 & 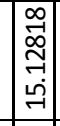 & 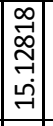 & 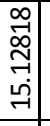 & 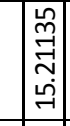 & 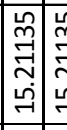 & & 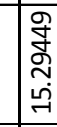 & 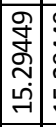 \\
\hline & & -1 & & & $\sim$ & & & $m$ & & & H \\
\hline
\end{tabular}


Table B.3: Four-stage VMEMD experimental data for $22 \% \mathrm{LiCl}$ concentration at different heating temperatures and flow rates. Cooling water temperature is $28{ }^{\circ} \mathrm{C}$.

\begin{tabular}{|c|c|c|c|c|c|c|c|c|c|}
\hline 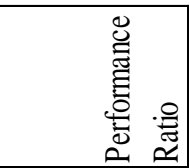 & 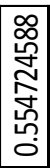 & 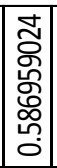 & 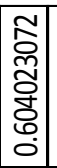 & 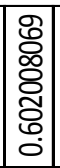 & 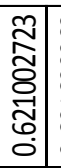 & 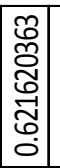 & 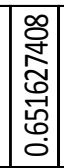 & 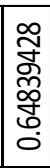 & 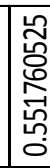 \\
\hline 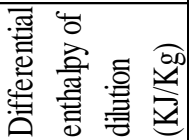 & 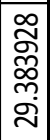 & 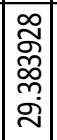 & 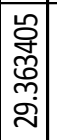 & \begin{tabular}{|c|}
$\infty$ \\
\\
\\
\\
\end{tabular} & 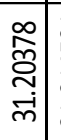 & 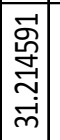 & 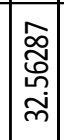 & 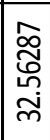 & 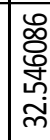 \\
\hline 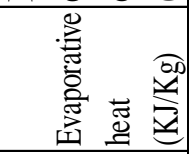 & 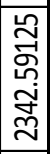 & 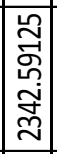 & 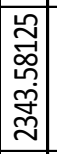 & 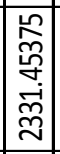 & 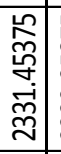 & 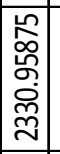 & \begin{tabular}{|c|}
$\underline{n}$ \\
$\tilde{n}$ \\
$\tilde{n}$ \\
$\sigma$ \\
$\tilde{n}$ \\
\\
\end{tabular} & 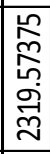 & 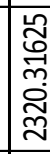 \\
\hline 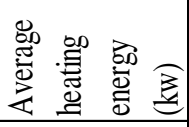 & 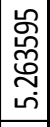 & 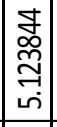 & 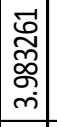 & 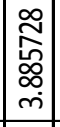 & 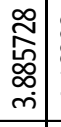 & 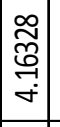 & 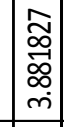 & 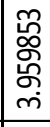 & 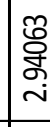 \\
\hline$\stackrel{1}{\dot{E}} 0$ & $\begin{array}{ll}0 \\
0 \\
0 \\
\end{array}$ & $\begin{array}{l}9 \\
8 \\
8\end{array}$ & \begin{tabular}{|c|} 
\\
$\tilde{6}$ \\
\end{tabular} & $\stackrel{2}{\mathbb{N}}$ & $\stackrel{\sim}{\mathbb{N}}$ & $\stackrel{N}{N}$ & $\approx$ & $R$ & $\stackrel{\text { I }}{\stackrel{5}{\pi}}$ \\
\hline 吉主 & ำ & ำ & $\vec{c}$ & $\stackrel{2}{\sim}$ & ㄴ. & 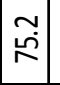 & $\begin{array}{l}\infty \\
\stackrel{R}{R}\end{array}$ & $\begin{array}{l}\infty \\
\infty \\
\Gamma\end{array}$ & भू \\
\hline $\begin{array}{l}\text { 总 } \\
\text { 言 } \\
\text { 至 }\end{array}$ & 疋 & 䗆 & ₹̊ & 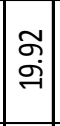 & న్ & \begin{tabular}{|} 
S̆ \\
ğ
\end{tabular} & बุ. & 穴 & ت̈ \\
\hline 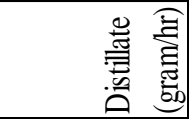 & 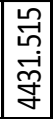 & 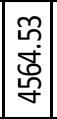 & 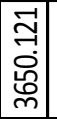 & 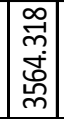 & \begin{tabular}{|l|} 
\\
0 \\
0 \\
0 \\
0 \\
$n$ \\
\end{tabular} & 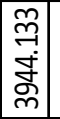 & 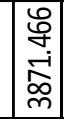 & 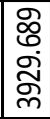 & 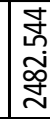 \\
\hline 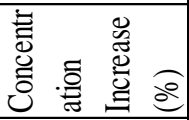 & 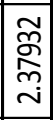 & 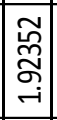 & 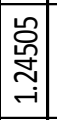 & 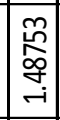 & \begin{tabular}{|c|}
0 \\
0 \\
0 \\
\hdashline \\
- \\
\end{tabular} & 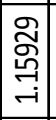 & 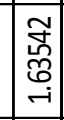 & 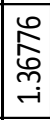 & 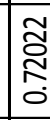 \\
\hline 总志 & 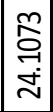 & 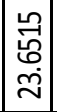 & 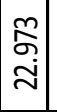 & 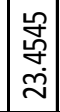 & $\mid \begin{array}{c}\hat{\tilde{m}} \\
\underset{\sim}{\sim} \\
\end{array}$ & 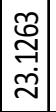 & \begin{tabular}{l|}
0 \\
0 \\
0 \\
$\tilde{n}$ \\
$\tilde{\sim}$
\end{tabular} & 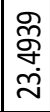 & 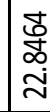 \\
\hline 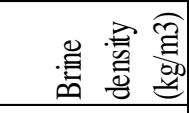 & 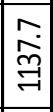 & 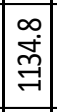 & 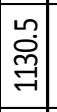 & 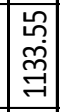 & 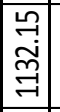 & \begin{tabular}{|c|}
\multirow{2}{*}{} \\
$\vec{i}$ \\
$\vec{g}$ \\
\end{tabular} & 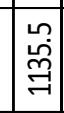 & 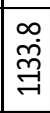 & Эิ \\
\hline 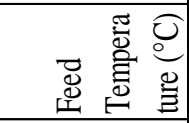 & \begin{tabular}{|c} 
号 \\
$\sim$
\end{tabular} & 㟔 & 岂 & 点 & 望 & 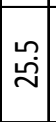 & 눔 & 兄 & 望 \\
\hline 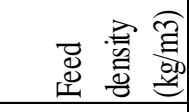 & 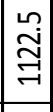 & 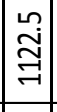 & 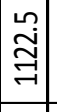 & $\underset{\Xi}{\Xi}$ & $\underset{\exists}{\Xi}$ & $\underset{\exists}{\sharp}$ & $\stackrel{\sim}{\exists}$ & $\stackrel{2}{\underset{\exists}{ت}}$ & $\stackrel{\llcorner}{\exists}$ \\
\hline 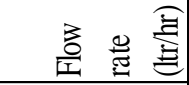 & q & 요 & 8 & 요 & 8 & R & in & 8 & $R$ \\
\hline 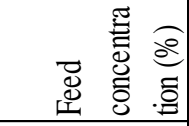 & 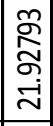 & 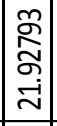 & 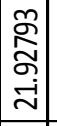 & 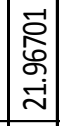 & 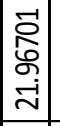 & 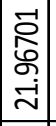 & 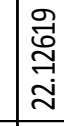 & 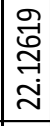 & 㤩 \\
\hline & & -1 & & & $\sim$ & & & $m$ & \\
\hline
\end{tabular}




\section{Appendix C}

\section{Experimental Data of 1S-3L VMEMD regenerator operations}

The experimental investigation reported in Chapter 6of this thesis. The experimental data for 1S-3L VMEMD regenerator are reported in this section.

Table C.1: 1 S-3L VMEMD experimental data for $27 \% \mathrm{LiCl}$ concentration at different heating temperatures and flow rates. Cooling water temperature 28 is ${ }^{\circ} \mathrm{C}$.

\begin{tabular}{|c|c|c|c|c|c|c|c|c|c|c|}
\hline 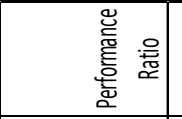 & 量| & 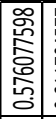 & 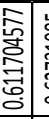 & 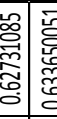 & \begin{tabular}{l|l|}
0 \\
$\vdots$ \\
0
\end{tabular} & 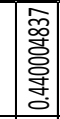 & \begin{tabular}{|c|}
\multirow{3}{*}{} \\
点 \\
号 \\
\end{tabular} & & & $\begin{array}{l}0.0 \\
0 \\
0\end{array}$ \\
\hline 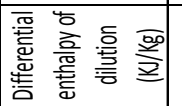 & 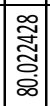 & 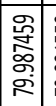 & 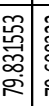 & & 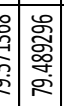 & 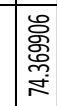 & 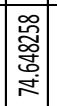 & & & \\
\hline 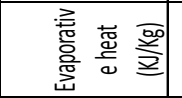 & 氛 & 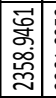 & \begin{tabular}{l|l} 
\\
\end{tabular} & & \begin{tabular}{ll|l}
0 \\
$\vdots$ \\
$\vdots$
\end{tabular} & 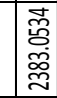 & 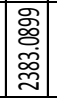 & 密 & & \\
\hline 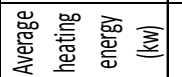 & 产 & 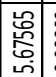 & $\left.\begin{array}{l|l}0.0 \\
0 \\
0\end{array}\right]$ & & 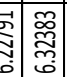 & $\mid$ & | & & & 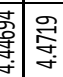 \\
\hline 咅空 & $\vec{b}$ & : & बi: & 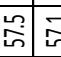 & $\begin{array}{ll}3 \\
\end{array}$ & 芯 & $\approx$ & 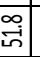 & تi & H \\
\hline 咅斊 이 & 㻤 & 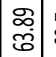 & ఫิ & 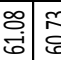 & 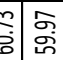 & 学 & 疍 & 密 & 尺 & \\
\hline 흔초 츨 & 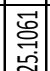 & $\mid$ & $\stackrel{g}{\square}$ & & 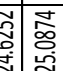 & & & & & \\
\hline 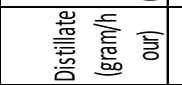 & 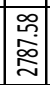 & 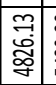 & 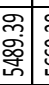 & & 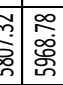 & 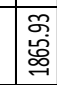 & \begin{tabular}{|c|} 
: \\
ڤ్లి
\end{tabular} & & & \\
\hline 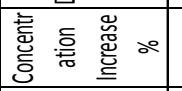 & $\begin{array}{l}\text { 各 } \\
\text { ob } \\
\infty \\
\infty\end{array}$ & 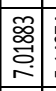 & 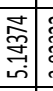 & & 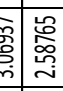 & \begin{tabular}{|l|}
9 \\
8 \\
g. \\
\end{tabular} & \begin{tabular}{|l|}
\multirow{9}{:}{} \\
字 \\
\end{tabular} & & & \\
\hline 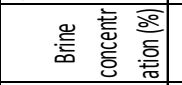 & 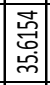 & \begin{tabular}{|l|}
\multirow{2}{*}{} \\
\multirow{z}{m}{} \\
\end{tabular} & 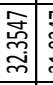 & & 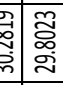 & 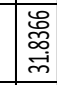 & \begin{tabular}{|l|}
$\overrightarrow{0}$ \\
$\ddot{0}$ \\
$\bar{m}$
\end{tabular} & & & \\
\hline 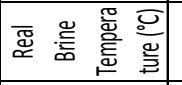 & \begin{tabular}{|c|}
$\vec{z}$ \\
0 \\
$\stackrel{0}{m}$ \\
\end{tabular} & 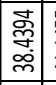 & 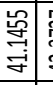 & & 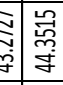 & \begin{tabular}{|l|}
0 \\
0 \\
$m$ \\
$m$
\end{tabular} & $\stackrel{\infty}{m}$ & & & \\
\hline 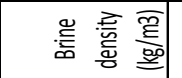 & $\underset{\Xi}{\exists}$ & | & 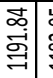 & 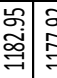 & 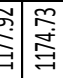 & 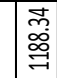 & 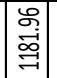 & 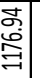 & & \\
\hline 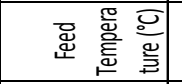 & $\stackrel{\sim}{\approx}$ & $\underset{\sim}{\approx}$ & $\stackrel{\substack{7 \\
\sim}}{\sim}$ & 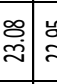 & \begin{tabular}{l|l}
$\stackrel{2}{2}$ & $\stackrel{\infty}{\approx}$ \\
\end{tabular} & $\stackrel{8}{9}$ & 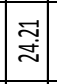 & \pm & & \\
\hline 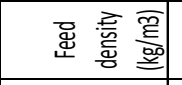 & 疍 & \begin{tabular}{|l|}
\multirow{2}{*}{} \\
o \\
g. \\
\end{tabular} & 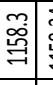 & 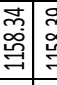 & $\begin{array}{lll}0 \\
0 \\
0\end{array}$ & 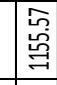 & $\mid$ & 总 & & \\
\hline 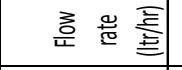 & ذ̊. & 芯 & $\begin{array}{ll}\overrightarrow{0} & \\
\dot{\tau} & \end{array}$ & 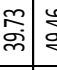 & fol & $\overrightarrow{\vec{c}}$ & 콤 & 苟 & & ?8 \\
\hline 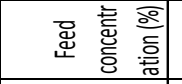 & 岂 & $\vec{a}$ & \begin{tabular}{l|l}
$\vec{\vdots}$ \\
$\vdots$
\end{tabular} & 尝| & ה: & $\begin{array}{l}\text { 总 } \\
\text { o. } \\
\text { ¿ } \\
\end{array}$ & \begin{tabular}{|l|} 
\\
\\
2 \\
0 \\
0 \\
$ن$ \\
\end{tabular} & 产 & & \\
\hline$\sum_{1}$ & & & & & & & & & & \\
\hline
\end{tabular}


Table C.2: $1 \mathrm{~S}-3 \mathrm{~L}$ VMEMD experimental data for $27.5 \% \mathrm{LiCl}$ concentration at different heating temperatures and flow rates. Cooling water temperature is $18{ }^{\circ} \mathrm{C}$.

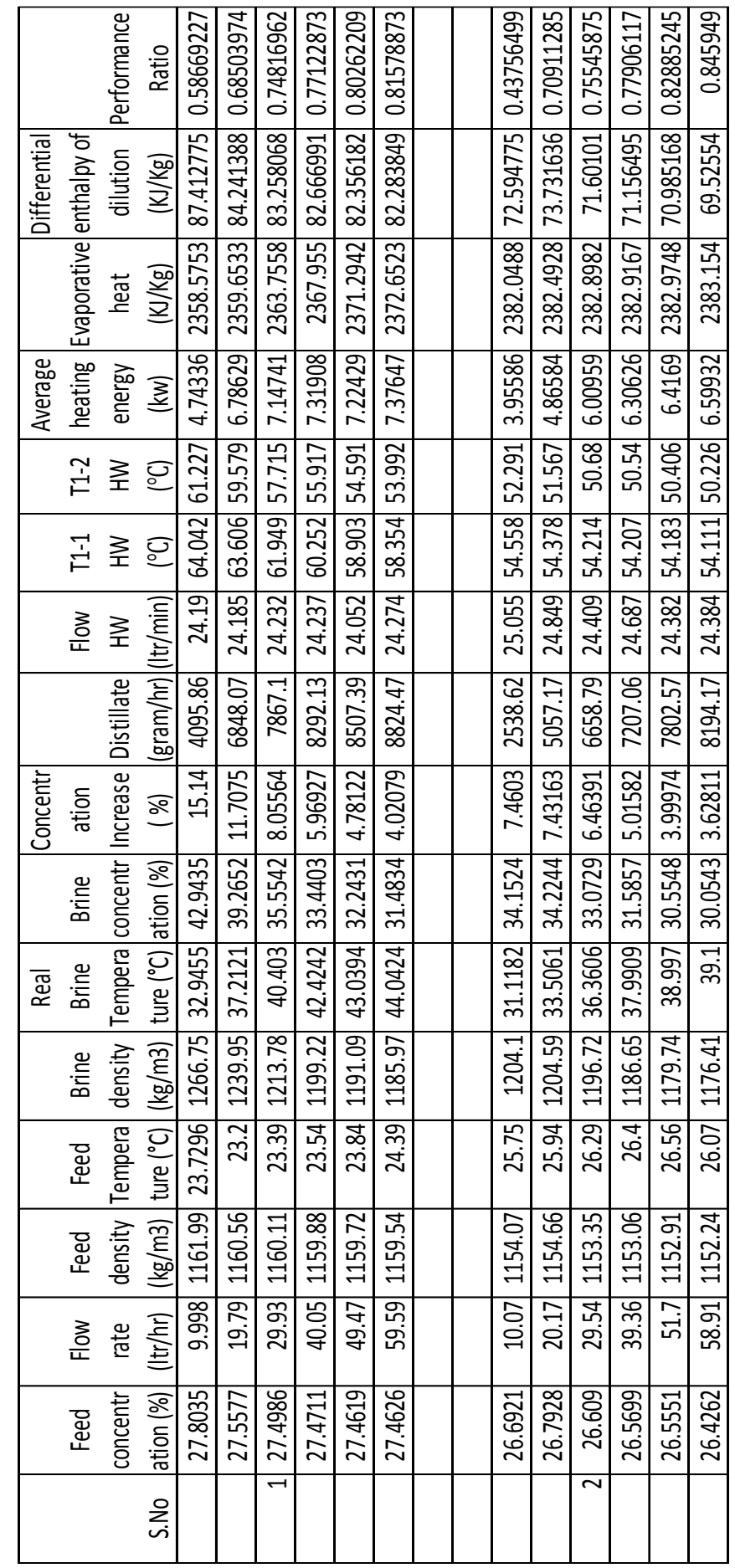


Table C.3: $1 \mathrm{~S}-3 \mathrm{~L}$ VMEMD experimental data for $32 \% \mathrm{LiCl}$ concentration at different heating temperatures and flow rates. Cooling water temperature is $28^{\circ} \mathrm{C}$.

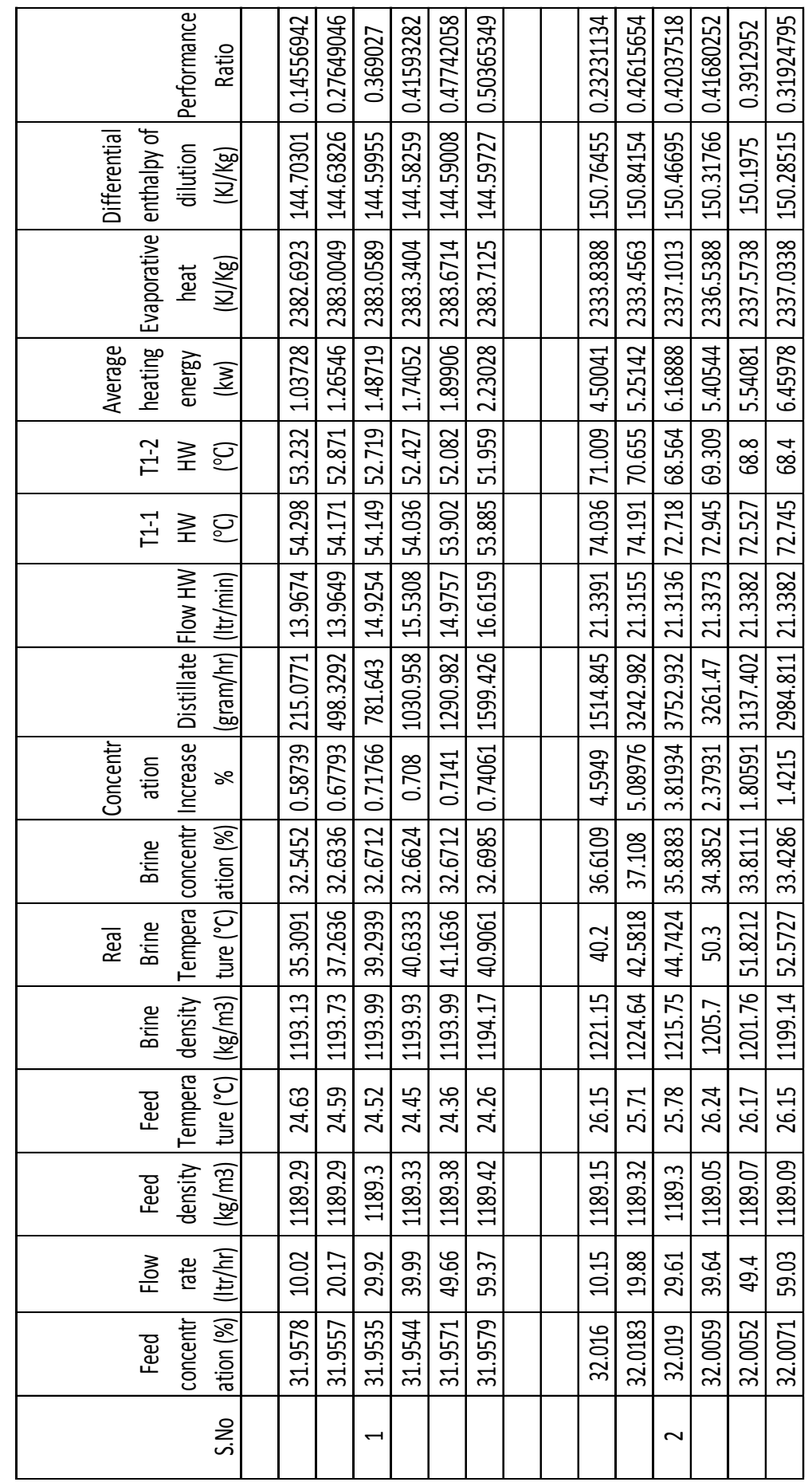


Table C.4: $1 \mathrm{~S}-3 \mathrm{~L}$ VMEMD experimental data for $33 \% \mathrm{LiCl}$ concentration at different heating temperatures and flow rates. Cooling water temperature is $18{ }^{\circ} \mathrm{C}$.

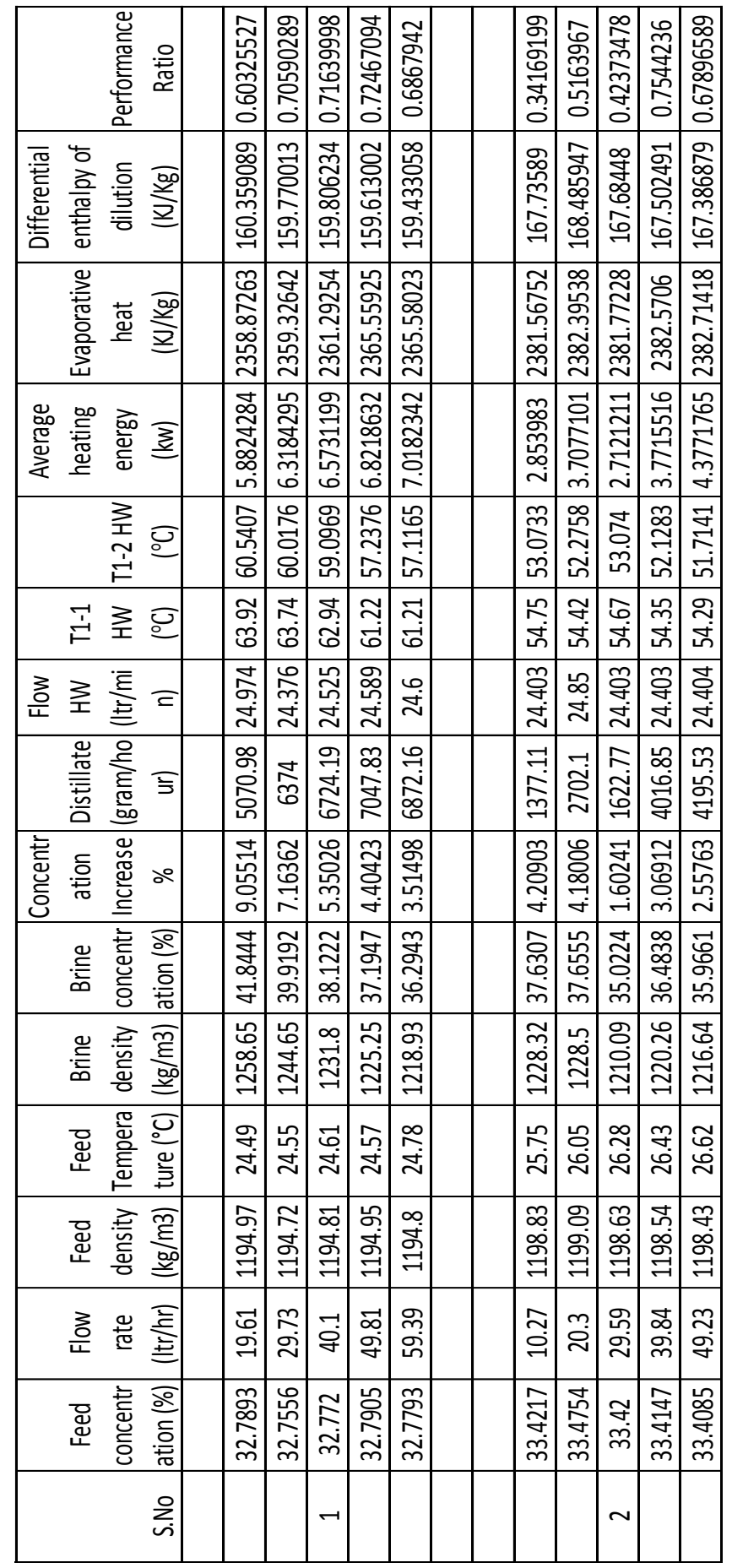


Table C.5: $1 \mathrm{~S}-3 \mathrm{~L}$ VMEMD experimental data for $35 \% \mathrm{LiCl}$ concentration at different heating temperatures and flow rates. Cooling water temperature is $18{ }^{\circ} \mathrm{C}$.

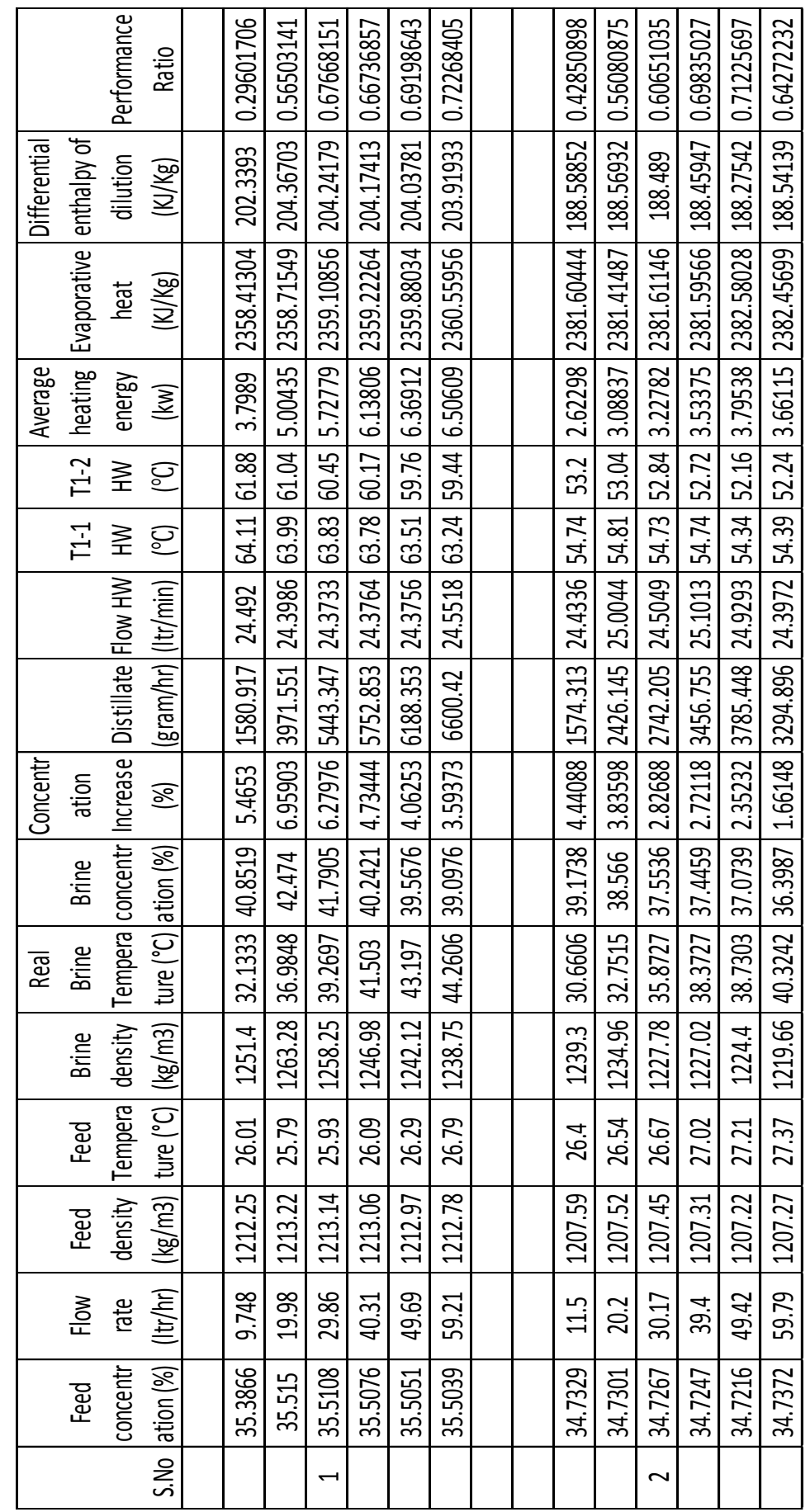


Table C.6: $1 \mathrm{~S}-3 \mathrm{~L}$ VMEMD experimental data for $38 \% \mathrm{LiCl}$ concentration at different heating temperatures and flow rates. Cooling water temperature is $18{ }^{\circ} \mathrm{C}$.

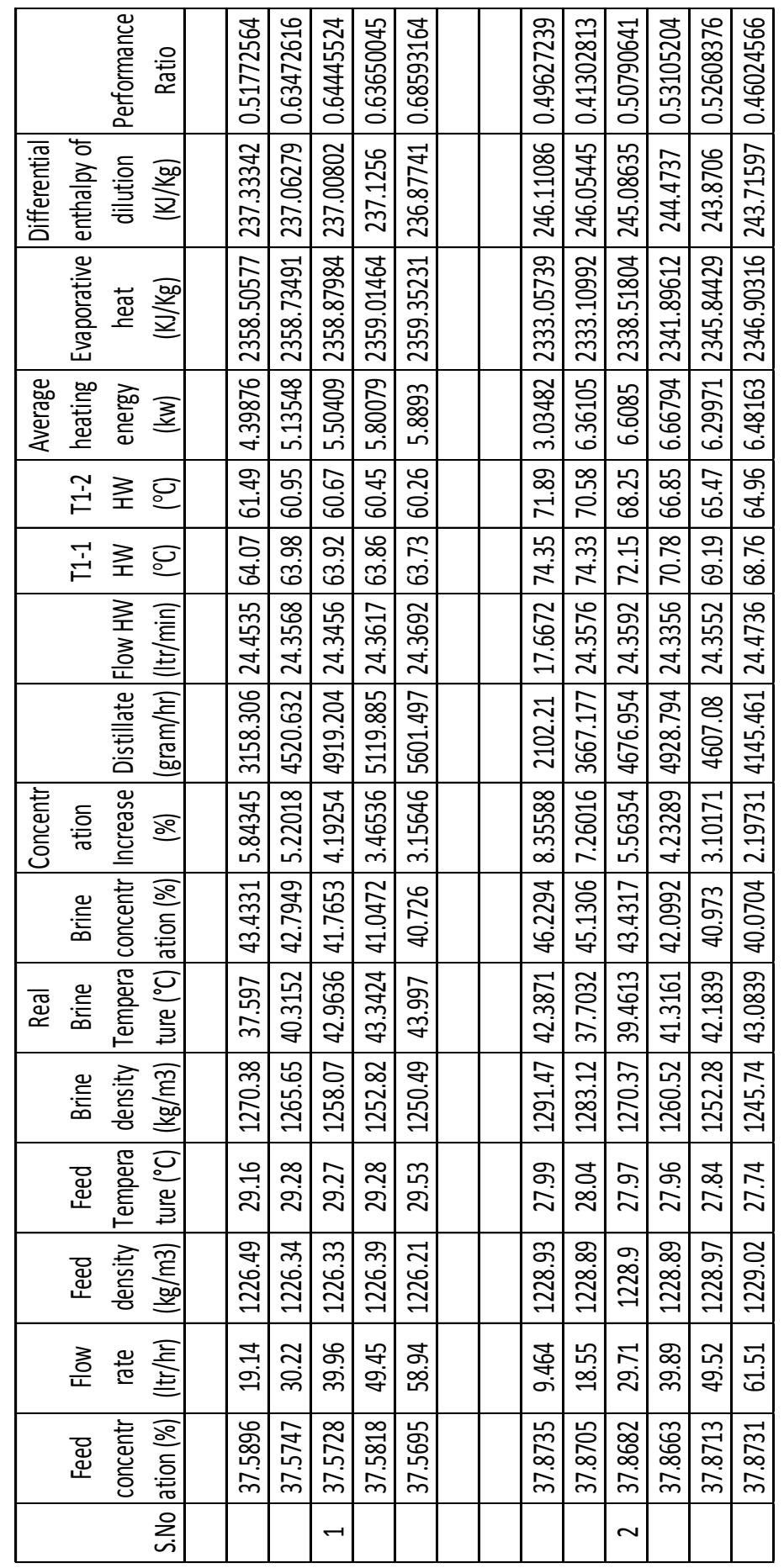


Table C.7: $1 \mathrm{~S}-3 \mathrm{~L}$ VMEMD experimental data for $38 \% \mathrm{LiCl}$ concentration at different flow rates. Cooling water temperature is $28{ }^{\circ} \mathrm{C}$. Heating water temperature is $65{ }^{\circ} \mathrm{C}$.

\begin{tabular}{|c|c|c|c|c|c|c|c|}
\hline 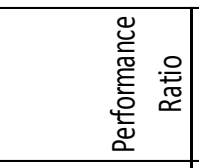 & 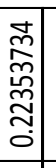 & 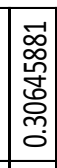 & 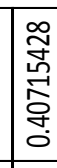 & & \begin{tabular}{|c|} 
\\
0 \\
0 \\
\\
\\
\\
0 \\
\end{tabular} & 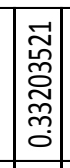 & 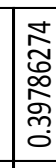 \\
\hline 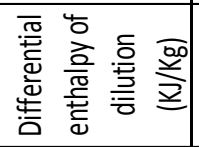 & 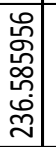 & 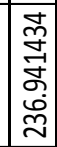 & 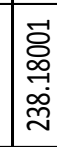 & & | & 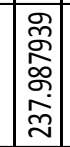 & 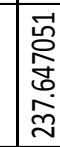 \\
\hline 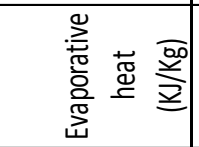 & $\mid \begin{array}{c}\overrightarrow{\tilde{D}} \\
\tilde{D} \\
\infty \\
\infty \\
\tilde{\sim} \\
\tilde{N}\end{array}$ & 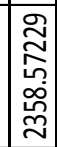 & 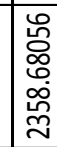 & & 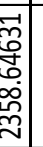 & 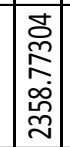 & 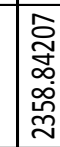 \\
\hline 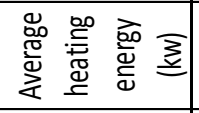 & 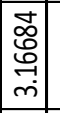 & $\begin{array}{l}\underset{\sim}{\sim} \\
\dot{n} \\
\end{array}$ & 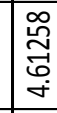 & & 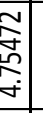 & 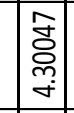 & 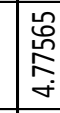 \\
\hline$\stackrel{\sim}{\risingdotseq} \geqq 0$ & \begin{tabular}{|l|}
\multirow{3}{*}{} \\
\end{tabular} & \begin{tabular}{|l|} 
\\
\\
\\
\end{tabular} & $\begin{array}{l}m \\
m \\
\dot{\sigma} \\
\end{array}$ & & స్ & \begin{tabular}{|c|}
\multirow{6}{*}{} \\
\end{tabular} & $\stackrel{\text { 염 }}{-1}$ \\
\hline 咅主 & \begin{tabular}{|l|}
\multirow{7}{*}{} \\
$\dot{0}$ \\
\end{tabular} & \begin{tabular}{|l|} 
\\
0 \\
0 \\
\end{tabular} & 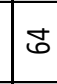 & & \begin{tabular}{|l|} 
\\
\\
\end{tabular} & \begin{tabular}{|l|}
\multicolumn{1}{|c|}{} \\
\\
\end{tabular} & $\begin{array}{l}\mathscr{\Omega} \\
\tilde{\theta} \\
\end{array}$ \\
\hline 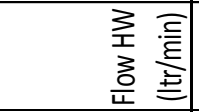 & 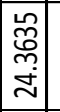 & 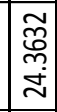 & 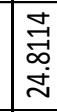 & & $\begin{array}{l}\infty \\
0 \\
\\
\\
\\
\end{array}$ & 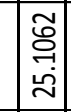 & $\begin{array}{l}\text { 合 } \\
\dot{\sim} \\
\dot{I}\end{array}$ \\
\hline 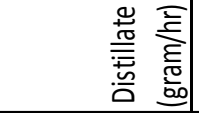 & \begin{tabular}{|c|}
$\infty$ \\
0 \\
0 \\
$\infty$ \\
$o$ \\
\end{tabular} & $\begin{array}{l}7 \\
7 \\
6 \\
0 \\
- \\
\end{array}$ & 夺 & & 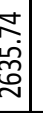 & 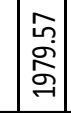 & 兽 \\
\hline 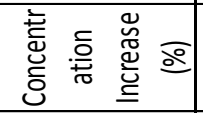 & 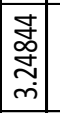 & 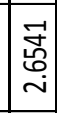 & 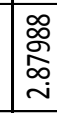 & & 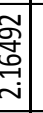 & 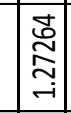 & $\begin{array}{l}\stackrel{8}{8} \\
\text { O } \\
\end{array}$ \\
\hline 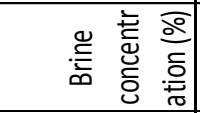 & \begin{tabular}{|l|}
0 \\
0 \\
0 \\
\\
\end{tabular} & 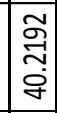 & 离 & & $\begin{array}{l} \\
\\
0 \\
\\
\\
\end{array}$ & 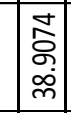 & 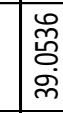 \\
\hline 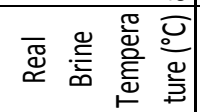 & $\mid$\begin{tabular}{|c|} 
\\
0 \\
0 \\
\\
$m$
\end{tabular} & \begin{tabular}{|l|} 
\\
$\vdots$ \\
$\vdots$ \\
$\infty$ \\
$\dot{m}$
\end{tabular} & $\begin{array}{l}n \\
\tilde{m} \\
\stackrel{m}{n}\end{array}$ & & 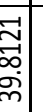 & 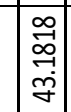 & 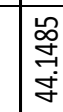 \\
\hline 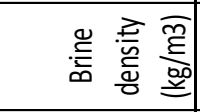 & 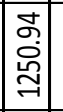 & 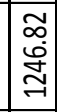 & 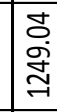 & & | & 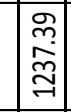 & 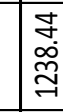 \\
\hline 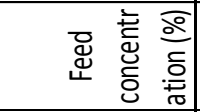 & 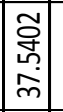 & 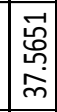 & \begin{tabular}{|c|}
$\vec{O}$ \\
$\dot{\sigma}$ \\
$\tilde{m}$ \\
\end{tabular} & & 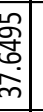 & \begin{tabular}{|l|}
$\infty$ \\
$\bar{w}$ \\
$\stackrel{1}{m}$ \\
$\hat{m}$ \\
\end{tabular} & 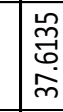 \\
\hline 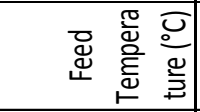 & 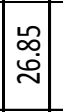 & $\begin{array}{l}\tilde{~} \\
\text { ஸు }\end{array}$ & 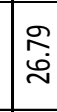 & & $\begin{array}{c}\infty \\
\stackrel{w}{\infty}\end{array}$ & 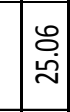 & 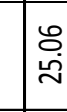 \\
\hline 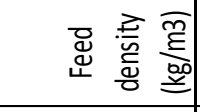 & $\underset{\Xi}{\Xi}$ & 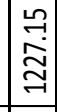 & $\underset{\Xi}{\stackrel{\Xi}{\Xi}}$ & & 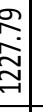 & 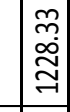 & 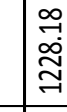 \\
\hline 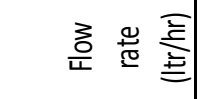 & 号 & 亩 & 离 & & ơ & \begin{tabular}{l}
\multirow{2}{q}{} \\
$\dot{q}$
\end{tabular} & 串 \\
\hline & & & & - & & & \\
\hline
\end{tabular}

